\section{onil}

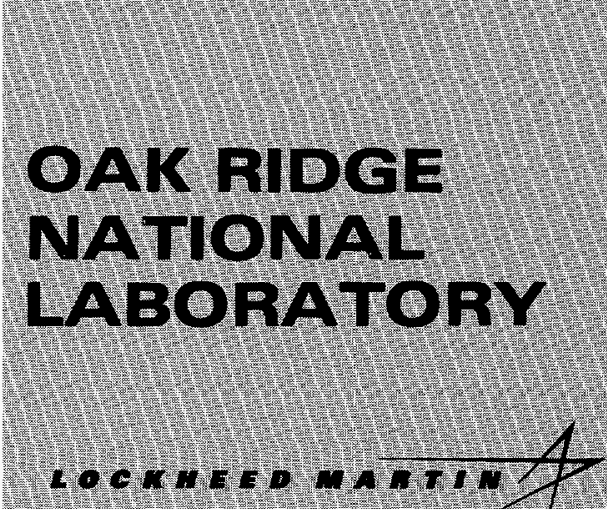

WAYLEED ANO OPEAMTED BY

LOCKHEZO WARII ENERGY BLSEARCH COAPORATION FOR THE UTIED STATES

DEPARTIET OF ENEREY

\section{RECEIVED}

\section{AUG 261995 \\ Egespy Division}

\section{Progress Report}

\section{Fiscal Years 1994-1995}
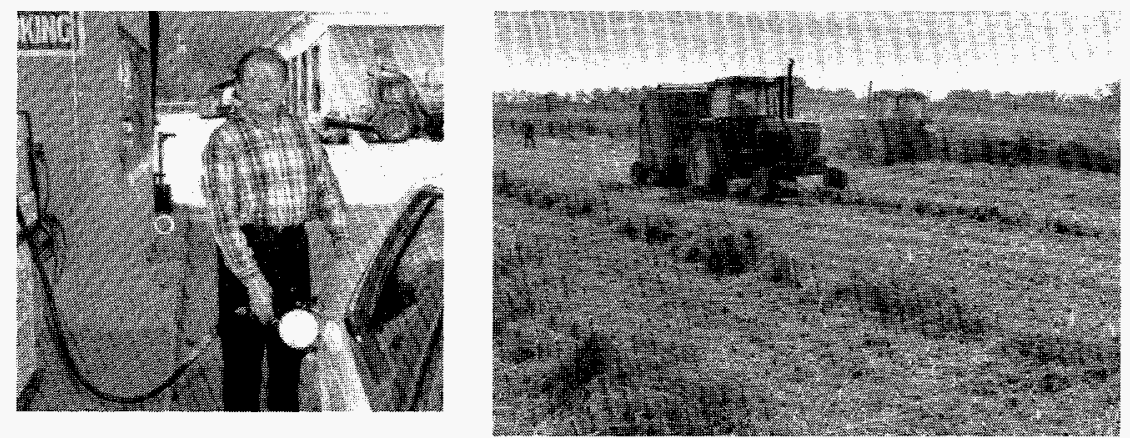

Providing innovative solutions to energy and related issues of national and global importance
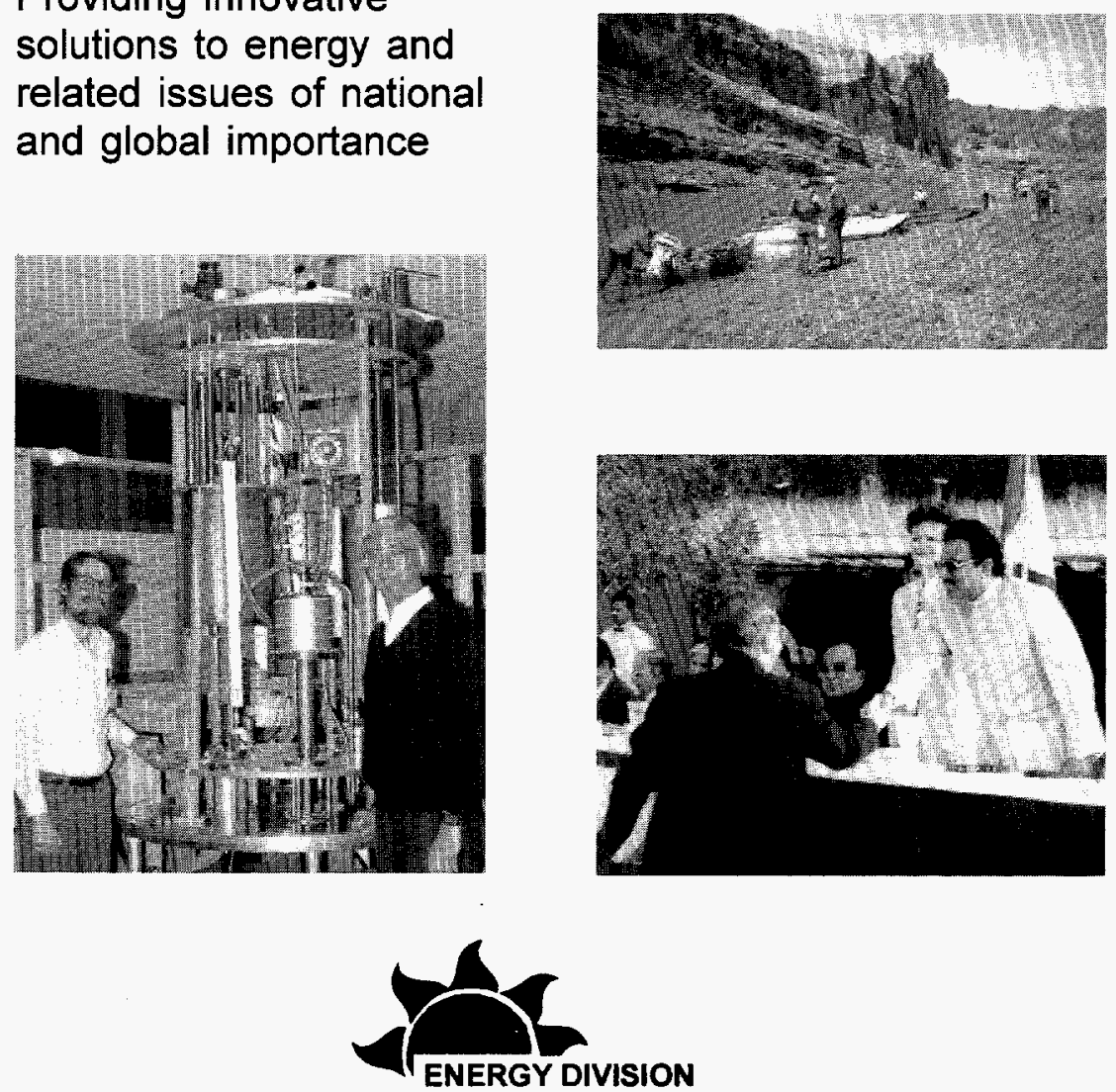
This report has been reproduced directly from the best available copy.

Available to DOE and DOE contractors from the Office of Scientific and Technical Information, P.O. Box 62, Oak Ridge, TN 37831; prices available from (423) 576-8401, FTS 626-8401.

Available to the public from the National Technical Information Service, U.S. Department of Commerce, 5285 Port Royal Rd., Springfield, VA 22161.

This report was prepared as an account of work sponsored by an agency of the United States Government. Neither the United States Government nor any agency thereof, nor any of their employees, makes any warranty, express or implied, or assumes any legal liability or responsibility for the accuracy, completeness, or usefulness of any information, apparatus, product, or process disclosed, or represents that its use would not infringe privately owned rights. Reference herein to any specific commercial product, process, or service by trade name, trademark, manufacturer, or otherwise, does not necessarily constitute or imply its endorsement, recommendation, or favoring by the United States Government or any agency thereof. The views and opinions of authors expressed herein do not necessarily state or reflect those of the United States Government or any agency thereof.

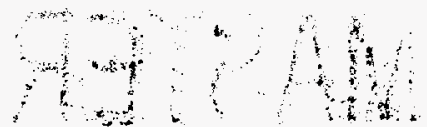




\section{PROGRESS REPORT}

\section{Fiscal Years 1994-1995}

Robert B. Shelton, Director George E. Courville, Associate Director

Michael S. Bronzini, Section Head, Center for Transportation Analysis James VanCoevering, Section Head, Efficiency and Renewables Research Section

T. Randall Curlee, Section Head, Energy and Global Change Analysis Section Robert M. Reed, Section Head, Environmental Analysis and Assessment Section

Date Published-June 1996

Carolyn I. Moser, Editor Cheryl A. Buford and Karen M. Dobbs, Electronic Publishers

Prepared by the

OAK RIDGE NATIONAL LABORATORY

Oak Ridge, Tennessee 37831-6285

managed by

LOCKHEED MARTIN ENERGY RESEARCH CORP.

for the

U.S. DEPARTMENT OF ENERGY

under contract DE-AC05-96OR22464 


\section{DISCLAIMER}

Portions of this document may be illegible in electronic image products. Images are produced from the best available original document. 


\section{Contents}

ABSTRACT . . . . . . . . . . . . . . . . . . . . . . . . . .

ACKNOWLEDGMENTS . . . . . . . . . . . . . . . . . . . . . vii

ACRONYMS AND ABBREVIATIONS . . . . . . . . . . . . . . . . . . . . ix

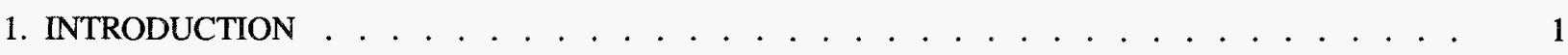

2. CENTER FOR TRANSPORTATION ANALYSIS . . . . . . . . . . . . . . . . . . . . . . 5

Transportation Energy and Environmental Issues . . . . . . . . . . . . . . . . . . . . . . 6

Transportation Energy Data Book . . . . . . . . . . . . . . . . . . . . . . 6

Conference on the Social Costs and Benefits of Transportation . . . . . . . . . . . . . . . 6

Oil Costs . . . . . . . . . . . . . . . . . . . . . . . . . . . . . . . . . 7

Reformulated Gasoline . . . . . . . . . . . . . . . . . . . . . . . . . . . . . 8

Transportation Planning and Policy . . . . . . . . . . . . . . . . . . . . . . . . . . . . . . . 8

Transportation Network-Based Geographic Information Systems . . . . . . . . . . . . . . 8

Environmental Implications of Transportation-Land Use Interaction ～～. . . . . . . . . . . 9

Commodity Flow Survey . . . . . . . . . . . . . . . . . . . . . . . . . . . . . . 10

Personal Travel Behavior . . . . . . . . . . . . . . . . . . . . . . . . . . . . . 10

Military Transportation and Logistics . . . . . . . . . . . . . . . . . . . . . . . . . . 11

Air Mobility . . . . . . . . . . . . . . . . . . . . . . . . . . . . . . . . 11

Shipping . . . . . . . . . . . . . . . . . . . . . . . . . 11

Intelligent Transportation Systems ． . . . . . . . . . . . . . . . . . . . . . . 15

ITS Spatial Data Integration and Location Referencing System ～. . . . . . . . . . . . . . 15

Advanced Transportation Management Training Center . . . . . . . . . . . . . . . . . 15

TRAF Simulation System ． . . . . . . . . . . . . . . . . . . . . . . . . . . . . 16

Dynamic Traffic Assignment Systems ． . . . . . . . . . . . . . . . . . . . . 16

References . . . . . . . . . . . . . . . . . . . . . 16

3. EFFICIENCY AND RENEWABLES RESEARCH SECTION _ . . . . . . . . . . . . . . . . 17

Buildings Technology Center Programs . . . . . . . . . . . . . . . . . . . . . . 18

Building Envelope Research . . . . . . . . . . . . . . . . . . . . . . . . . . . . . 18

Building Equipment Technology Development . . . . . . . . . . . . . . . . . . . . . 20

Existing Buildings Research . . . . . . . . . . . . . . . . . . . . . . . . . . . . . 23

Technology Transfer for Buildings . . . . . . . . . . . . . . . . . . . . . . 25

Thermal and Environmental Control Systems . . . . . . . . . . . . . . . . . . . . . . . 25

Power Systems Technology Program . . . . . . . . . . . . . . . . . . . . . . . . 25

Electromagnetic Fields Research . . . . . . . . . . . . . . . . . . . . . . . . . . . 28

Transmission and Distribution Technologies . . . . . . . . . . . . . . . . . . . . . . 29

References . . . . . . . . . . . . . . . . . . . 30 
4. ENERGY AND GLOBAL CHANGE ANALYSIS SECTION . . . . . . . . . . . . . . . . . . 33

Electric-Industry Policy Studies . . . . . . . . . . . . . . . . . . . . . . . . . . . . 33

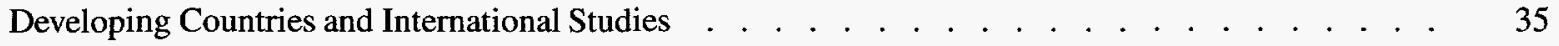

Global Climate Change . . . . . . . . . . . . . . . . . . . . . . . . . . . 36

Environmental and Health Studies . . . . . . . . . . . . . . . . . . . . . . . . . . . 36

Environmental Resource Valuation . . . . . . . . . . . . . . . . . . . . . . . . . . . 37

Biomass for Energy . . . . . . . . . . . . . . . . . . . . . . . . . . . . . . . . . 38

Alternative Fuels . . . . . . . . . . . . . . . . . . . . . . . . . . . . . . . . . . 38

Oil Imports: An Assessment of the Costs and Benefits . . . . . . . . . . . . . . . . . . . . 38

Energy Program Evaluation . . . . . . . . . . . . . . . . . . . . . . . . . . . 39

Regional Studies . . . . . . . . . . . . . . . . . . . . . . . . . . . . . . . . . . . . . . 39

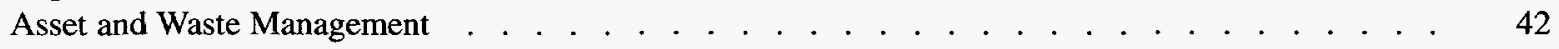

References . . . . . . . . . . . . . . . . . . . . 43

5. ENVIRONMENTAL ANALYSIS AND ASSESSMENT SECTION . . . . . . . . . . . . . . . 45

NEPA Support to Federal Agencies . . . . . . . . . . . . . . . . . . . . . . . . . . . . . . . . 46

NEPA Support to DOE . . . . . . . . . . . . . . . . . . . . . . . 46

Federal Energy Regulatory Commission Projects . . . . . . . . . . . . . . . . . . . . 49

NEPA Support to Other Federal Agencies . . . . . . . . . . . . . . . . . . . . . . . 49

Emergency Preparedness and Response . . . . . . . . . . . . . . . . . . . . . . . . . 50

Chemical Stockpile Emergency Preparedness Program (CSEPP) . . . . . . . . . . . . . . 50

Emergency Preparedness Support for DOE's Office of Defense Programs . . . . . . . . . . . 53

Waste Management, Environmental Restoration, and Safety Analysis Upgrade

Program Support . . . . . . . . . . . . . . . . . . . . . . . . . . . . . . . 53

Performance Assessment for Solid Waste Storage Area 6 (SWSA 6) . . . . . . . . . . . . . 53

Pinellas Plant Dose Assessment . . . . . . . . . . . . . . . . . . . . . . . . . . . 53

Groundwater Contaminant Plume Interception and Treatment . . . . . . . . . . . . . . . 56

Use of Groundwater Models in Remedial Action Performance Assessment . . . . . . . . . . 56

Solid Waste Landfill Operating Limit Evaluation at the Paducah Gaseous

Diffusion Plant . . . . . . . . . . . . . . . . . . 57

Other EAAS Activities . . . . . . . . . . . . . . . . . . . . . . . . . . . . . . . . . . . . . . . . . . 5

DOE Materials Inventory . . . . . . . . . . . . . . . . . . . . 57

Life Cycle Analysis Study for the Army . . . . . . . . . . . . . . . . . . . . . . . . 58

Key Factors Responsible for Changes in Electric-Utility DSM Usage . . . . . . . . . . . . 58

References . . . . . . . . . . . . . . . . . . . . 59

APPENDIX: SUMMARY DATA, AWARDS, AND PUBLICATIONS . . . . . . . . . . . . . . 61

Energy Division Advisory Committee, FY 1994-FY 1995 ． . . . . . . . . . . . . . . . . . 61

Energy Division Sponsors, Expenditures, and Commitments of Scientific Staff
$\quad$ for FY 1994 . . . . . . . . . . . . . . . . . . . . . . . . . . . . . . . 62

Energy Division Sponsors, Expenditures, and Commitments of Scientific Staff for FY $1995 \ldots \ldots$. . . . . . . . . . . . . . . . . . . . . . . . . 63

Industrial and University Partners of the Energy Division . . . . . . . . . . . . . . . . . . 64

Workshops and Symposia Organized by Energy Division Staff . . . . . . . . . . . . . . . . 66

Energy Division Professional Honors and Awards, FY 1994-FY 1995 . . . . . . . . . . . . . 67

Energy Division Publications, FY 1994-FY 1995 . . . . . . . . . . . . . . . . . . . . . 69

ORGANIZATION CHART . . . . . . . . . . . . . . . . . . . . . . . . . . 86 


\section{Abstract}

One of 16 research divisions at Oak Ridge National Laboratory (ORNL), the Energy Division's mission is to provide innovative solutions to energy and related issues of national and global importance through interdisciplinary research and development. Its goals and accomplishments are described in this progress report for FY 1994 and FY 1995. The Energy Division is committed to (1) understanding the mechanisms by which societies make choices in energy use; (2) improving society's understanding of the environmental, social, and economic implications of technological change; (3) developing and transferring energy-efficient technologies; (4) improving transportation policy and planning; (5) enhancing basic knowledge in the social sciences as related to energy and associated issues; and (6) providing a unique climate that allows engineers and physical, environmental, and social scientists to address major societal problems and to develop professionally in their respective disciplines.

The Energy Division's expenditures in FY 1995 totaled $\$ 44.9$ million. Sixty percent of the division's work was supported by the U.S. Department of Energy. Other significant sponsors include the U.S. Department of Transportation, the U.S. Department of Defense, other federal agencies, and some private organizations. Disciplines of the 131 scientific and technical staff include the social sciences, engineering, physical and life sciences, and data systems.

The division's programmatic activities cover three main areas: (1) analysis and assessment, (2) transportation systems, and (3) energy use and delivery technologies. Analysis and assessment activities involve energy and resource analysis, preparation of environmental assessments and impact statements, research on emergency preparedness, analysis of energy and environmental needs in developing countries, and transportation analysis. Transportation systems research seeks to improve the quality of both civilian and military transportation efforts. Energy use and delivery technologies focus on building equipment, building envelopes (walls, foundations, roofs, attics, and materials), improvement of energy efficiency in buildings, and electric power systems.

The division's research is disseminated by the staff's involvement in professional and trade organizations and workshops; by joint research with universities and private-sector firms; by collaboration with industry and state and local governments; by training sessions for government and the private sector; by presentations of work at conferences; and by publication of research results in journals, reports, and conference proceedings. 


\section{Acknowledgments}

The authors wish to thank the following individuals for assistance in preparing this document. Energy Division group leaders provided information about their projects and activities during the reporting period. Teresa Ferguson identified a number of photographs for use in the report and provided guidance in the planning process. Jane Rollow, Jonnie Sorensen, Naomi Myers, Cynthia Moody, and Sue Damewood assisted in compiling information for their sections while continuing to fulfill their multitude of daily responsibilities. Linda Edwards, Susan Diegel, Jan Draine, Caroline Patillo, and Kim Grubb also contributed essential information. A number of staff members of Information Management Services (IMS) contributed to the production of the document. Publishing Services staff members Carolyn Moser, Karen Dobbs, and Cheryl Buford provided editing, document design, and electronic publishing services. Curtis Boles and Brett Pate provided photography services, and Renée Balogh provided graphics support; in addition, Dobie Gillispie, Ernestine Sloan, and Vicki Beets provided electronic photograph and graphics files. Jim Mason, Robert $\mathrm{M}^{\mathrm{C}} \mathrm{Gaffey}$, and other members of the IMS Viking Group provided SGML expertise to produce both the printed and World Wide Web documents. 



\title{
Acronyms and Abbreviations
}

\author{
ADANS \\ AMC Deployment Analysis System \\ AFV \\ alternative fuel vehicle \\ AISI \\ American Iron and Steel Institute \\ AMC \\ Air Force Air Mobility Command \\ ASHRAE \\ American Society of Heating, Refrigerating and Air Conditioning Engineers \\ ATIS \\ Advanced Traveler Information Systems \\ ATMTC Advanced Transportation Management Training Center \\ ATSDR Agency for Toxic Substances and Disease Registry \\ BFDP \\ Biofuels Feedstock Development Program \\ BTC \\ BTS \\ CAAA \\ . \\ CERCLA \\ Bureau of Transportation Statistics \\ Clean Air Act Amendments \\ CES \\ CFC \\ Comprehensive Environmental Response, Compensation, and Liability Act \\ constant elasticity of substitution \\ chlorofluorocarbon \\ CFS \\ Commodity Flow Survey \\ coefficient of performance \\ CRADA \\ CSDP \\ CSEPP \\ CTA \\ CY \\ cooperative research and development agreement \\ Chemical Stockpile Disposal Program \\ Chemical Stockpile Emergency Preparedness Program \\ Center for Transportation Analysis \\ calendar year \\ DOD \\ U.S. Department of Defense \\ DOE \\ U.S. Department of Energy \\ DOT \\ DNNP \\ DSM \\ DTA \\ DU \\ U.S. Department of Transportation \\ Denali National Park and Preserve \\ demand-side management \\ Dynamic Traffic Assignment \\ depleted uranium \\ EA \\ EAAS \\ EC \\ environmental assessment \\ Environmental Analysis and Assessment Section \\ EGCAS \\ EIA \\ EIS \\ European Community \\ EMF \\ Energy and Global Change Analysis Section \\ Energy Information Administration \\ environmental impact statement \\ electromagnetic field \\ EPA \\ U.S. Environmental Protection Agency \\ EPI \\ Environmental Protection Initiative \\ EPRI \\ Electric Power Research Institute
}




\begin{tabular}{|c|c|}
\hline ERIP & Energy-Related Inventions Program \\
\hline ERRS & Efficiency and Renewables Research Section \\
\hline FACTS & flexible ac transmission \\
\hline FEMA & Federal Emergency Management Agency \\
\hline FERC & Federal Energy Regulatory Commission \\
\hline FFCA & Federal Facilities Compliance Act \\
\hline FHWA & Federal Highway Administration \\
\hline GAX & generator-absorber-heat exchanger \\
\hline GIS & geographic information system \\
\hline GRI & Gas Research Institute \\
\hline HCCP & Healy Clean Coal Project \\
\hline $\mathrm{HCFC}$ & hydrochlorofluorocarbon \\
\hline HFIR & High Flux Isotope Reactor \\
\hline HPO & high phase order \\
\hline HUD & U.S. Department of Housing and Urban Development \\
\hline HVAC & heating, ventilation, and air-conditioning \\
\hline HVDC & high-voltage dc \\
\hline ICDB & Integrated Cargo Database \\
\hline ITS & Intelligent Transportation Systems \\
\hline KEP & kinetic energy penetrator \\
\hline LCA & life-cycle analysis \\
\hline LMER & Lockheed Martin Energy Research Corp. \\
\hline LMES & Lockheed Martin Energy Systems, Inc. \\
\hline LRMP & location referencing message protocol \\
\hline MLLW & mixed low-level waste \\
\hline MOU & Memorandum of Understanding \\
\hline MTMC & Military Traffic Management Command \\
\hline NAAQS & National Ambient Air Quality Standards \\
\hline NEAT & National Energy Audit \\
\hline NEPA & National Environmental Policy Act \\
\hline NGB & National Guard Bureau \\
\hline NMSS & Nuclear Material Safety and Safeguards \\
\hline NO & nitric oxide \\
\hline $\mathrm{NO}_{2}$ & nitrogen dioxide \\
\hline $\mathrm{NO}_{x}$ & nitrogen oxides \\
\hline NPS & National Park Service \\
\hline NPTS & Nationwide Personal Transportation Survey \\
\hline NRC & Nuclear Regulatory Commission \\
\hline $\mathrm{O}_{3}$ & ozone \\
\hline O-D & origin-destination \\
\hline OPEC & Organization of Petroleum Exporting Countries \\
\hline ORNL & Oak Ridge National Laboratory \\
\hline PADD & Petroleum Administration for Defense District \\
\hline PADRE & Protective Action Dose Reduction Estimator \\
\hline PAECE & Protective Action Evaluator for Chemical Emergencies \\
\hline PGDP & Paducah Gaseous Diffusion Plant \\
\hline PIMA & Polyisocyanurate Insulation Manufacturers Association \\
\hline PNGV & Partnership for a New Generation of Vehicles \\
\hline $\mathrm{R} \& \mathrm{D}$ & research and development \\
\hline RFG & reformulated gasoline \\
\hline
\end{tabular}


RRPM Regional Recruiting Potential Model

SMES superconducting magnetic energy storage

$\mathrm{SO}_{2} \quad$ sulfur dioxide

SPR

SSC

T\&D

TIP

TPE

Strategic Petroleum Reserve

Superconducting Super Collider

transmission and distribution

Technology Introduction Partnerships

Technical Planning and Evaluation

TRB Transportation Research Board

USAID U.S. Agency for International Development

USAP U.S. Antarctic Program

USPCI U.S. Pollution Control, Inc.

UT University of Tennessee

VEIKI Hungarian Electric Power Research Institute

VOC volatile organic compound

WAG Waste Area Grouping

WPS Worldwide Port System

WTE waste-to-energy 


\section{Introduction}

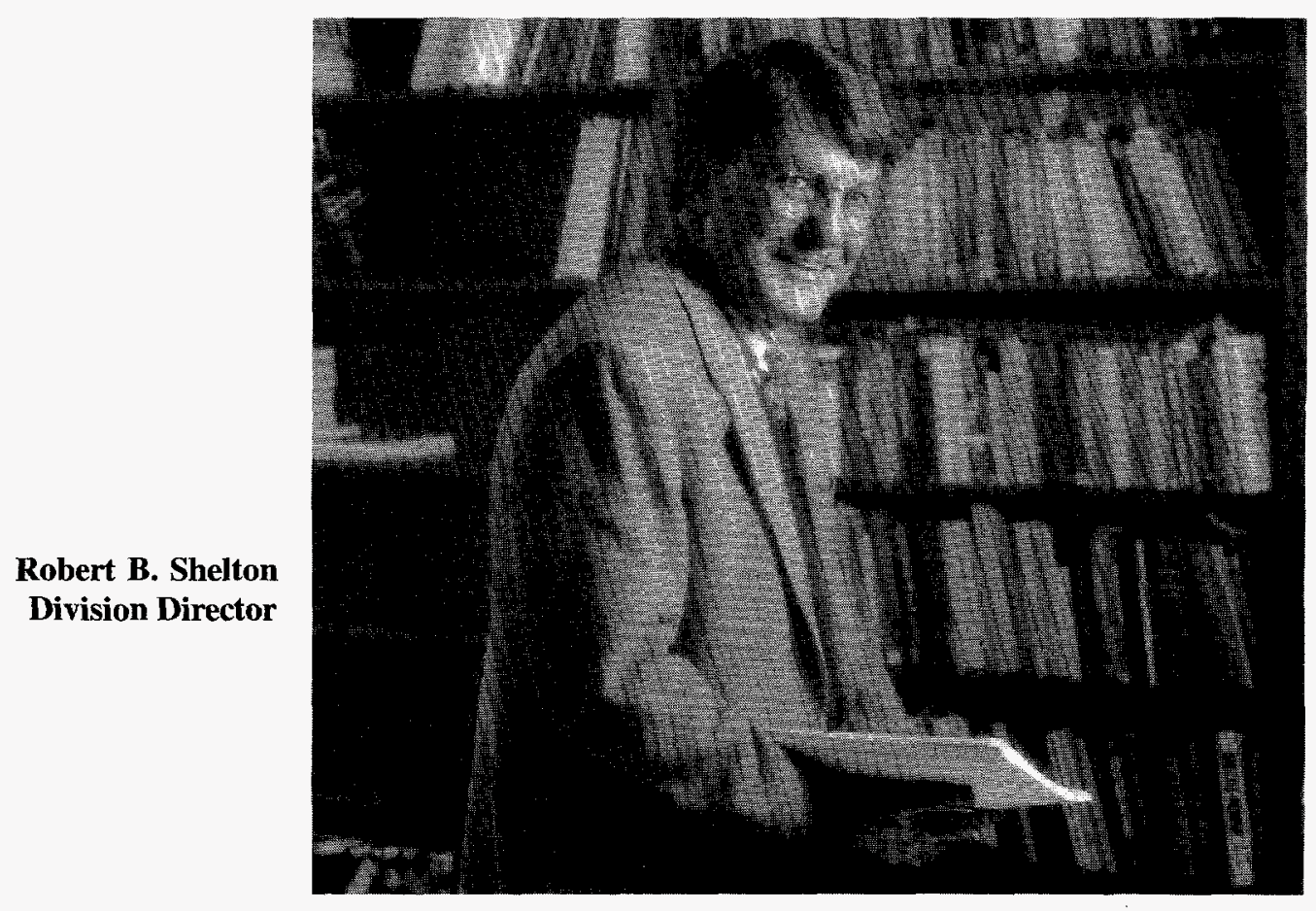

One of 16 research divisions at Oak Ridge National Laboratory (ORNL), the Energy Division was established in 1974 to consolidate work on environmental, technological, and regional assessments related to energy development and to conduct research on improving the efficiency of energy use and conversion. Our mission reflects those themes: To provide innovative solutions to energy and related issues of national and global importance through interdisciplinary research and development (R\&D).

The Energy Division focuses on technology and human systems through three principal thrusts: (1) performing environmental, technological, regional, and policy analysis and assessments related to energy production and use; (2) conducting research on improving the efficiency of transportation systems; and (3) performing R\&D to improve the efficiency of energy use and delivery technologies. While much of our work emphasizes energy and environmental issues, we also address other pressing concerns on the national agenda, reflecting the division's problem-driven nature. In 1995, the division assigned staff to the Lockheed Martin Energy Systems/Energy Research (LMES/LMER) Washington, D.C., office to facilitate interaction with national leaders in the division's principal thrust areas. 


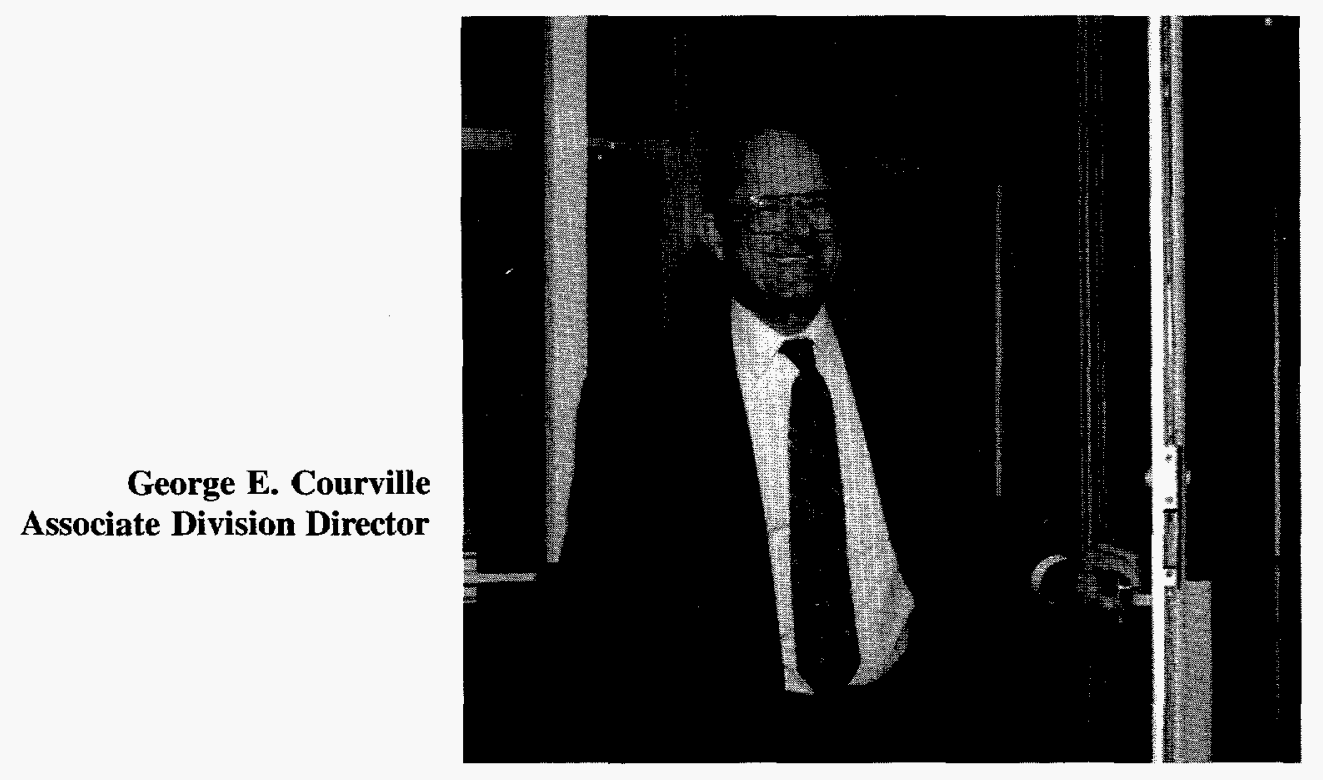

Work in the building equipment area involves developing thermally activated heat pumps for residential and commercial applications, novel refrigeration cycles, and refrigeration systems. Building envelope research deals with energy efficiency in walls, foundations, roofs, attics, and building materials; research on existing buildings explores technical and implementation issues to improve the energy

Analysis and assessment activities comprise five main areas: (1) energy and resource analysis, (2) environmental assessment, (3) emergency preparedness, (4) developing country analysis, and (5) transportation analysis. Energy resource analysis is common to every section within the division, covering topics such as energy security, utility resource planning, integrated analysis, and life cycle assessment. Assessment work includes preparing formal environmental assessments (EAs) and environmental impact statements (EISs) for sponsors to comply with the National Environmental Policy Act (NEPA). Emergency preparedness research aims to improve society's ability to cope with natural and technological disasters. Developing country programs address pressing environmental and energy concerns in countries such as Guatemala and India. Transportation analysis develops data and analytical methods through civilian-sector research for the U.S. Department of Energy (DOE) and other agencies concerned with transportation.

Transportation system R\&D seeks to improve the quality of both civilian and military transportation efforts. The Energy Division's Intelligent Transportation Systems (ITS) team is supporting the Federal Highway Administration (FHWA) in two primary research clusters dealing with commuter mobility. Military transportation researchers are conceptualizing new approaches to planning and executing strategic deployment of personnel and materiel.

Energy use and delivery technologies incorporate programs by the Buildings Technology Center, a National User Facility, and by the Electric Power Systems Program. efficiency of existing structures. Outreach programs to encourage communities, businesses, and homeowners to use more energy-efficient technologies are an important part of the Buildings Technology Center. Research on electric power systems focuses on developing options to increase transmission and distribution (T\&D) capacity, and on research to determine if low-frequency $(60-\mathrm{Hz})$ electric and magnetic fields cause adverse human health effects.

The Energy Division is one of ORNL's most diverse research divisions in terms of its sponsorship, research activities, and range of staff expertise. As shown in Fig. 1.1, division expenses in fiscal year (FY) 1995 totaled $\$ 44.9$ million. Roughly $60 \%$ of the budget was provided by DOE, $16 \%$ by the U.S. Department of Transportation (DOT), and $15 \%$ by the U.S. Department of Defense (DOD). The remainder came from other agencies and the private sector. As Fig. 1.2 indicates, the division's expenses have increased slightly in recent years.

At the end of FY 1995, the division was composed of 177 full-time equivalent staff and 91 on-site guests. The full-time equivalent staff consisted of 131 scientific and technical, 28 administrative, and 18 technical support personnel. As shown in Fig. 1.3, about $38 \%$ of the technical staff are social scientists, $37 \%$ are engineers, $17 \%$ are physical and life scientists, and the remaining $8 \%$ are data systems personnel. About $90 \%$ of the technical staff hold doctorates or master's degrees (Fig. 1.4).

Subcontractors and consultants also perform work for the Energy Division, along with staff from other ORNL and LMES divisions, including Chemical and Analytical Sciences, Chemical Technology, Engineering 
ORNL-DWG 96M-2658

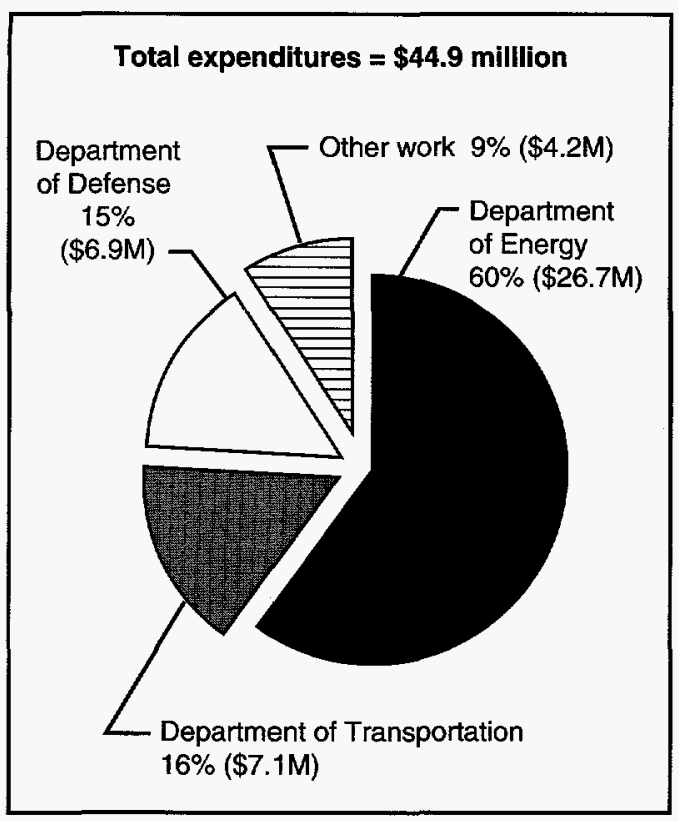

Fig. 1.1. Energy Division expenditures by sponsor for fiscal year 1995 .

ORNL-DWG 96M-2659

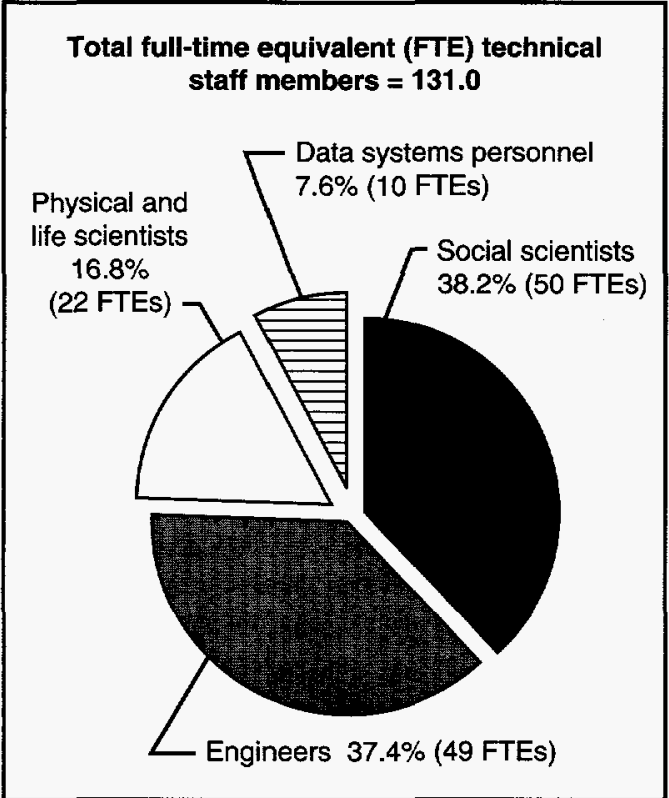

Fig. 1.3. Energy Division technical staff by discipline for period ending September 30, 1995.
ORNL-DWG 96M-2661

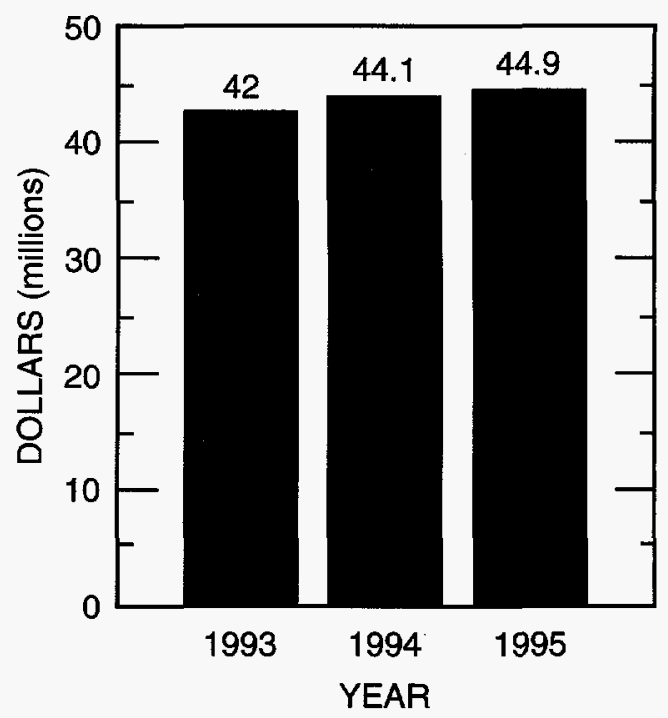

Fig. 1.2. Energy Division expenses have edged up slightly in the past 3 years.

ORNL-DWG 96M-2660

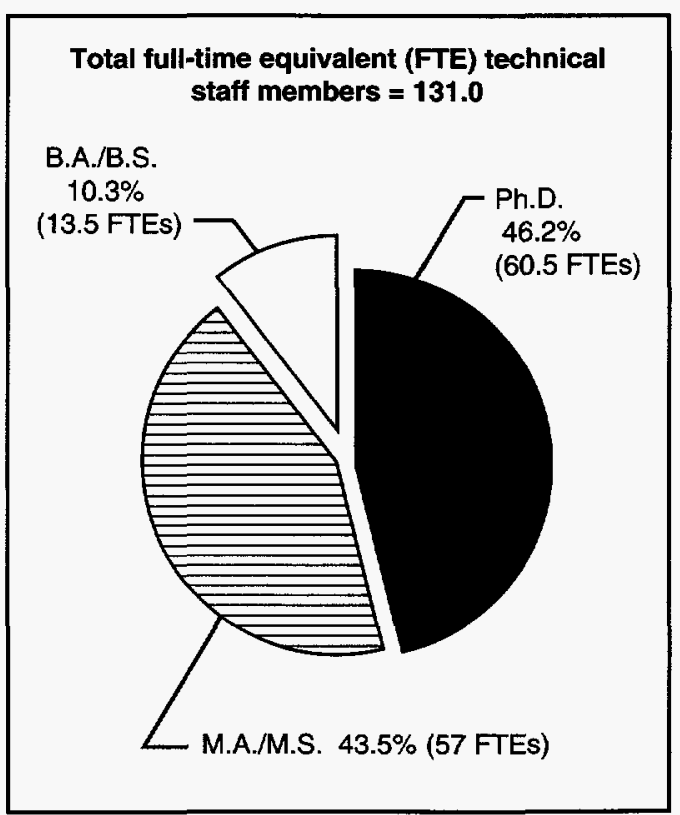

Fig. 1.4. Energy Division technical staff by education level for period ending September 30, 1995. 
Technology, Environmental Sciences, Health Sciences Research, Metals and Ceramics, Research Reactors, and Information Management Services divisions.

This report highlights the division's achievements for FY 1994 and FY 1995 (October 1, 1993, through September 30,1995), summarizing by chapter the work of the four sections within the division. Chapter 2 details work performed by the Center for Transportation Analysis (CTA), directed by Michael S. Bronzini. Chapter 3 surveys the work of the Efficiency and Renewables Research Section (ERRS), headed by James VanCoevering. Chapter 4 describes work performed by the Energy and Global Change Analysis Section (EGCAS), led by T. Randall Curlee, and Chapter 5 covers the work of the Environmental Analysis and Assessment Section (EAAS), headed by Robert M. Reed. An appendix provides summary data, a list of awards, and a list of staff publications. The report concludes with a division organization chart.

Interested readers can obtain more information about the Energy Division, its sections, and its programs by accessing the division's home page on the World Wide Web (http://www.ornl.gov/divisions/energy/energy.html). 


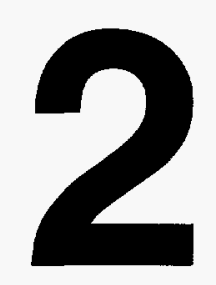

\section{Center for Transportation Analysis}

Michael S. Bronzini Section Head

The Center for Transportation Analysis (CTA) conducts innovative, cost-effective $R \& D$ on transportation energy and environmental issues, national transportation planning and policy, military transportation and logistics, and transportation systems engineering. CTA focuses on multimodal national and international transportation systems. Staff members develop and apply advanced computational techniques, analytical methods, and information resources to improve economic and energy efficiency, environmental quality, mobility, national security, and public safety.

A mixture of technical and scientific backgrounds and diverse project sponsors strengthens CTA's interdisciplinary

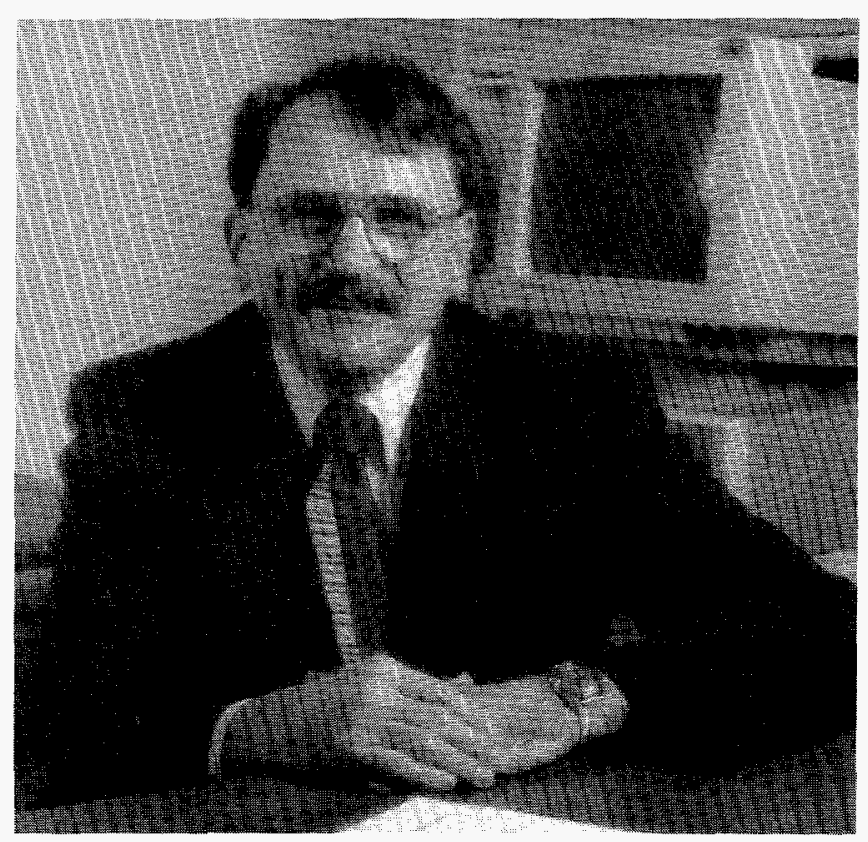

approach to problem solving. Staff expertise includes transportation engineering, transportation geography, transportation economics, operations research, mathematics and statistics, computation and computer science, and other physical and social sciences. The staff actively support the Transportation Research Board (TRB) and other professional societies by making presentations at annual meetings and participating in technical committees. CTA enjoys a close association with the worldwide academic community, and special support from the nearby University of Tennessee (UT) and from Vanderbilt University. Work is performed for DOE and other federal agencies, most notably the FHWA of DOT. Within FHWA, several 
offices involved in the ITS program sponsor a significant amount of CTA research. Other sponsors include the DOT Bureau of Transportation Statistics; the Federal Railroad Administration; the U.S. Environmental Protection Agency (EPA); and in DOD, the U.S. Air Force Air Mobility Command (AMC) and the Military Traffic Management Command (MTMC).

Further information about CTA is available on the Internet at CTA's World Wide Web home page, at http://www-cta.ornl.gov.

\section{TRANSPORTATION ENERGY AND ENVIRONMENTAL ISSUES}

\section{Transportation Energy Data Book}

The Transportation Energy Data Book ${ }^{1}$ is a statistical compendium prepared and published for DOE's Office of Transportation Technologies. Designed as a desktop reference, the data book assembles statistics characterizing transportation activity and presents information on other factors that influence transportation energy use. Its purpose is to present relevant statistical data in the form of table and graphs. For example, Fig. 2.1 shows trends in U.S. petroleum production, consumption, and transportation use over the past 20 years. Each of the major transportation modes-highway, air, water, rail, and pipeline-is addressed, as well as alternative fuels and transportation emissions. The Transportation Energy Data Book is internationally recognized as a primary source for transportation data; its users include the U.S. Congress, the automobile industry, numerous federal and state government agencies, regulatory boards, and foreign governments and research institutes.

\section{Conference on the Social Costs and Benefits of Transportation}

Transportation generates large costs and benefits. Some of these, such as the cost of shipping goods or of owning and operating an automobile, are reasonably well known and easy to measure because they are transacted in markets. Others-for example, the health costs of air pollution or the value of lost time in traffic congestion-are not transacted in markets and are much more difficult to measure. To evaluate how well our transportation system is serving us, we need to know all the benefits and all the costs. The analytical community has been studying these nonmarket impacts of transportation for a number of years, particularly on the cost side, and a number of studies have produced estimates of various external costs. The time is right to foster discussion and debate over these numbers, the methodologies that produced them, and the concepts and theories on which the methodologies are based.

ORNL-DWG 96M-2662

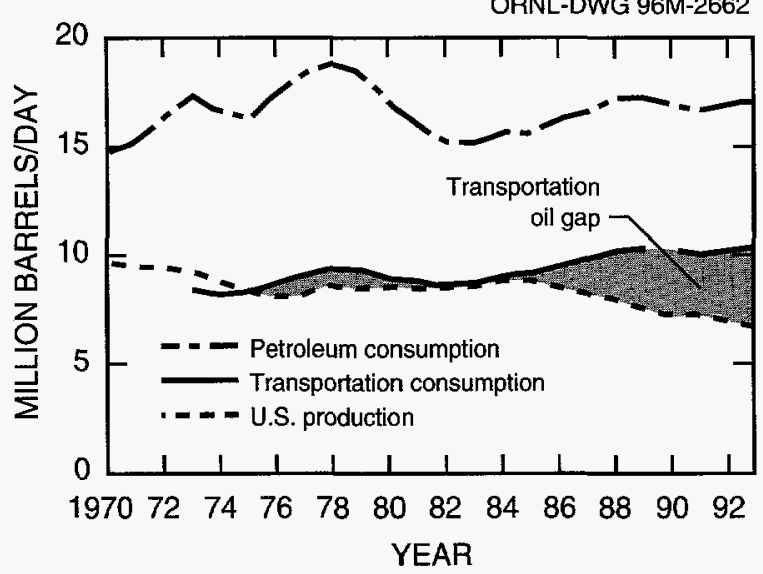

Fig. 2.1. Petroleum production, consumption, and transportation use in the United States, 1970-1993.

Toward this end, CTA and ORNL researchers helped the Bureau of Transportation Statistics (BTS) plan and conduct the Conference on the Full Social Costs and Benefits of Transportation held on July 6-8, 1995, at the National Academy of Science's Beckman Center on the campus of the University of California, Irvine. BTS is interested in monitoring the social costs and benefits of transportation and wanted to assess the state of knowledge in those fields to help decide what information to collect and how to interpret it for the public. The "Irvine Conference" assembled researchers from the United States, Canada, Europe, and Australia who have been working in these fields. The goal of the conference was to advance understanding in the areas of theory, methods, and data on external costs and benefits. The conference provided the first opportunity in the United States for these researchers to interact directly. Fifteen papers were presented in two days of sessions, and about 60 other attendees participated.

The first day's program focused on theoretical topics related to defining and estimating external (or "social") costs and benefits in transportation. The afternoon session included a report on full transportation cost estimates in Europe. On the second day, individual researchers reported on cost estimation in specific areas. In the closing session on Saturday morning, three invited panelists offered their reflections on the proceedings of the conference and the implications for BTS programs. This discussion emphasized the need to go beyond data sets and to help 
improve the understanding of the relationships within transportation. There is a need for continuous, or at least recurrent and regular, monitoring of many transportation indicators. One panelist recommended the revision of transportation components of the Commerce Department's national economic accounts to permit closer examination of the indirect uses of transportation.

\section{Oil Costs}

A recent report by CTA and ORNL researchers ${ }^{2}$ examined the issue of U.S. oil dependence two decades after the first energy crisis. Their study focused on the economic fundamentals: (1) the distribution of petroleum resources, (2) the determinants of oil market power, and (3) the vulnerability of the U.S. economy to price shocks and stable higher prices. The report looked at the economic potential for Organization of Petroleum Exporting Countries (OPEC) nations to exercise monopoly influence in world oil markets. Rather than attempt to predict the likelihood of future oil price shocks, it assessed what their impact on the U.S. economy would be if they occurred. The results of this analysis caution strongly against complacency about the United States' energy security.

A review of recent studies of the impact of the 1990-91 price shock caused by the Persian Gulf War indicates that, taking into consideration its short duration, the Gulf War did proportionately as much harm to the U.S. economy as did previous shocks. The damage of a price shock to the economy depends primarily on total oil cost as a share of GNP; the ease with which the economy adjusts wages and prices to achieve full employment when oil prices spike; and the ability to substitute capital, labor, and other energy sources for oil. The growing concentration of oil use in the transportation sector-with its known reluctance to substitute other fuels for oil and the low short-run price elasticity of oil demand-suggests that the vulnerability of the U.S. economy has not improved.

CTA and ORNL researchers simulated the impact of a 2-year oil supply disruption in the year 2005 . They measured its effect on world oil prices versus the Reference Case forecast of the 1995 Energy Information Administration (EIA) and estimated the damage those higher prices might do to the U.S. economy in terms of lost national product. The results suggest that oil dependence remains a potentially serious problem for the United States. A 13\% reduction in OPEC supply over the EIA's 1995 Reference Case projection would cause oil prices to more than double, from $\$ 21$ a barrel in 2004 to
\$54 per barrel in 2005 (1993 dollars). An additional 8\% reduction in supply would be needed in 2006 to hold the world oil price at $\$ 46$ per barrel for that year. In 2007 , OPEC is assumed to ease up, allowing prices to fall to $\$ 28-\$ 30$ per barrel through 2010 . This requires holding production below the levels of the Reference Case in the out-years but generates an equal amount of revenue. The 2-year supply shock scenario nets OPEC an additional $\$ 600$ billion profit (present value in 1993 dollars).

The cost to the U.S. economy of the 2-year shock is also enormous, about half a trillion dollars (present value, 1993 dollars). Furthermore, use of the U.S. Strategic Petroleum Reserve (SPR) appears to have little impact on either OPEC's profits or damage to the U.S. economy. If the entire SPR is used in the first year of the supply curtailment, the price of oil falls in that year by about $\$ 10$ per barrel to $\$ 44$ per barrel. But if OPEC goes ahead with the 2006 curtailment as assumed, prices jump by $\$ 9$ per barrel to $\$ 55$ per barrel in 2006. It is as if the SPR were jumping on the high end of a seesaw. This same general result applies if the entire SPR is used in the second year, or even if it is spread equally over the 2 years. Use of the SPR dampens prices but also delays the full market response. As a result, once it is used up, prices go higher than they would have gone had it never been used. When the reserve is spread over 2 years, prices increase in 2007.

The best peaceful solution, if it is feasible, turns out to be increasing the short-run and long-run price elasticities of supply and demand. Elasticities can be changed by changing consumer preferences-which is difficult, uncertain, and often politically unacceptable-or by changing technology. R\&D of technology to significantly reduce the cost of energy efficiency improvements, alternative fuels, and alternative vehicle technology, as well as to make it easier and cheaper to find and produce petroleum, could conceivably reduce the cartel's market power to the point where price shocks would be a fruitless strategy. Prices would also be lower during unperturbed market conditions, since the long-run profit-maximizing price would also fall. The maximum benefit to the United States would be achieved if the entire world, and not just the United States, adopted or had access to advanced efficiencies, alternative fuels, and oil supply technologies. The benefit could well amount to trillions of dollars over the next two decades.

Can it be done? Does the Partnership for a New Generation of Vehicles (PNGV), together with other energy research efforts, have the potential to double the price elasticities of oil demand and supply in the United States and the world? CTA and ORNL researchers suggest 
that such questions are both timely and critical to the nation's economic well-being.

\section{Reformulated Gasoline}

The Clean Air Act Amendments (CAAA) of 1990 called for a broad, aggressive attack on the chronic air quality problems of urban America. Among the many innovations of the act was the requirement that "clean fuels," not just clean vehicles, be a part of the solution for cities not attaining the National Ambient Air Quality Standards (NAAQS). Although several fuels qualify as clean fuels, the leading candidate for widespread adoption is none other than gasoline, reformulated to produce lower emissions in conventional vehicles. The major aim of gasoline reformulation (that is, the changing of physical and chemical properties) is to reduce ozone formation by reducing emissions of volatile organic compounds (VOCs) and nitrogen oxides $\left(\mathrm{NO}_{x}\right)$, the principal precursors to ozone formation. Phase I of the reformulated gasoline (RFG) program began in 1995, and emissions requirements will be further tightened in the year 2000 (Phase II). RFG demand in 1995 accounted for about $25 \%$ of the total U.S. gasoline demand.

Under CAAA, EPA is responsible for implementing the RFG program. DOE has worked closely with EPA in analyzing the impacts of RFG requirements for emissions performance. DOE's interest in the RFG program is the development of beneficial regulations without adverse effects on the gasoline production and distribution system. In support of the DOE Office of Energy Demand Policy, CTA staff have analyzed RFG production using the ORNL Refinery Yield Model (Fig. 2.2). ${ }^{3}$

CTA research for DOE has focused on defining RFG specifications that provide cost-effective emissions reduction. Cost-effectiveness is calculated as the cost of an emissions control strategy per ton of emissions reduced. The cost-effectiveness concept allows for a general comparison of gasoline control to other measures such as enhanced vehicle inspection and maintenance programs or retrofit of stationary sources with low-emission burners. Figure 2.3 shows regional RFG costs for Phases I and II. CTA's key findings for Phase II summer RFG production include the following:

- VOC reduction can be achieved at a relatively low cost by reducing gasoline vapor pressure to its lower limit. Further VOC reduction, by changing other gasoline properties such as sulfur content, is dramatically more costly.
- Cost-effective $\mathrm{NO}_{x}$ reduction is about $6.8 \%$, at a reformulation cost of 9.3 cents per gallon for RFG produced in Petroleum Administration for Defense District (PADD) I, the U.S. East Coast.

- Cost-effective $\mathrm{NO}_{x}$ reduction is about $7.6 \%$, at a cost of 6.9 cents per gallon for RFG produced in PADD III (the U.S. Gulf Coast).

- Based on the reformulation costs shown in Fig. 2.3, the total cost of a cost-effective Phase II $\mathrm{NO}_{x}$-reduction policy versus a Phase I policy is about $\$ 790$ million for a summer RFG production season in PADDs I and III.

- Sulfur and olefin reductions are the dominant mechanisms for $\mathrm{NO}_{x}$ reduction in RFG.

Areas with less severe ozone problems than the nine cities that have not attained the NAAQS can also adopt alternative strategies, including RFG programs with less stringent requirements than the federal program. CTA's analysis suggests that substantial reductions in the reformulation costs can be realized by removing requirements that are not related to ozone reduction. VOC and $\mathrm{NO}_{x}$ reductions equivalent to those obtained with federal RFG can be achieved with a $40 \%$ savings in reformulation cost.

\section{TRANSPORTATION PLANNING AND POLICY}

\section{Transportation Network-Based Geographic Information Systems}

By its very nature, transportation is a spatial phenomenon, and the fundamental role of a transportation network is to connect places of opportunity. While the world may not be getting any smaller, better communication and information systems and better transportation networks are bringing places closer in ways only dimly conceived of 30 years ago. As a result, a highly competitive business and transportation sector has begun to take a geographically global and more strategic view of its operations.

For the past decade, CTA staff have been developing and using national transportation network databases in support of a variety of nationwide traffic forecasting and routing studies for various federal agencies. With the support of FHWA's Office of Policy Development, CTA staff in collaboration with UT staff have developed a geographic information system (GIS)-based Highway Network Design and Evaluation System. The goal of 




Fig. 2.2. Jerry Hadder of CTA conducts research on defining reformulated gasoline (RFG) specifications that provide cost-effective emissions reduction.

ORNL.DWG 96M-2663R

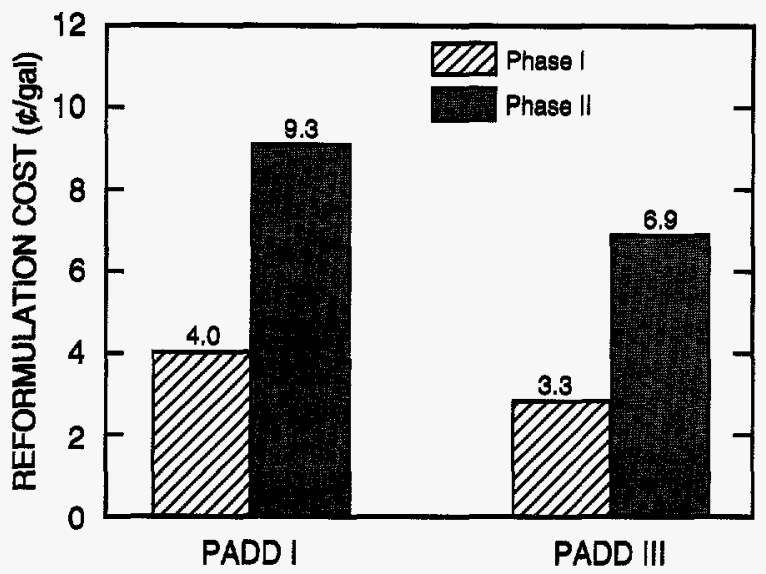

Phase I requires no NOx reduction

Phase II provides $\mathrm{NO}_{x}$ reduction at cost-effectiveness of $\$ 10,000$ per summer ton

Fig. 2.3. Regional reformulation costs for Phases I and II of the reformulated gasoline program.

the research team was to develop rigorous methods for network design that could select national networks in a reasonable amount of time and also allow considerable freedom in specifying the selection criteria. The team successfully solved some very large network design problems within reasonable computing times on a workstation, demonstrating that these methods are usable for actual applications.

CTA staff have worked to combine a number of network analysis routines and supporting national network databases to provide more complex decision support aids, sometimes within commercially available GIS-based software. GIS research within CTA is currently focusing on the following efforts:

- a Mobilization Control System used for operational military convoy routing and management;

- a Prototype Highway Network Design and Evaluation System for the FHWA;

- support for the 1993 Commodity Flow Survey;

- a Freight Network Model that uses GIS-linked analytical procedures to convert regional tonnage estimates by commodity type into approximate vehicle ton-miles;

- a National Transportation Atlas Database that will be a geographical, multilayered transportation database for DOT;

- support for the 1995 American Travel Survey; and

- investigation of alternative geographic data structures and protocols in support of FHWA's Intelligent Transportation Systems initiative.

We anticipate that these efforts will result in a more geographically accurate, multiattribute, and multimodal network database for the nation's (and possibly the continent's) highway, rail, and water transportation systems.

\section{Environmental Implications of Transportation-Land Use Interaction}

CTA staff have been studying how transportation systems can impact the environment through their effects on the subsequent development and use of land. The functional relationship between transportation and other forms of land use is bidirectional and has important implications for the evolution of our urban environments.

Extricating the role of transportation in this land development process is often difficult, especially within urban settings. ${ }^{4}$ While empirical information relating the different types and intensities of site-specific land use to daily trip-making is readily available, there remains considerable uncertainty about how particular spatial arrangements of different land uses impact aggregate demands for vehicle travel. Two complicating factors are involved. First, the process is a dynamic one-the locational decisions being made within each of the 
residential and employment activity sectors ultimately impact each other. Where workers live determines the available labor pool, and where residents work affects their choice of residence. Second, uncertainty as to the eventual outcome of adding transportation capacity grows as we expand consideration from the local scale to consider complete urban areas and multi-city regions. However, it is also over these wider geographic areas that the full impacts of many of our largest investments in transportation infrastructure need to be measured.

Similarly, the effects of adding highway or transit services on future residential development are often difficult to forecast. Urban land use is largely under local control, and development decisions depend on negotiations between land developers and local governments. Here, zoning and other land use regulations have taken priority over concerns about regional developments and interjurisdictional travel impacts. ${ }^{5}$

CTA staff are investigating how the information society is likely to alter the transportation-land use connection in the coming century. A growing number of service and information-based companies already find themselves no longer tied to the geographic location of either their key resource inputs or local markets for their products. Industrial practices such as just-in-time scheduling may also affect the siting needs of companies, as well as their use of freight vehicles. How the nation's households and companies will respond to telecommuting, teleshopping, and other potential travel-reducing options remains an open question. Will our present lifestyles and land use arrangements encourage adoption of these technologies, and will these technologies in turn help to perpetuate or change lifestyles and, subsequently, land use? If these changes in both land use and travel behavior significantly reduce traffic growth rates, then fewer new highway lane-miles may be needed, while future highway expansion projects may be able to provide greater travel time benefits to users of congested roads.

\section{Commodity Flow Survey}

The 1993 Commodity Flow Survey (CFS) was the first attempt to gather nationwide data on the flow of goods and materials within the United States since the Commodity Transportation Survey of 1977. Conducted by the Bureau of the Census, with additional funding and support from DOT, the CFS collected shipment data from a sample of approximately 200,000 domestic establishments engaged in mining, manufacturing, wholesale, and selected retail and service activities. Each selected establishment provided information on a sample of its outbound shipments for a 2-week period in each of the four calendar quarters of 1993. Data reported for each shipment included the city, state, and ZIP code of the origin and destination; the domestic modes of transportation used; the 5-digit Standard Transportation Commodity Classification code of the commodity; the value and weight of the shipment; and an indication of whether the shipment involved a hazardous material, was containerized, or was an export.

One important item shippers could not provide to CFS was the distance covered by a shipment for each mode of transport involved because the shippers generally had no way of knowing the distances that their outbound shipments covered. Therefore, distance by mode of transport had to be obtained by other means. CTA undertook the task of estimating this important piece of information. CTA staff used computer simulation to find probable routes or paths between origin and destination ZIP codes over digital representations of the highway, rail, waterway, air, and pipeline networks and their interconnections.

Estimating mode-specific origin-destination (O-D) distances for the 1993 CFS was a major undertaking that required the time and expertise of CTA as well as UT staff members. Validating the mode-specific distances for millions of $O-D$ pairs required at least as much effort as producing them. Fortunately, GIS software was available to facilitate the validation process. Commercial GISs were used to display selected single-mode and multimodal paths along with the underlying networks, intermodal connections, and ZIP code boundaries. Nevertheless, a considerable amount of manual effort was required.

Intentions are to repeat CFS every 5 years, and planning for the next survey will commence very soon. Already consideration is being given to how the various mode networks and network routing procedures could be improved to yield better results.

\section{Personal Travel Behavior}

Policymakers rely on data about personal travel to measure and understand the reliability, efficiency, capacity, and flexibility of the nation's transportation system and to project its ability to meet future demand. Knowledge about personal travel patterns is also important for assessing the feasibility and efficiency of various new congestion-alleviating alternatives (e.g., high-speed rail, magnetically levitated trains) and the air quality impacts and energy security implications of different policies. An issue of critical importance is how demographic, economic, and social trends will affect personal mobility 
and vehicle travel in the future. The 1990 Nationwide Personal Transportation Survey clearly points to an American society that is becoming more, rather than less, mobile. (See the highlight "Analysis of the 1990 Nationwide Personal Transportation Survey.”)

\section{MILITARY TRANSPORTATION AND LOGISTICS}

\section{Air Mobility}

When the United States provides humanitarian relief or responds to military aggression by deploying forces, the fastest means of moving troops, equipment, and supplies is by air. For this purpose, the U.S. Air Force AMC maintains a fleet of more than 1300 aircraft dedicated to moving military or relief forces into any region of the world. Over the past 7 years, AMC has been working with CTA to develop a state-of-the art scheduling system integrating all of its different peacetime and wartime air mobility planning functions. This system is called the AMC Deployment Analysis System (ADANS).

Since becoming operational in early 1990, ADANS has been used for normal peacetime military movements, training deployments, response to worldwide crises (including Operation Desert Storm), and response to natural disasters such as hurricane Andrew. ADANS was used to develop plans for the recent Bosnian peacekeeping effort. AMC and ORNL staff work as a team to continually define and develop new capabilities for ADANS. For example, CTA staff worked in the Tanker Airlift Control Center at Scott Air Force Base side by side with the airlift planners scheduling the Restore Hope relief operation to Somalia, allowing them to identify firsthand any changes needed in the system. One major change in the Somalian operation was the extensive use of air refueling for aircraft. The ADANS programming staff made changes to facilitate this new mode of operation and provided a basic capability to the schedulers within only a few days. Support for this new approach to air mobility, which integrates the planning of airlift and air refueling, has been developed as a major component of ADANS.

The system provides three optimization modules developed by the CTA Operations Research Group, in addition to the essential tools for editing, managing, and analyzing data.

1. A linear programming-based model estimates the capability of the airlift system to support a large movement.
2. A second model supports schedulers who plan the regularly scheduled peacetime movement of aircraft from the United States to overseas locations. Combining linear and integer programming techniques, this model suggests how often each route should be flown to satisfy the projected demand.

3. The largest model is a dynamic programmingbased scheduler that automatically generates detailed aircraft itineraries based on the planner's constraints.

Although 1996 will be the final year for full-scale development of the ADANS system, ORNL's work with AMC will continue. The airlift planning problem is so massive and difficult that it demands the state of the art in computer hardware and operations research tools. The ADANS team will continue research to "expand the envelope," ensuring the U.S. armed forces the ability to respond quickly and effectively to whatever crises they must deal with, wherever they may be.

\section{Shipping}

The armed forces realized, and it became apparent during Desert Storm, that they needed to be able to track supplies that were sent to support troops. Often no one knew what was inside a container until the container was opened. CTA staff and subcontractors are completing the development of a computer system and database for MTMC that provides worldwide visibility of military surface cargo that passes through common-user ocean ports. This system, called the Worldwide Port System (WPS) Integrated Cargo Database (ICDB), was developed in conjunction with two other MTMC organizations to provide the status of cargo shipments through all stages, from the request for movement through final documentation.

The project presented several challenges for CTA staff. The system needed to be designed to ensure survivability. It had to be able to collect data from all port sites on both coasts and put these data into a central repository. Because CTA was involved only in the completion of the continental United States portion of the system, and because port sites may be temporarily added in contingency situations, the system had to be designed to be flexible and extensible enough to accommodate temporary port sites as well as the expansion of the system to include overseas capability. After careful consideration of several architecture configurations, CTA staff recommended a distributed three-tiered architecture. The top tier consists of one large central database server 


\section{HighLighT}

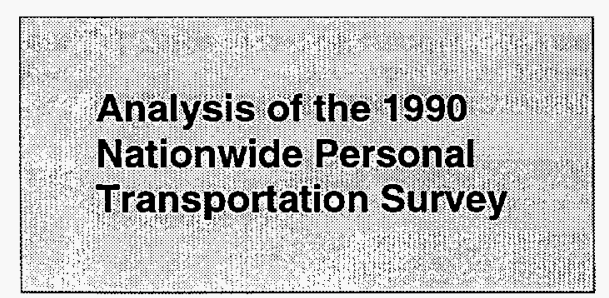

CTA is currently helping DOT analyze and summarize the 1990 Nationwide Personal Transportation Survey (NPTS) results. In the 1990 NPTS, a total of 26,172 households were selected for the sample. The $84 \%$ response rate resulted in a total of 21,869 completed household interviews. Detailed trip information-such as the purpose of trips, mode of transportation, starting time of the trip, trip length (in miles), and trip duration (in minutes) - was recorded for more than 92,000 vehicle trips and close to 150,000 person trips.

Since travel activities are strongly related to demographic characteristics and vehicle-ownership patterns, it is essential to examine changes in these factors in relation to changes in travel behavior. Comparing 1990 and 1969 data, we see the following:

- A 58\% (60 million) increase in the number of licensed drivẹrs, 38 million of whom are women. The percentage of women 16 years and older who were licensed to drive increased from $61 \%$ to $86 \%$. Women's participation in the labor force increased by over $50 \%$, thereby contributing to this enormous increase in the number of female drivers.

- The percentage of households that did not own a vehicle decreased ( $9 \%$ vs $21 \%$ ), while the percentage of households that owned three or more vehicles quadrupled (20\% vs $5 \%$ ).

- By 1990, there were more household-based vehicles than licensed drivers.

- More older individuals were licensed to drive.

Americans not only took more trips and longer trips, but also drove more in 1990 than in 1969. Travel to and from work and errand-running continued to be the most common reasons for trips. However, men and women clearly have somewhat different needs for travel: women traveled more for errand-running than men, while men traveled more for earning a living. For the first time in 1990 , women took more trips than men. Nevertheless, women still drove

\author{
Distribution of vehicle trips \\ taken by households within \\ a Metropolitan Statistical Area \\ by weekday vs weekend \\ and starting time of trip \\ (1990 Nationwide Personal \\ Transportation Survey).
}

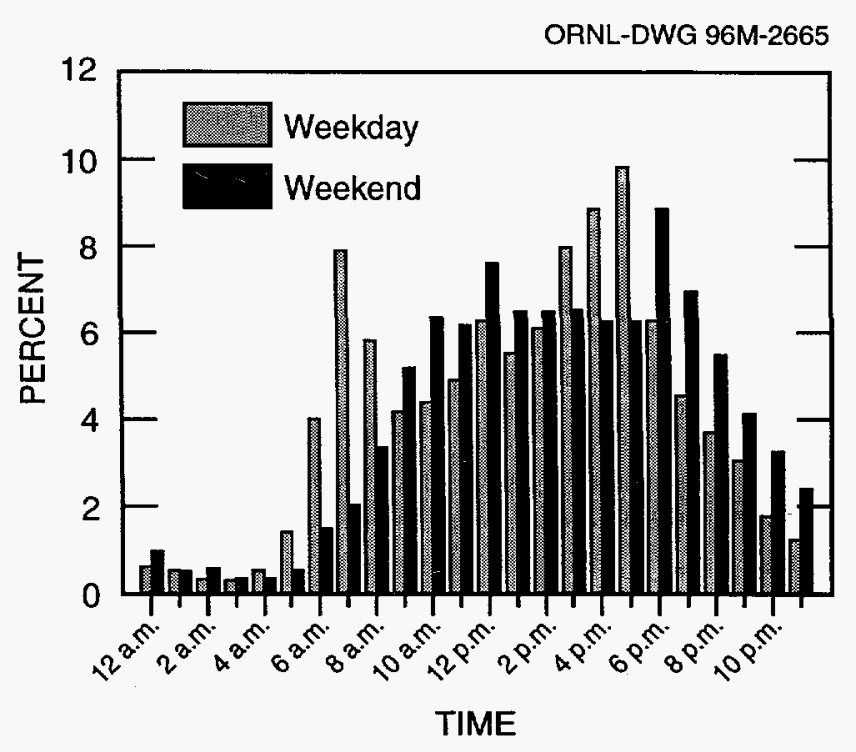


roughly 7000 fewer miles per year than men despite the fact that women in 1990 drove $76 \%$ more than women in 1969.

One idea strongly suggested by the 1990 NPTS data is that several major demographic revolutions, such as the changing societal roles of women, the aging of America, and increasing vehicle ownership, all point to a society that is growing more mobile.
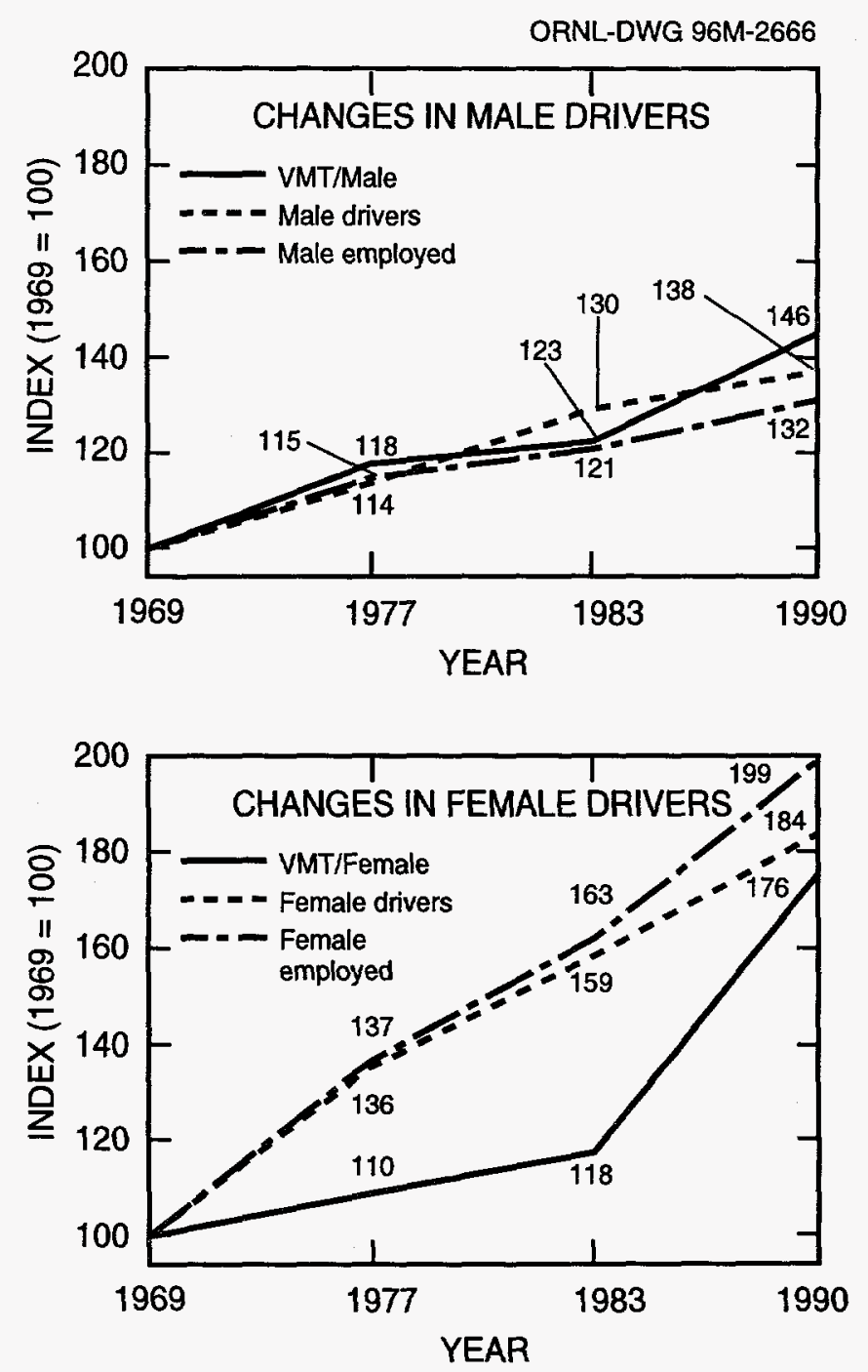

Changes in male and female travel behavior from 1969 to 1990. 
located in Falls Church, Virginia. The middle tier consists of regional processing servers, called hubs. Currently, one is located on the East Coast for Atlantic Coast ports, and one is on the West Coast for Pacific Coast ports. For initial operating capability, Gulf Coast ports were assigned to either the Atlantic or the Pacific hub. The hubs are designed to do most of the data transfers from the sites to the server and from the server to the sites, as well as data processing. Additional hubs will be added for overseas capability. All of the port sites are components of the bottom tier of the architecture. Figure 2.4 shows the architectural configuration for the ICDB.

The system consists of a user interface, automated data processing modules, data extraction modules, and a system administration/database administration module. The user interface processes allow a user to build shipment records, to divert or resend manifests, to perform shipment (single or aggregate summary) queries of the database, to produce reports, or to perform some functional tasks, such as editing and redistributing code tables. The user interface is designed so that very few users will see all of the user interface processes. For example, most users will have the ability to perform queries, but few will have the ability to perform functional tasks.

The second category of ICDB processes includes those that occur automatically. These include program code written as UNIX shell scripts and ORACLE stored procedures that are automatically activated every 5 minutes on each hub to pull data from the hub's associated port sites. There are also scripts to validate and convert data into the ICDB format, as well as scripts that extract data and automatically transmit them to other systems. The automated scripts that perform integrity checks on the system hardware and software are an integral part of these processes. ICDB is designed so that there are three connection routes from the server to the hubs. If a hub fails an integrity check because the server cannot make a connection, the system will automatically attempt the other two routes. If no connection can be made through any of these routes, the active hub will take over for the "unreachable" hub until a connection with it is made. This design ensures system survivability.

The third category of ICDB processes includes those that help to maintain the system. Some of these scripts are aids to be used by a system and/or database administrator. Others automate the process of adding or deleting a user, a site, or a hub to the system. This key feature provides the capability to quickly add port sites during contingency or emergency situations, as well as the ability to expand hubs as ICDB becomes an overseas system.

CTA became involved in helping MTMC develop ICDB in 1992. During 1995, staff members have often been on travel, either in Washington, D.C., or (more frequently) on the West Coast to participate in system development and system qualification tests. CTA staff are proud that the system they helped develop passed

ORNL-DWG 96M-2664

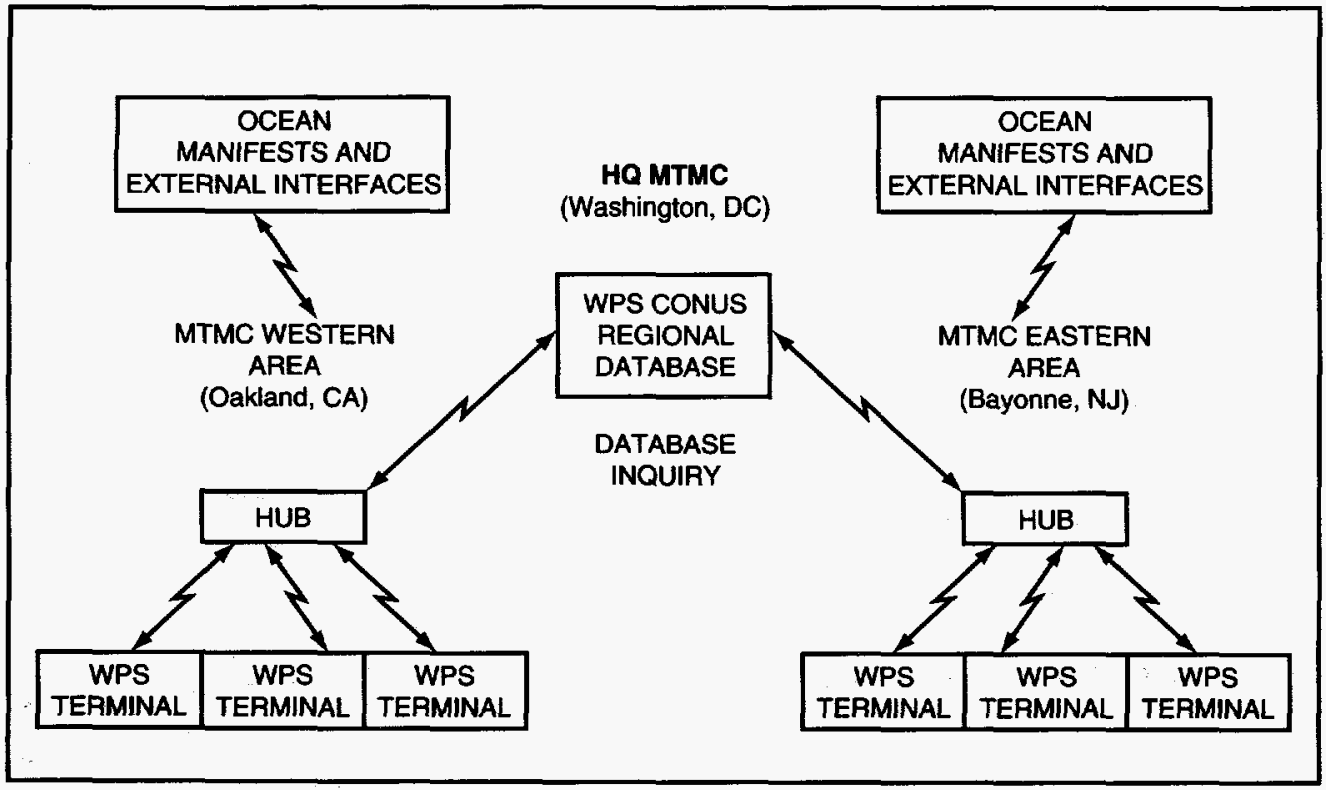

Fig. 2.4. The architectural configuration for the Integrated Cargo Database System. 
qualification tests in August 1995. In September 1995, ICDB was successfully implemented.

\section{INTELLIGENT TRANSPORTATION SYSTEMS}

Past approaches to alleviating urban traffic congestion by simply building and extending new roadways are becoming more difficult and expensive because of increased land costs and greater public concern over the environmental and social costs of transportation systems. Future improvements must rely on using existing facilities more wisely. To provide such improvements, Intelligent Transportation Systems are being developed to exploit computer technologies and electronic communications to improve the efficiency, productivity, and safety of existing transportation facilities.

\section{ITS Spatial Data Integration and Location Referencing System}

The CTA ITS staff were tasked by FHWA to analyze ITS spatial data requirements and to recommend federal action to meet those needs. Deployment of ITS will greatly expand the need for interoperability between spatial databases. Many of the data that will be exchanged between ITS applications involve the location of things (incidents, congestion, transit vehicles, routes). This need to transfer spatially referenced data between systems with heterogeneous databases is not adequately met by current standards and conventions.

CTA is currently working on carrying out one of the key recommendations resulting from this work-development of a common location referencing system for ITS. This system is needed because existing spatial databases have been created for specific needs and usually within limited geographic areas. Each application developed under existing spatial databases employs a unique referencing method. This method is unacceptable for ITS vehicles capable of cross-country travel.

CTA's work has two principal components. The first is referencing information that consists of a collection of points on the major roads that will be incorporated into all ITS spatial databases. This data will create a common frame of reference to support the transfer of spatial information between databases. The second component is a location referencing message protocol (LRMP). Because different applications will have different referencing needs (points, addresses, links, routes), the location referencing system must be able to support multiple methods. The LRMP will provide a framework for transmitting location information using different referencing methods in a common format. Taken together, these two components will result in a standard system for location referencing that will overcome a critical barrier to nationwide deployment of ITS.

\section{Advanced Transportation Management Training Center}

A central element of ITS will be advanced transportation management systems-ATMS-to control the movement of vehicles on networks of urban streets and freeways (Fig. 2.5). In addition to the technical challenges of implementation, ATMS will represent a learning challenge to the operators who must use them to manage city traffic. In a project for the FHWA Office of Traffic Management and ITS Applications, CTA staff have designed and are implementing a prototype Advanced Transportation Management Training Center (ATMTC). The ATMTC is designed to give transportation management center staff hands-on experience with state-of-the-practice traffic management software and will ultimately allow direct comparison of available commercial products. Realistic operation of the ATMTC features simultaneous, linked operation of commercial traffic control software, and a microsimulation of traffic on the street network. Combined operation of the two computer programs will allow operators to experience and manage a close approximation of events that would actually take place in a traffic management center.

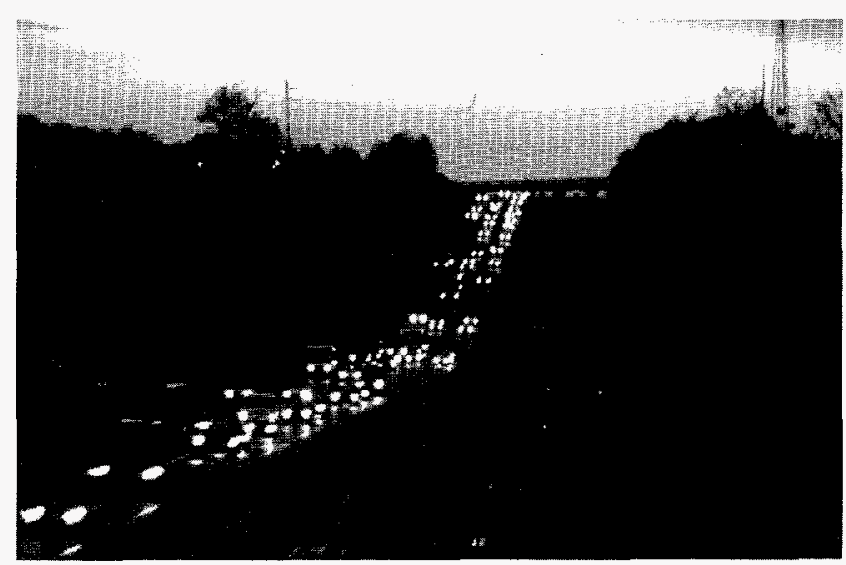

Fig. 2.5. Intelligent Transportation Systems staff work on the challenge of managing city traffic through ATMS-advanced traffic management systems. 


\section{TRAF Simulation System}

Intelligent transportation systems are based on the premise of using advanced technologies in telecommunications, electronics, and computers to improve the nature and quality of highway travel while making it safer and more efficient. One of the key players in the analysis and assessment of ITS technologies is computer simulation. For more than a decade, ORNL has participated in the development of the FHWA TRAF simulation system. This system includes microsimulation models (i.e., NETSIM and FRESIM, together known as the CORSIM model) and macrosimulation models (i.e., NETFLO I, NETFLO II, and FREFLO, constituting the CORFLO model). ORNL's work with these traffic simulation models has been in the area of user interfaces, database management, and statistical analysis of the simulation output data.

More recently, CTA has been developing ITRAF (Interactive Traffic Data Editor for TRAF), a graphical user interface for the TRAF simulation models. ITRAF also provides comprehensive error checking, ensuring the accuracy and consistency of the data.

Currently, ITRAF 2.0 is being tested by FHWA. When released, sometime in 1996, it is expected to significantly expand the usage of traffic simulation models, restricted up to now because of the difficulties in setting up the data for those models.

\section{Dynamic Traffic Assignment Systems}

The success of important ITS subsystems such as Advanced Traveler Information Systems (ATIS) and ATMS depends on the availability and dissemination of accurate and timely estimates and predictions of traffic conditions. FHWA is currently addressing the requirement for such information through its sponsorship of the development of a Dynamic Traffic Assignment (DTA) system. The DTA system will use state-of-the-art traffic estimation and prediction models running on a networked collection of workstations and will form a bridge between real-time traffic surveillance systems and the ATIS and ATMS systems.
CTA's ITS group has been designated to oversee the development and evaluation of the required DTA subsystems and is responsible for integrating these components into an effective system. The DTA system will be developed in multiple phases over several years beginning with Phase I, which will produce a functional DTA system. Later phases will result in a deployable, real-time system.

In October 1995, the ITS group concluded a competitive procurement with the award of two contracts supporting the Phase I effort. The winning proposers were the Massachusetts Institute of Technology and the University of Texas at Austin. The ITS group looks forward to cooperating with these two preeminent institutions in the development of the DTA system over the next 2 years.

\section{REFERENCES}

1. S. C. Davis and S. G. Strang, Transportation Energy Data Book: Edition 15, ORNL-6856, Oak Ridge National Laboratory, Oak Ridge, Tenn., March 1995.

2. D. L. Greene, D. W. Jones, and P. N. Leiby, The Outlook for U.S. Oil Dependence, ORNL-6873, Oak Ridge National Laboratory, Oak Ridge, Tenn., May 1995.

3. G. R. Hadder, Reformulated Gasoline: Costs and Refinery Impacts, ORNL-6747, Oak Ridge National Laboratory, Oak Ridge, Tenn., March 1994.

4. F. Southworth, A Technical Review of Urban Land Use-Transportation Models as Tools for Evaluating Vehicle Travel Reduction Strategies, ORNL-6881, Oak Ridge National Laboratory, Oak Ridge, Tenn., July 1995.

5. F. Southworth and D. W. Jones, Travel Reduction Through Changes in Urban Spatial Structure: A Search for Relationships and Policy Instruments, Energy Efficiency in the U.S. Economy, Technical Report Four, Office of Energy Efficiency and Alternative Fuels, U.S. Department of Energy, in press. 


\section{3}

\section{Efficiency and Renewables Research Section}

James VanCoevering Section Head

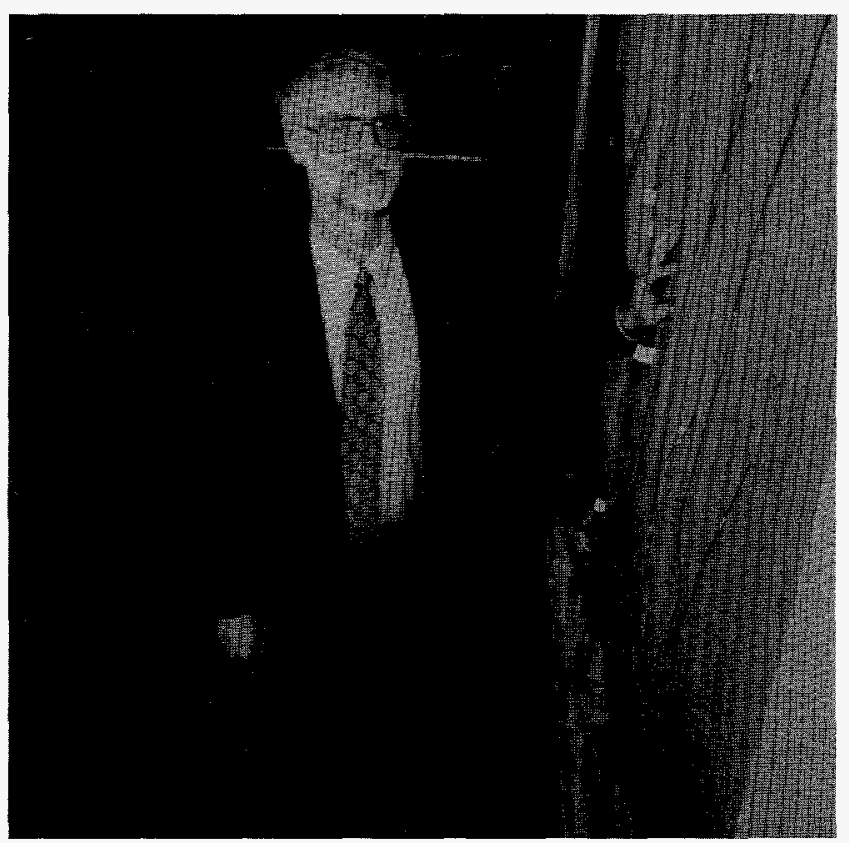

buildings, equipment, and appliances. The Thermal and Environmental Control Systems program applies advanced thermodynamic techniques to improve energy efficiency in such diverse areas as refrigeration and thermal management of paper mill processes. The Power Systems Technology program pursues opportunities to increase the effectiveness of the nation's electric transmission and distribution systems by helping to resolve the concerns over the health effects of electromagnetic fields, as well as by developing advanced methods for power system control and high voltage transmission. Major sponsors include DOE - especially the Office of Utility Technologies, the Office of Building Technologies, and the Federal Energy 
Management Program-as well as DOD under various programs and offices.

In an era when the value of research is measured not by the technical sophistication of the work, but by the speed with which the results can be put to use, ERRS has sought closer ties with a wide range of government and private partners. For instance, since the dedication of the BTC in May 1994, more than 200 private users have made use of its staff and testing facilities to search for solutions to real problems in building science. ERRS staffers have also worked directly with industrial partners-in some cases for long periods on assignment at the partner's location-to resolve production problems and speed commercialization of advanced technologies. Such partnerships and collaborative relationships replace the old sequential model of technology development followed by technology transfer with a new approach emphasizing concurrent development and deployment to improve research targeting and to speed market acceptance of useful technologies.

\section{BUILDINGS TECHNOLOGY CENTER PROGRAMS}

The BTC is ORNL's newest National User Facility and provides the building and appliance industries with a unique combination of testing and analytical capabilities. The technical focus of the BTC is a systems approach that combines analytical and modeling expertise on real buildings with research staff and test facilities. The Center's goal is to develop and validate cost-effective, energy-efficient, environmentally acceptable new and retrofit building envelope and heating/cooling equipment technologies. Organizationally, the BTC encourages partnerships with users such as manufacturers, universities, government agencies, or private individuals worldwide to conduct proprietary or nonproprietary research and to provide technical support for resolution of in-field building energy-efficiency problems.

Until June 1995, most users were accommodated through cooperative research and development agreements (CRADAs). Since then, user agreements have provided a simpler method. This new approach is intended for producers of building materials or equipment and allows them to perform tests of a proprietary nature using the staff and facilities of the BTC without the need for the DOE cofunding required by a CRADA. Testing and computer modeling services can be provided and a report jointly authored by BTC staff and the user. This approach has been especially attractive to users seeking to demonstrate compliance with the Building Officials
Model Energy Code and the American Society of Heating, Refrigerating and Air Conditioning Engineers (ASHRAE) 90 series standard for energy-efficient design of new buildings.

A ceremony dedicating the BTC in May 1994 was the centerpiece for a series of activities highlighting Center capabilities (Fig. 3.1). A workshop on low-slope reroofing brought together roofing professionals to discuss alternatives in the reroofing decision-making process. An all-day Southeast Region Building Energy Efficiency Research Roundtable explored development of energy-efficient building technologies by regional research organizations. An industry panel on housing innovation discussed the significant forms of past and present innovation in the housing industry, and a project review session examined global warming impacts of next-generation, ozone-safe technologies for refrigeration, air conditioning, and insulation.

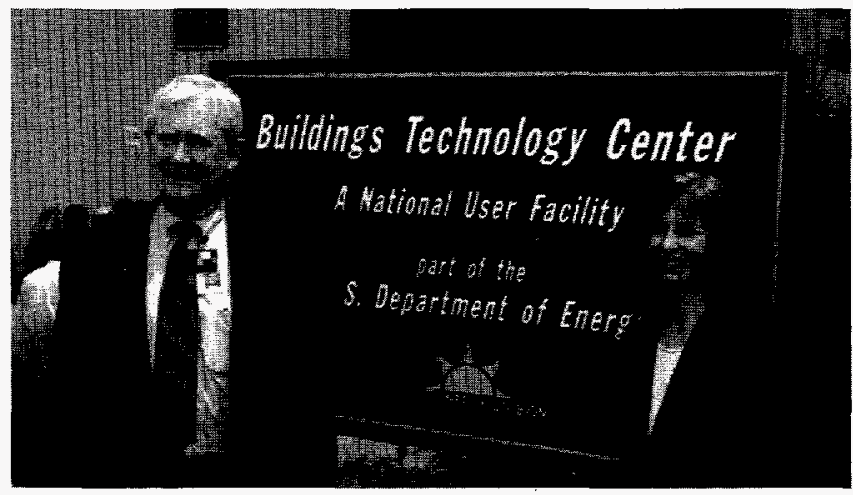

Fig. 3.1. Christine Ervin, DOE Assistant Secretary for Energy Efficiency and Renewable Energy, and Al Trivelpiece, ORNL director, at the dedication ceremony for the Buildings Technology Center.

\section{Building Envelope Research}

In addition to forming a structural shell, the building envelope (the walls, roof, and foundation) functions as a system to minimize unwanted energy flows into or out of the building. In conjunction with industrial partners, the BTC program in envelope research carries out large-scale experiments to quantify the behavior of proposed envelope improvements and provide a solid basis for technology development and validation. Testing facilities at the BTC include the large-scale climate simulator, capable of testing nearly full-size attics under climate conditions that simulate any location on earth. A rotatable, guarded hot box permits testing of 
full-size upright or inclined wall sections-including windows, doors, and/or skylights-under static or dynamic conditions of temperature and wind pressure. Outdoor facilities allow monitored, large-scale testing under actual ambient conditions.

A significant focus of building envelope research has been technology support for sustainable development. Sustainable technologies are those that either reduce waste generation, limit aging of building assets, or provide pathways for reuse or recycling of materials. Examples of such research include the study of aging of insulating foams, reduction of waste from reroofing, and greater use of recycled materials in foundation blocks. ${ }^{1-3}$

\section{Roofs}

Polyisocyanurate foam board insulation is widely used in the roofing industry. As currently manufactured, this board uses a chlorofluorocarbon (CFC) blowing agent whose production has been banned because of ozone-depletion concerns. The requirement for alternative blowing agents has heightened industry interest in the aging properties of insulating board specifically. There are concerns about the ability of accelerated-aging tests to simulate the field-aged behavior of the material accurately. In 1990 the Polyisocyanurate Insulation Manufacturers Association (PIMA) supplied ORNL with samples of insulating board under a CRADA, with the intent that a suitable accelerated-aging test be developed and validated against actual aging data. This 5-year study, completed in 1995 , confirms that a 180-day accelerated-aging procedure developed under the CRADA predicts within $2 \%$ the actual integrated resistivity of full 1.5 -in.-thick polyisocyanurate boards blown with hydrochlorofluorocarbon (HCFC)-141b after more than 5 years of field exposure in the roof of the ORNL outdoor test facility.

Transportable manufactured housing represents a significant share of new housing in rural areas. Unique construction details, such as limited attic space and an absence of attic eave overhang, constrain application of traditional energy-efficiency measures in ways that are difficult to model. Clayton Homes, a local East Tennessee manufacturer and CRADA partner, supplied the BTC with a full-sized attic section to explore thermal performance of its product and examine opportunities for improving efficiency. Envelope research staff developed necessary measurement and modeling techniques and completed full-scale tests of advanced insulation designs for single-wide manufactured attic systems. The project found that insulation compression and inherent thermal short circuits make significant thermal efficiency improvements difficult. The test protocols developed under the CRADA provide the industry a means of accurately comparing attic insulation alternatives and validating calculations for Energy Code compliance.

\section{Walls}

Envelope researchers and users are working to establish an improved national rating and labeling system that would more accurately reflect a wall's thermal resistance, or insulation value. Current rating procedures result in a wall $\mathrm{R}$-value based on calculations at the center of a wall at best and typically at the center of a wall cavity. For example, a wall with R-19 insulation would typically be rated as R-19. However, this approach does not take into account thermal shorts caused by corners, doors, windows, and studs made of wood or metal, which have negligible insulating value. Industry-funded tests now under way will lead to a nationally accepted consumer label for rating whole-wall thermal performance. Four companies are involved in the program; 36 more have expressed interest in participating. This project not only attracts private industry investment but makes a major contribution toward promoting greater application of energy-saving wall systems. A World Wide Web site (http://www.cad.ornl.gov/kch/demo.html) has been set up for distributing the results, and an open invitation to participate has been extended worldwide to wall-system developers. The ASHRAE journal presented a technical article that describes results from this project in the March 1996 issue. $^{4}$

As wood prices increase, more houses are being constructed with metal wall framing rather than traditional wooden studs. The difference in thermal conductivity between metal and wood clearly affects the thermal performance of such a wall system, though there is little agreement in the industry on how to quantify the effect. The ORNL modified zone method-developed under a CRADA with the American Iron and Steel Institute (AISI), the National Association of Home Builders, and ASHRAE-is the most accurate simplified thermal performance calculation procedure for lightweight metal frame thermal conductivity factors. ${ }^{5}$ This modified zone method provides an accurate estimate of the zone factor input to the ASHRAE calculation that is sensitive to common metal stud wall variations. An accompanying step-by-step calculating form provides less opportunity for user calculation errors than the explanation found in the current literature. This new method is to be included in the next issue of ASHRAE's Handbook of Fundamentals, available in 1997. 


\section{Foundations}

Jan Kosny and Jeff Christian received an Innovation Certificate of Recognition upon the filing of a patent application with the U.S. Patent Office for a mortarless block system. A half-page story on this system in the December 1995 issue of Popular Science generated dozens of letters and phone calls expressing interest in licensing this technology. The system uses interlocking block sections and reinforcement units to form a self-supporting wall that can be erected without mortar. One layer of the wall can be made of high-density concrete for load-bearing purposes, and the other of low-density concrete that could contain recycled products such as fly ash, wood scraps, or foam waste for insulation purposes.

\section{Fenestration}

In the last year and a half, the rotatable guarded hot box in the BTC was modified with the necessary instrumentation and peripheral equipment to evaluate the thermal performance of fenestration (window) products. Validation tests were performed on a wood casement window to generate a thermal transmittance value that agrees with its label thermal performance to within $3 \%$. These experiments place the BTC in a position to confidently support the National Fenestration Rating Council.

\section{Education}

While students at both the secondary and university level have been regular participants at the BTC for years (see Fig. 3.2), the development of teaching materials for middle and high school science teachers is a new endeavor. With funding from the National Science Foundation and the Appalachian Regional Commission, ERRS was able to offer Research Immersion seminars, aimed at improving the understanding of real world energy issues, to 26 high school and elementary science teachers. The teachers actually designed and constructed an energy-efficient building, which they then tested in the Center's large-scale climate simulator. The $4 \times 4 \times$ $5 \mathrm{ft}$ structure was designed with metal framing according to AISI-approved structural details, and the low-slope self-dryable roof was constructed according to a patent application filed by André Desjarlais (see the highlight "Self-Drying Roof Will Save Energy and Reduce Waste").

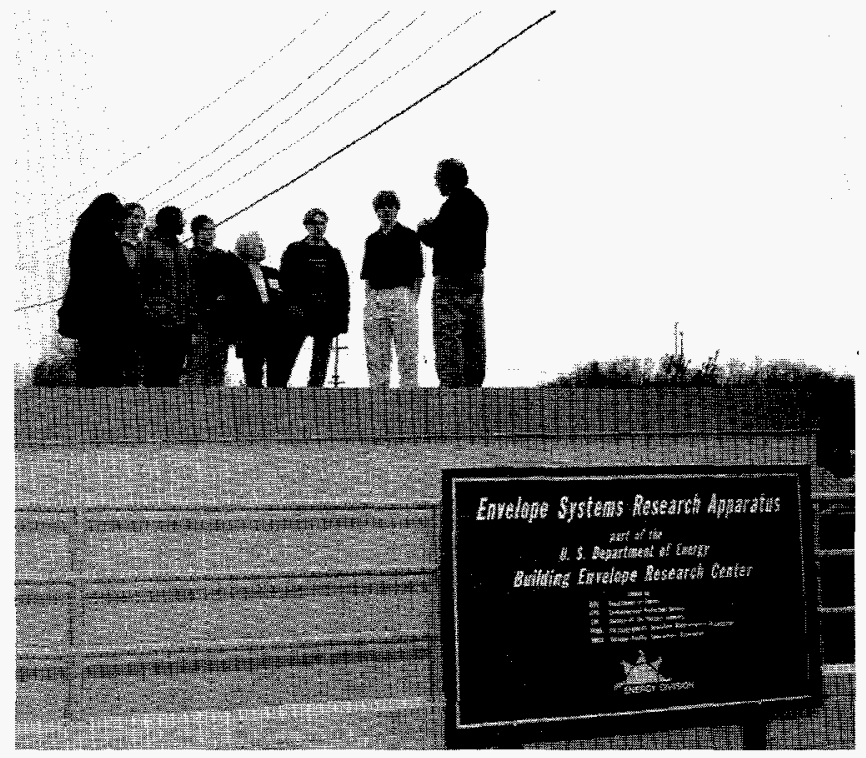

Fig. 3.2. André Desjarlais giving a rooftop orientation of the Building Envelope Research Center to students attending the 30th Annual Junior Science and Humanities Symposium, February 1995.

\section{Building Equipment Technology Development}

The building equipment component of the BTC focuses on developing and deploying more efficient heating, cooling, and refrigeration equipment for residential and commercial buildings. The program also contributes to the transition by U.S. industry from CFC and HCFC refrigerants to energy-efficient, atmospherically safe alternatives. Execution of the program emphasizes strong ties with industry, including work with individual companies, industry consortia, and major trade associations on several current CRADAs. Sponsors include the Electric Power Research Institute (EPRI) and the Gas Research Institute (GRI).

\section{Thermally Activated Heat Pumps}

Current and projected low prices for natural gas, as well as environmental concerns about the production of greenhouse gases when coal is burned to produce electricity, have stimulated interest in gas-fired absorption heat pump and chiller technology. Generator-absorber-heat exchanger (GAX) technology is a breakthrough that 
promises heating efficiency at least $50 \%$ higher than that of the best current gas-fired technology, plus competitive cooling efficiency. ${ }^{6,7}$ The National GAX Program partnership was formed in late 1994 to expedite moving the GAX technology from laboratory proof-of-concept to a market-ready GAX heat pump product. A DOE-ORNL partnership with Carrier/United Technologies [a major heating, ventilation, and air-conditioning (HVAC) manufacturer] and the natural gas utility industry (led by the American Gas Cooling Center and GRI) plans to introduce GAX products into the market by 1997 . In 1995, the Carrier/United Technologies team completed a critical design review of the available GAX hardware for functionality, cost, performance, and manufacturability. The two design approaches that emerged are being pursued in parallel. The current development involves evaluating manufacturing processes and performance/cost trade-offs in prototype hardware for the two different designs, leading to selection of a design in early 1996.

ORNL and DOE, working with the U.S. absorption chiller manufacturers and the U.S. gas industry, have also taken the lead in developing the next generation of absorption chiller technologies, known as "triple-effect" cycles. Two different triple-effect cycles, both patented by ORNL researchers, are currently under development. ${ }^{8}$ The dual-loop triple-effect technology was licensed by Trane Company. The Trane development and commercialization program, cosponsored by GRI, has a 190-ton prototype in operation (see Fig. 3.3), with commercialization expected in 1996-97. In a second program, York International is cost-sharing with DOE and ORNL to

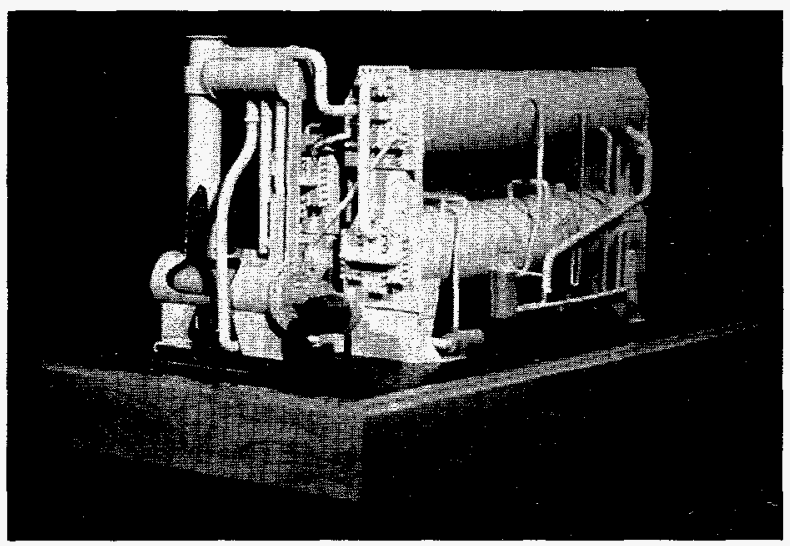

Fig. 3.3. A model of the Trane triple-effect absorption chiller, a technology licensed from ORNL, which will offer efficient gas cooling performance and lower operating costs in large commercial applications. develop and commercialize a triple-effect chiller based on a double-condenser coupled cycle patented in 1993. These programs are targeted at high-efficiency cooling with coefficients of performance (COPs) of 1.4-1.6. Market introduction is anticipated in 1997.

To maintain U.S. technical leadership in the absorption heating/cooling area, ORNL and DOE have initiated research on second-generation concepts using both advanced cycles and advanced working fluids. For example, an ammonia-based quaternary (four-part) fluid mixture has been developed for use in advanced systems (Fig. 3.4). Through a competitive solicitation, several candidate advanced cycles were selected and are being evaluated. These technical developments will be integrated into an advanced-cycle $H I-C O O L$ absorption heat pump system that has a targeted cooling performance at least $30 \%$ better than that of the GAX heat pump. This advanced system is intended for small commercial buildings nationwide and residential buildings in the South, where cooling loads are high.

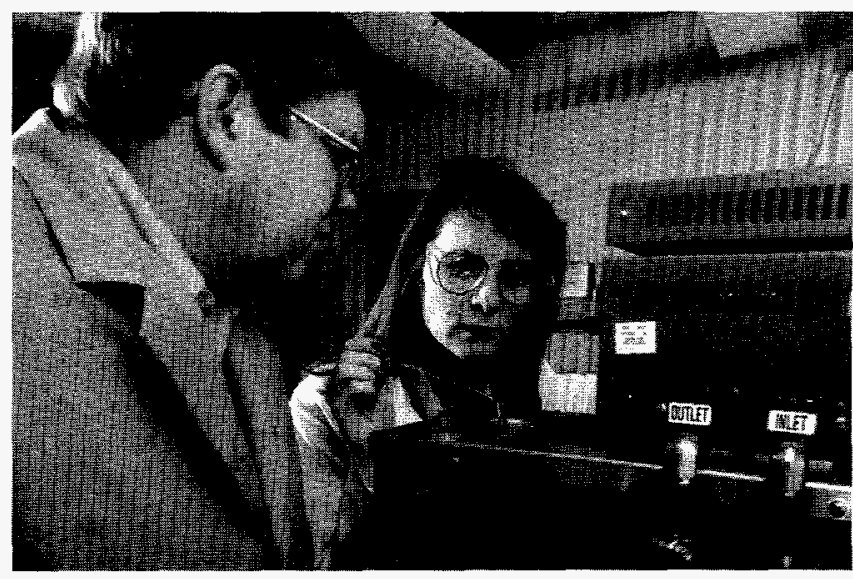

Fig. 3.4. ERRS staff members Patricia Adcock and Delmar Fraysier measure the specific gravity of a potential multicomponent working fluid for advanced absortion chiller applications.

ERRS is also developing modular computer software for simulating and comparing the performance of various absorption cycles. ${ }^{9}$ A first-generation model, called ABSIM, has been used to evaluate advanced-cycle absorption equipment configuration options. ABSIM is now being transferred to industry, and its capabilities are being enhanced. The goal of the computer-aided design activity is to provide designers of absorption systems the same level of design and performance optimization tools available for electric heat pumps (see Fig. 3.5). 


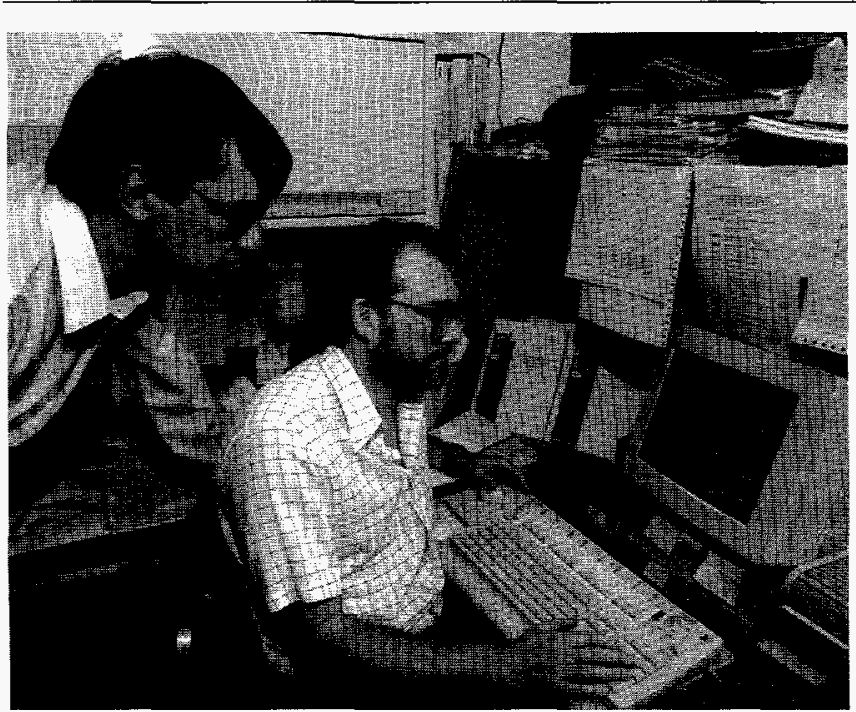

Fig. 3.5. Van Baxter (left) and Keith Rice examine a graphical output screen generated by the DOE/ORNL heat pump design model. DuPont is collaborating with ORNL under a CRADA to generate a new version of this model suitable for heat pump and air-conditioner design analysis using chlorine-free alternative to $\mathbf{R - 2 2}$, including zeotropic blends.

ERRS also began work in FY 1995 to develop thermally regenerated desiccant cooling and dehumidification technology. Recent advancements in desiccant materials and manufacturing technology have substantially improved the performance and reduced the cost of desiccant equipment. Through a competitive proposal process, two development partnerships were selected to develop, demonstrate, and facilitate market acceptance of desiccant equipment: SEMCO teamed with Trane, and Engelhard/ICC teamed with Carrier. Both partnerships involve substantial industry cost-sharing. DOE and ORNL are also collaborating with a broader consortium of HVAC, desiccant component, and materials manufacturers to benchmark current performance, develop rating/certification methods, and develop generic design tools and application software.

\section{Refrigeration Systems}

Concern over the ozone-depletion potential of CFC refrigerants used in residential and commercial cooling equipment has led to efforts to find alternative refrigerants. ORNL's Refrigeration Systems program focuses on development of non-CFC refrigeration, air-conditioning, and heat pump technologies that simultaneously establish new benchmarks for efficiency.

Significant progress was made on a major CRADA with the Appliance Research Consortium on advanced refrigerator/freezer technology. Tests were completed with R-134a and high-efficiency components in a 1993 baseline $20-\mathrm{ft}^{3}$ domestic refrigerator-freezer (Table 3.1). ${ }^{10,11}$ The $1.41-\mathrm{kWh} / \mathrm{d}$ energy use experimentally achieved to date substantially exceeds the $2-\mathrm{kWh} / \mathrm{d}$ level required by the 1993 industry standard. Further experimental activities are planned in FY 1996 to move closer to the project goal of $1.0 \mathrm{kWh} / \mathrm{d}$.

Table 3.1. Measured and calculated energy consumption of Appliance Research Consortium CRADA test refrigerator/freezer

\begin{tabular}{lccc}
\hline Case & $\begin{array}{c}\text { Measured } \\
\text { results }\end{array}$ & $\begin{array}{c}\text { Calculated } \\
\text { results }\end{array}$ & $\begin{array}{c}\text { Manufacturer's } \\
\text { data }\end{array}$ \\
\hline A. Baseline unit & 1.80 & 1.79 & 1.76 \\
$\quad$ Energy, $\mathrm{kWh} / \mathrm{d}$ & 41.3 & 41.3 & 40.3 \\
$\quad$ Run time, \% & 1.70 & 1.52 & \\
$\begin{array}{l}\text { B. Case A + 2-in. freezer + 1-in. fresh food insulation } \\
\text { Energy, kWh/d }\end{array}$ & 38.6 & 35.1 & \\
$\quad$ Run time, \% & & & \\
C. Case A + 4-in. freezer + 2-in. fresh food insulation & 1.65 & 1.47 \\
$\quad$ Energy, kWh/d & 37.4 & 33.8 & \\
$\quad$ Run time, \% & & & \\
$\begin{array}{l}\text { D. Improved insulation + 5.95 EER compressor, } \\
\text { high-efficiency fans, larger evaporator, and liquid-line } \\
\text { shut-off valve }\end{array}$ & & & \\
$\quad$ Energy, kWh/d & 1.41 & 1.18 \\
$\quad$ Run time, \% & 42.3 & 43.0 \\
\hline
\end{tabular}


Research continued to develop heat exchanger technologies that deliver improved performance with zeotropic refrigerant mixtures. A preliminary design/analysis code for air-refrigerant heat exchangers using zeotropes was written based on algorithms developed in FY 1993. Comparisons with data obtained using the new test loop in Building 3115 showed that the code predicted loads to within $\pm 20 \% .^{12}$

\section{The Technology Introduction Partnerships Program}

DOE is expanding its energy-efficiency activities from its traditional $R \& D$ role into market-oriented cooperative programs. With authority granted by the Energy Policy Act of 1992, DOE initiated the Technology Introduction Partnerships (TIPs) program to promote retail sales of energy-efficient appliances. The program covers equipment and appliances for space heating and cooling, water heating, lighting, refrigeration, laundry, cooking, and other services in residential and commercial buildings. This program emphasizes understanding the market barriers for new and emerging high-efficiency equipment technologies and using partnerships with private-sector stakeholders to stimulate "market pull" to increase market penetration of high-efficiency products.

In the first half of FY 1994, the ERRS Building Equipment Technology program assisted DOE in organizing eight workshops to identify what is preventing highly efficient appliances and equipment from attaining greater market acceptance. More than 200 representatives from manufacturing and building industries, utilities, retailers, wholesalers, state/local government agencies, and nonprofit organizations participated. Based on the interaction with stakeholders at these workshops and on direct contact, DOE concluded that federal action and technical assistance is not only desired but also crucial to the expansion of these markets. ${ }^{13}$ The information and insight gained from this process was used to develop and structure the TIPs program.

ORNL has lead responsibility for three major program elements under TIPs: the Efficiency Retailer Partnership, the High-Efficiency Laundry Market Transformation Program, and the Energy Service Company Partnership. These partnership programs were all initiated in FY 1995 and will continue into FY 1996.

\section{Existing Buildings Research}

The Existing Buildings Research program works to improve the energy efficiency of residential, commercial, and industrial buildings in the United States, placing a balanced emphasis on improved technologies and practices, validation of performance and savings potential, and wide deployment and implementation of cost-effective strategies. The Existing Buildings staff support programs in existing-buildings efficiency research, Rebuild America, weatherization, industrialized housing, and advanced housing. The staff also supports the U.S. Department of Housing and Urban Development (HUD), public housing authorities, and the DOD military family housing programs.

\section{Residential Buildings}

Efforts to improve energy efficiency in housing continued with a major project supporting military family housing revitalization efforts. The project-sponsored by DOE, the U.S. Air Force, and the U.S. Army-developed a final version of a design guide for energy-efficient military family housing. This guide, written for the architectural and engineering firms developing detailed revitalization and new construction designs, provides information on the most current efficiency technologies as well as detailed procedures for selecting cost-effective measures.

Another goal-to develop and test advanced diagnostic techniques, audits, and efficiency measureswas addressed through several projects. A cooperative field test completed in Phoenix, Arizona, found that typical houses have repairable air-distribution problems that lead to increased energy usage and diversified electric demand. ${ }^{14}$ The benefits from consumer and/or utility perspectives are sufficient to justify repairs of these systems.

The efficiency of electric space-cooling equipment has increased tremendously in recent years, but the cost of completely replacing an entire system in an existing home is prohibitive for most homeowners. Laboratory tests demonstrated the feasibility of replacing the compressors in existing residential and small commercial heat pumps and air conditioners with smaller, more efficient compressors. A $30 \%$ increase in system efficiency was measured from this proof-of-concept testing, and efforts are now under way to conduct field tests and evaluate the costs and benefits from a national perspective.

Work continued on enhancing National Energy Audit (NEAT) software by including additional efficiency measures and adding features to facilitate the user interface. NEAT was used by approximately 500 local agencies in 30 states during 1995 to make retrofitting decisions for more than 80,000 low-income dwellings as 
part of the DOE Weatherization Program. Savings from the use of NEAT rather than conventional approaches in these 80,000 homes are projected to total $\$ 70$ million over the lifetime of the retrofits performed this year.

A major new Weatherization Program effort to improve the effectiveness of retrofits in 13 southern and southwestern states began in 1995 with a major workshop to identify recommendations for a Warm Climate Initiative. The Existing Buildings staff are investigating 21 technology options for energy savings, installation costs, and implementation issues in order to develop "best practices" protocols for warm-climate energy-efficiency improvements.

\section{DOE-HUD Initiative}

One of the primary goals of HUD is the expansion of affordable housing and home ownership. In 1990, recognizing that energy efficiency is a key component in an affordable housing strategy, HUD and DOE created the Initiative on Energy Efficiency in Public and Assisted Housing. The Initiative produced 27 projects between 1990 and 1995 involving research, field demonstrations, institutional/administrative changes, financing/partnerships/leveraging, and education/training/technical assistance for a wide range of HUD programs. The Existing Buildings Research staff, along with staff of other DOE laboratories, were involved in a number of these projects, and a Program Summary Report was prepared to provide detailed descriptions of projects carried out with Initiative funding. ${ }^{15}$

A workshop on energy performance contracting was conducted in 1994 for the larger public housing agencies in HUD Region V (Chicago), using the guidebook on energy performance contracting developed in $1992 .^{16}$ An additional training workshop will be held, and direct technical assistance will be provided to assist several troubled housing agencies in implementing performance contracts.

In a joint effort involving DOE, HUD, ORNL, Lawrence Berkeley National Laboratory, the Massachusetts Division of Energy Resources, the Chelsea Housing Authority, Boston Edison Company, and the New England Power Service Company, a case study evaluation was conducted of energy retrofits in a large high-rise building housing mainly elderly tenants. ${ }^{17}$ The evaluation showed a savings of $15 \%$ of total energy use in this all-electric building for a comprehensive set of efficiency measures and highlighted the importance of controlling the air flows through the building.
In FY 1995, the Existing Buildings staff began a joint effort with the Atlanta Housing Authority to reduce utility bills by $30 \%$ in half of its public housing units over a 5-year period. ORNL is providing technical analysis, financial management, and project development support, and will apply knowledge developed to improve the energy efficiency and affordability of public and assisted housing throughout the nation. This effort is aimed at a second phase of the DOE-HUD partnership that would achieve a large-scale implementation of the successful results achieved through the original initiative.

\section{Commercial Buildings}

Several major efforts that resulted in completed studies included documenting energy measurement and analysis methods used in the Texas LoanSTAR program, assessing retrofit energy savings in a large commercial office building in Washington, D.C., ${ }^{18}$ identifying the savings potential in small commercial buildings in North Carolina, ${ }^{19}$ examining possible energy savings in industrial buildings, and specifying high-speed, nondisruptive monitoring systems. ${ }^{20}$ These efforts have helped develop improved simulation, surveying, and monitoring techniques for determining energy-efficiency improvements in large commercial buildings and helped identify specific issues and measures to be addressed in the relatively untouched sectors of small commercial and industrial structures.

The Existing Buildings Research efforts have facilitated the creation of Rebuild America, a major new DOE program designed to help community and regional partnerships improve energy efficiency in commercial and multifamily buildings through energy-efficient renovations. As a major part of DOE's Energy Partnerships for a Strong Economy, Rebuild America provides technical and financial support to stimulate capital investment in energy-efficiency efforts by local communities. Existing Buildings Research staff collaborated in the design and program plan of Rebuild America in 1994. In FY 1995, a major technical manual ${ }^{21}$ and marketing materials to assist with program efforts were completed, and assessment of the technical support requirements of partners was initiated. $^{22}$

In FY 1995, DOE awarded six regional Rebuild America partnership teams $\$ 4.29$ million in grants to improve energy efficiency in existing buildings. The six award-winning teams, selected from a pool of 32 proposals, represent groups in Boston, Kansas City, the San Francisco Bay Area, Wisconsin, Colorado, and Tennessee. Each team represents diverse coalitions formed 
among state and local governments, utilities, and private companies. Award recipients will contribute $\$ 70$ for every $\$ 1$ of federal funds received, for a total project investment of over $\$ 300$ million.

\section{Technology Transfer for Buildings}

The main objective of the technology transfer activity of BTC is to disseminate information on successful trials of energy-efficient and renewable building technologies. Strong working relationships have been developed with key professional and trade associations that serve as intermediaries and brokers in reaching the diverse and fragmented building-sector stakeholders. As a vehicle to showcase available technology, a demonstration house is under construction in Atlanta that will feature energy-efficient and renewable technologies available in the marketplace that were developed within DOE-OBT research programs. Other products of the program include a ZIP Code Insulation Program audit that assists consumers in determining the insulation requirements of new and existing homes and a guideline entitled Rebuilding Your Flooded Home that assists homeowners in replacing insulation and appliances. ${ }^{23}$ Three additional documents, discussing recovery from hurricanes, tornadoes, and earthquakes, are being planned. The documents will focus on replacing materials and equipment with energy-efficient and environmentally safe products, as well as on preparing for natural disasters by using preventive measures.

\section{THERMAL AND ENVIRONMENTAL CONTROL SYSTEMS}

Thermal energy, whether for heating or cooling, is the end product of much of the energy consumed in homes and factories in the United States. Advanced thermodynamic analysis can be used to improve the efficiency of energy conversion and management processes in many industrial and residential applications with benefits for a wide range of potential sponsors. Project activities for the Thermal and Environmental Control Group include thermal sciences research efforts sponsored by DOE, the U.S. Army, and private industries. Research on heat transfer processes resulted in the invention of the recuperative liquid overfeed heat exchanger, which can be used in various types of refrigeration and air-conditioning equipment. Further refinement and optimization of the heat exchanger technology for environmental control applications are being pursued in cooperation with government agencies and private industries, including DuPont and Coca-Cola.

In 1995 the Thermal and Environmental Control Group began a new program focused on providing thermal science support to the pulp and paper industry. ORNL is working with Ahlstrom, Inc., the Bowater Company, and the Georgia Institute of Technology to investigate the thermal characteristics of the evaporative concentration of black liquors, a critical technology in the pulping process. Several sets of bench-scale falling film evaporator modules similar to the ones installed at Bowater were fabricated by Ahlstrom for testing and analysis by the ORNL-Georgia Tech research team. Black liquors of various concentrations were provided by Bowater. This activity is intended as an initial step in developing an energy-efficient, cost-effective black liquor concentration process for optimal process operation. Additional activities include investigating an advanced impulse drying technique and surveying water-sensing techniques to quantify the dewatering efficiency of paper drying processes.

Other group projects include completion of a cooperative program with Astronautics Corporation of America to develop and test the performance of a prototype magnetic refrigerator (Fig. 3.6). Magnetic refrigeration may be especially useful in large-scale gas liquefaction and the cooling of superconducting magnets. Transcritical-cycle space-conditioning systems concepts were also explored as possible alternatives to systems that depend on ozone-depleting refrigerants. Testing and analysis of a transcritical mobile air-conditioning system using a natural substance as the refrigerant was completed for an industrial partner. In addition, thermal management issues related to storage of hydrogen in fullerenes were analyzed in cooperation with an industrial partner, Materials and Electrochemical Research Corporation.

\section{POWER SYSTEMS TECHNOLOGY PROGRAM}

The Power Systems Technology program carries out research, development, and demonstration projects that improve the safety, efficiency, capacity, and flexibility of the technologies used to deliver electric power (see the highlight "Energy Conservation Standards for Electric Distribution Transformers"). Focus areas include investigation of the human health effects of electromagnetic field (EMF) exposure, engineering analysis of field exposures and means of managing them, and the development 


\section{Highlights}

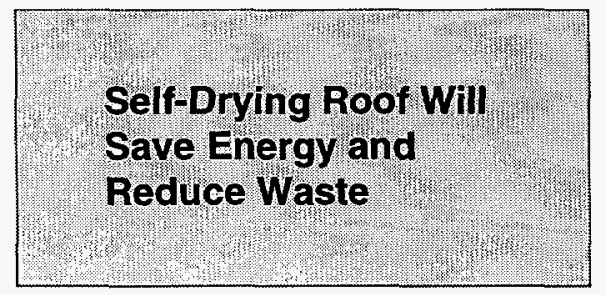

Most commercial buildings in the United States use low-slope roofs consisting of a membrane laid over a layer of insulation on top of a steel deck. Over time, leaks in the membrane allow water to leak into the interior, so that the roof must be repaired and eventually replaced. U.S. building owners spend $\$ 12$ billion annually on reroofing. In the process, they landfill some 400 million $\mathrm{ft}^{3}$ of debris, enough material to cover a square mile to a depth of $15 \mathrm{ft}$. Long before the roof becomes leaky enough to replace, though, moisture accumulation in the insulation compromises its thermal properties. Studies by ORNL researchers have determined that typical moisture levels cause a $40 \%$ reduction in the R-value of the U.S. roofing inventory, increasing by over $25 \%$ the consumption of energy for heating and cooling the country's buildings.

Traditionally, the roofing industry has tried to control the inflow of water into the roof by developing improved membranes. All membranes eventually leak, however, and for almost 30 years it has been recognized that the most practical and economical way to extend the life of a roof, as well as to improve its lifetime thermal performance, is to develop a roof design that will dry itself in service. This had proved an impossible problem because of limitations on the theoretical understanding of combined heat and mass transfer processes in roofs. Analytical tools have been too crude to reliably guide such a major change in the approach to roofing.

Now, however, André Desjarlais, a researcher at the BTC, has combined the testing and advanced computer modeling facilities of the Center to develop and patent a roof design that promises to be self-drying for any climate zone in the continental United States. The deceptively simple concept that emerged after over 1500 simulations and years of testing harnesses the physics of vapor pressure and the power of the summer sun. If construction is properly executed for a building's local climate, moisture absorbed by the roof during the winter is expelled in a controlled fashion downward into the building during the summer, where the air conditioning system can take care of it. This potentially revolutionary improvement in roofing consists of a sandwich of commercially available materials already used in the roofing industry.

Diagram of the self-drying roof concept developed at the ORNL Buildings Technology Center.

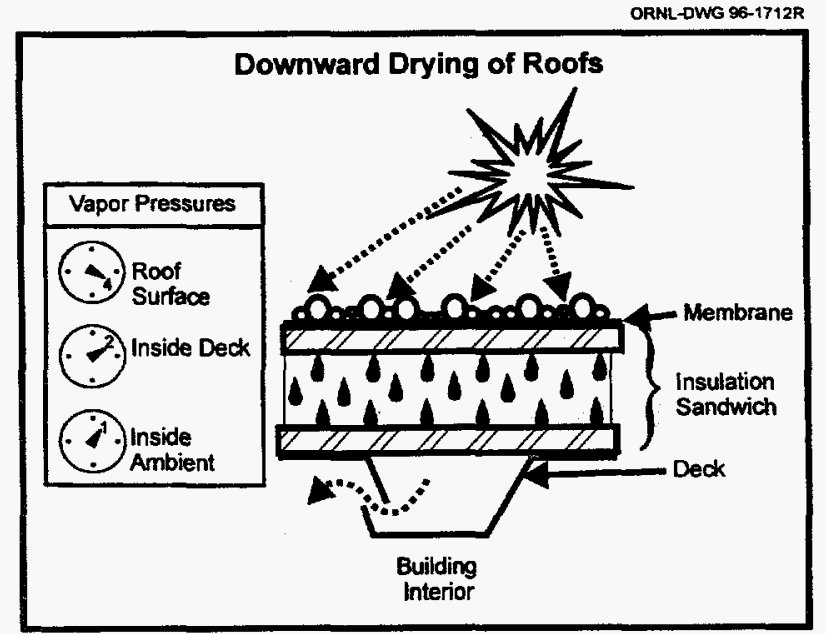




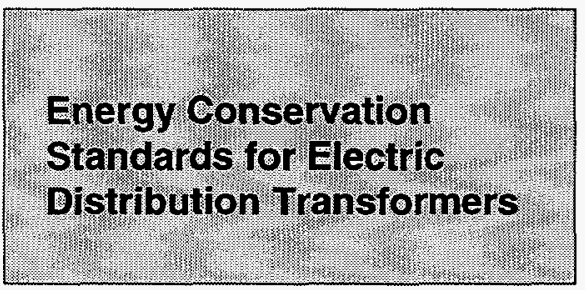

Distribution transformers are used by both electric utilities and their customers to convert electric distribution power line voltage to lower service voltages suitable for end-use equipment. They are well-developed devices with no moving parts, average lives of more than 20 years, and efficiencies of over $98 \%$. There are more than 50 million of them in service in the United States, and annual sales of new units represent a $\$ 1.5$ billion market. In spite of their high individual efficiency, their great numbers mean that distribution transformer losses annually amount to an estimated 140 billion $\mathrm{kWh}-\mathrm{or}$ about half of the energy lost in the delivery of electricity. A change of only $1 \%$ in the efficiency of the nation's total stock of distribution transformers would reduce annual energy losses by an amount equivalent to the output of six $1000-\mathrm{MW}$ power plants, or the electricity requirements of almost 4 million homes.

During 1995, a team of researchers from three of the four sections of the Energy Division worked with DOE's Office of Codes and Standards to determine if energy conservation standards for new distribution transformers would save significant energy and be technically feasible and economically justified. The study concluded that greater use of cost-effective, high-efficiency technologies already commercially available from transformer manufacturers could save up to 8 quads of primary energy by 2030 . About $80 \%$ of the savings could be realized by industrial and commercial customers and the remainder by utilities. The team found that with some exceptions, the market structure for transformers installed by commercial and industrial customers does not promote the purchase of cost-effective transformer. Most transformers in this market are not purchased by the entity ultimately responsible for paying the power bill, biasing purchase decisions toward low-cost transformers with a life cycle cost higher than that of more efficient units. By contrast, utilities are responsible for both first costs and operating costs, and about $85 \%$ are purchasing cost-effective transformers.

The report resulting from this study was reviewed by a special transformer review group consisting of manufacturers, utilities, commercial and industrial users, research laboratories, contractors, material suppliers, and public interest groups. This effort has since become the basis for development of a voluntary conservation standard by the National Electrical Manufacturers Association, an industry standard-setting group.

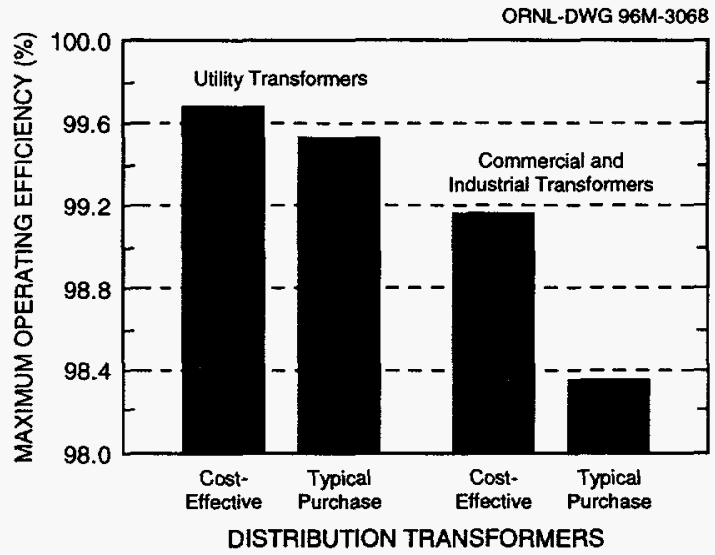

Comparison of peak efficiencies for cost-effective transformers and units typically purchased by utilities and by commerical and industrial customers. 


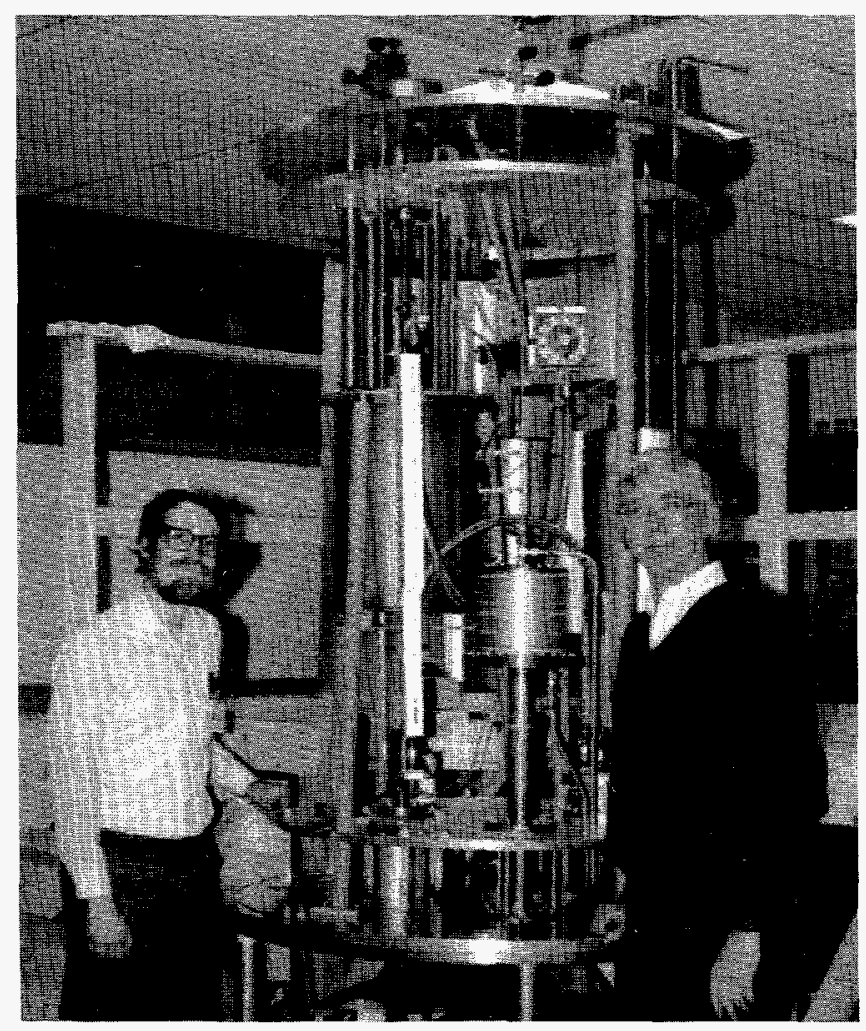

Fig. 3.6. Carl Zimm of Astronautics Corporation of America (left) and Richard Murphy of ORNL with a magnetic refrigerator designed, constructed, and operated as part of an industry-national laboratory cooperative effort.

of advanced power system controls and high-voltage transmission/distribution technologies.

\section{Electromagnetic Fields Research}

The EMF program conducts research to determine whether the extremely low-frequency $(50-$ to $60-\mathrm{Hz})$ EMFs associated with transmission lines, distribution lines, and support equipment cause adverse human health effects. Public perception of potential adverse effects is currently limiting, resulting in opposition to the siting and operation of new power lines, as well as causing concern for homeowners living near electric power facilities. In FYs 1994 and 1995, ORNL continued to provide program management support to DOE and quality assurance for the EMF Biological Effects research program.

One of the challenges faced by investigators in the EMF area is the difficulty of replicating reported field effects in laboratories other than the one in which the effects were originally observed. Repeatability is the key to acceptance of any research, and ORNL, in partnership with three other laboratories, has moved to address this deficiency. Identical EMF exposure systems have been installed at each laboratory to replicate key experiments (Fig. 3.7).

The 5-year EMF Research and Public Information Dissemination program, authorized by the Energy Policy Act of 1992, includes biological and engineering research as well as federal coordination and dissemination of research findings to the public. The biological research portion of this work is being conducted by the National Institute of Environmental Health Sciences, and DOE conducts the engineering research and the communications program. ORNL supports DOE by developing engineering studies examining EMF exposures in commercial and industrial settings. ORNL also develops public communication materials, including an EMF information brochure that has been widely distributed. ${ }^{24}$ As a result of international interest in this brochure, ORNL staffers translated it into Spanish.

EMF concerns are an international problem, and ORNL has led the effort to improve communication between researchers in all countries through formation of the International EMF Coordinators Conference. ORNL was also host during FYs 1994 and 1995 to Dr. Istvan

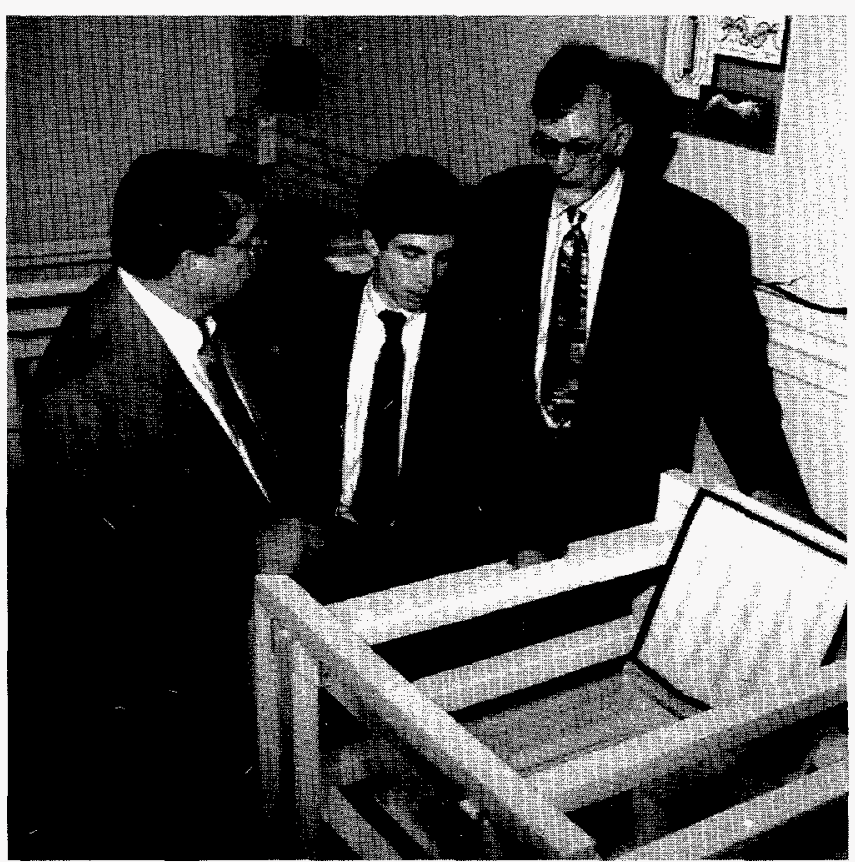

Fig. 3.7. David Reichle, Paul Gailey, and Guy Griffin at the dedication of the ORNL electromagnetic fields laboratory. 
Kromer, the head of the Hungarian Electric Power Research Institute (VEIKI). Dr. Kromer, supported by a Fulbright grant, conducted research on policy and technical options for mitigation of public exposure to EMFs from high-voltage transmission and distribution lines.

\section{Transmission and Distribution Technologies}

The electric utility industry is in the midst of a tumultuous period of restructuring away from a vertically integrated monopoly structure toward a competitive, open market in which customers may be able to choose between multiple power suppliers, much as long distance telephone customers have been able to do for some time. The key to enabling this market transformation is a robust and flexible transmission and distribution system that can reliably deliver a new range of services. During 1995, ORNL researchers from ERRS and the Energy and Global Change Analysis Section completed an analysis of the ancillary services that would have to be supplied to keep the transmission system viable under such a competitive market model. ${ }^{25}$

\section{Real-Time System Control}

Electric transmission systems are widely dispersed geographically but are linked by the physics of electricity so that disturbances propagate rapidly. Thus in 1994, seconds after a protective device failed to detect an overloaded transmission line in Idaho, electric service was shut down for millions of customers as far away as Los Angeles. Traditional approaches for dealing with such disturbances involve anticipatory analytical studies using models, as well as the construction of redundant transmission capacity and protective devices. ORNL and two DOE power-marketing agencies, in partnership with EPRI, are taking a different approach aimed at developing a measurement-based automatic control system that can react to developing situations in real time and implement remedial measures to curtail disturbances. The first step in this project, which began in FY 1995, is installation of a network of monitors across the western U.S. transmission grid, whose outputs are time-synchronized by satellite clocks. Comparison of data from different locations will permit detailed analysis of the progression of disturbances across the system. The second step will be development of artificially intelligent controls that will identify patterns in the data and act on them to execute control actions that will suppress the disturbance.

\section{High-Capacity Transmission Options}

Testing of the high phase order (HPO) demonstration line, partly funded by DOE through ORNL, was completed during FY 1995. HPO lines have the potential of transmitting up to three times as much power as a standard single-circuit ac transmission line while occupying less real estate. The HPO demonstration line was the first six-phase line to operate on a utility system and was constructed to test the performance of protection systems, substation components, and transmission line structural and electrical modifications under real-world conditions. Funding partners included the New York State Energy Research and Development Administration, the Empire State Electric Energy Research Corporation, EPRI, and the New York State Electric and Gas Company, the host utility for the project.

Power electronics inverters are at the heart of the EPRI-developed flexible ac transmission (FACTS) concept, as well as high-voltage dc (HVDC) transmission. Both technologies promise to greatly increase the power transfer capability of existing rights-of-way. The principal impediment to greater application of power electronics is the cost of the inverters, but ORNL researchers developed four novel inverter designs for transmission applications which have the potential to greatly reduce the cost of utility-scale power electronics equipment. In addition, ORNL researchers continued development of advanced semiconducting materials that may reduce the size and weight, and hence the cost, of high-power inverters.

Following up earlier studies of integration of renewable generation technologies at distribution voltages, ORNL completed during 1995 an analysis of transmission requirements for interconnection of large-scale renewable resources. The project involved development of nine case studies with utility partners and concluded that, while required transmission construction can add up to $20 \%$ to the cost of delivered renewable electricity, renewable generation could be sited in some parts of the country with little or no additional transmission construction. ${ }^{26}$

Studies of the benefits of superconducting magnetic energy storage (SMES) for utility applications were completed in 1994. The project, in conjunction with utility partners, developed case studies for applications such as diurnal storage, spinning reserve, power quality, and transmission stability. A follow-on study, performed using an ORNL-developed production costing routine as well as EPRI codes, involved quantification of benefits for a SMES spinning reserve application in Alaska. 


\section{REFERENCES}

1. J. E. Christian et al., "Five-Year Field Study Confirms the PIMA Standard for Estimating Polyisocyanurate Insulation Long-Term Thermal Performance," paper presented at the 11th Conference on Roofing Technology, National Roofing Contractors Association, Gaithersburg, Md., September 21-22, 1995.

2. A. O. Desjarlais et al., "A Whole Building Demonstration of Re-cover over an Existing Wet Roof," paper presented at the 11th Conference on Roofing Technology, National Roofing Contractors Association, Gaithersburg, Md., September 21-22, 1995.

3. J. Kosny and J. E. Christian, "Steady-State Thermal Performance of Concrete Masonry Unit Wall Systems," paper presented at the ASHRAE/DOE Thermal Performance of the Exterior Envelope of Buildings Conference VI, Clearwater Beach, Fla, December 4-8, 1995.

4. J. E. Christian and J. Kosny, "Thermal Performance and Wall Ratings," ASHRAE Journal 38(3), 56-65 (March 1996).

5. J. Kosny and J. E. Christian, "Reducing the Uncertainties Associated with Using the ASHRAE Zone Method for R-Value Calculations of Metal-Frame Walls," ASHRAE Transactions 101(2), 779-88 (June 1995).

6. P. J. Hughes, "Gas Heat Pumps Are Coming But by a Different Name," pp. 97-102 in Proceedings of the 1994 ACEEE Summer Study on Energy Efficiency in Buildings, Pacific Grove, Calif., August 28-September 3, 1994.

7. G. Grossman, R. C. DeVault, and F. A. Creswick, "Simulation and Performance Analysis of an Ammonia-Water Absorption Heat Pump Based on the Generator-Absorber Heat Exchange (GAX) Cycle," ASHRAE Transactions 101(1), 1313-23 (February 1995).

8. R. C. DeVault, G. Grossman, and M. Wilk, "Simulation and Performance Comparison of $\mathrm{LiBr} / \mathrm{H}_{2} \mathrm{O}$ Triple-Effect Absorption Cycles," in Proceedings of International Absorption Heat Pump Conference '94, New Orleans, January 19-21, 1994.

9. G. Grossman, Enhanced Absorption Cycle Computer Model, ORNL/Sub/91-SH641/1, Oak Ridge National Laboratory, Oak Ridge, Tenn., October 1993.

10. J. R. Sand, E. A. Vineyard, and R. H. Bohman, "Evaluation of Design Options for Improving the Energy Efficiency of an Environmentally
Safe Domestic Refrigerator-Freezer," ASHRAE Transactions 101(1), 1422-30 (1995).

11. J. R. Sand, E. A. Vineyard, and R. H. Bohman, "Investigation of Design Options for Improving the Energy Efficiency of Conventionally Designed Refrigerator-Freezers," ASHRAE Transactions 100(1), 1359-68 (1994).

12. M. Y. Poz and J. C. Conklin, "Heat Exchanger Analysis for Nonazeotropic Refrigerant Mixtures," ASHRAE Transactions 100(1), 727-35 (1994).

13. Partnerships for Technology Introduction-Putting the Technologies of Tomorrow into the Marketplace Today, DOE/EE-0066, U.S. Department of Energy, Washington, D.C., April 1995.

14. J. O. Kolb, and M. P. Ternes, "Investigation of Air Distribution System Deficiencies and Repair Benefits in Phoenix, Arizona," pp. 379-87 in Proceedings of the Thermal Performance of the Exterior Envelopes of Buildings VI, Clearwater Beach, Fla., December 4-8, 1995.

15. J. Brinch, Program Summary Report on the DOE-HUD Initiative on Energy Efficiency in Housing: A Federal Partnership, ORNL/Sub/93SM840V, Oak Ridge National Laboratory, Oak Ridge, Tenn., August 1995.

16. J. Kolb et al., Energy Performance Contracting for Public and Indian Housing: A Guide for Participants, HUD-CPD-1354, U.S. Department of Housing and Urban Development, Washington, D.C., February 1992.

17. M. M. Abraham, H. A. McLain, and J. M. MacDonald, Energy Retrofits Installed in the Margolis High-Rise Apartment Building, Chelsea Housing Authority, ORNL/CON-413, Oak Ridge National Laboratory, Oak Ridge, Tenn., December 1995.

18. H. A. McLain, S.-B. Leigh, and J. M. MacDonald, Analysis of Savings Due to Multiple Energy Retrofits in a Large Office Building, ORNL/CON-363, Oak Ridge National Laboratory, Oak Ridge, Tenn., May 1994.

19. M. M. Abraham and J. M. MacDonald, Energy Conservation Opportunities in Small Commercial Buildings, ORNL/CON-414, Oak Ridge National Laboratory, Oak Ridge, Tenn., August 1995.

20. T. R. Sharp, Development and Application of a High-Speed, High-Resolution Data Acquisition System for Monitoring Power at the Service Entrance to Buildings, ORNL/TM-12921, Oak Ridge National Laboratory, Oak Ridge, Tenn., February 1995.

21. Rebuild America Program, Rebuild America's Community Partnership Handbook, Office of Energy 
Efficiency and Renewable Energy, U.S. Department of Energy, Washington, D.C., 1995.

22. Information on the Rebuild America Program can be obtained at the program's World Wide Web site, http://www.eren.doe.gov/parternering/rebuild-am. A newsletter on DOE partnerships with a focus on Rebuild America is http://www.eren.doe.gov/ partnering/epse/update/cc_update5.html.

23. Rebuilding Your Flooded Home: Guidelines for Incorporating Energy Efficiency, DOE-EE-0019, U.S. Department of Energy, Washington, D.C., May 1994.

24. B. A. Beuscher et al., Questions \& Answers About Electric and Magnetic Fields Associated with the
Use of Electric Power, ORNL/M-4283, Oak Ridge National Laboratory, Oak Ridge, Tenn., May 1995.

25. B. J. Kirby, E. A. Hirst, and J. VanCoevering, Identification and Definition of Unbundled Electric Generation and Transmission Services, ORNL/CON-415, Oak Ridge National Laboratory, Oak Ridge, Tenn., March 1995.

26. P. R. Barnes et al., The Integration of Renewable Energy Sources into Electric Power Transmission Systems, ORNL-6827, Oak Ridge National Laboratory, Oak Ridge, Tenn., July 1995. 



\section{4}

\section{Energy and Global Change Analysis Section}

\section{T. Randall Curlee}

Section Head

The Energy and Global Change Analysis Section (EGCAS) conducts interdisciplinary research to provide insights for planning and policy decisions related to energy and environmental issues of national and global concern. Principal areas of focus include electric utility studies, program evaluation, developing country and international studies, and the social and economic assessment of new energy and environmental technologies.

Most of the section's research staff have Ph.D.'s or other advanced degrees in social science; economists and geographers account for the largest number. The section, also home to other social and engineering sciences, often collaborates with leading researchers in academia, industry,

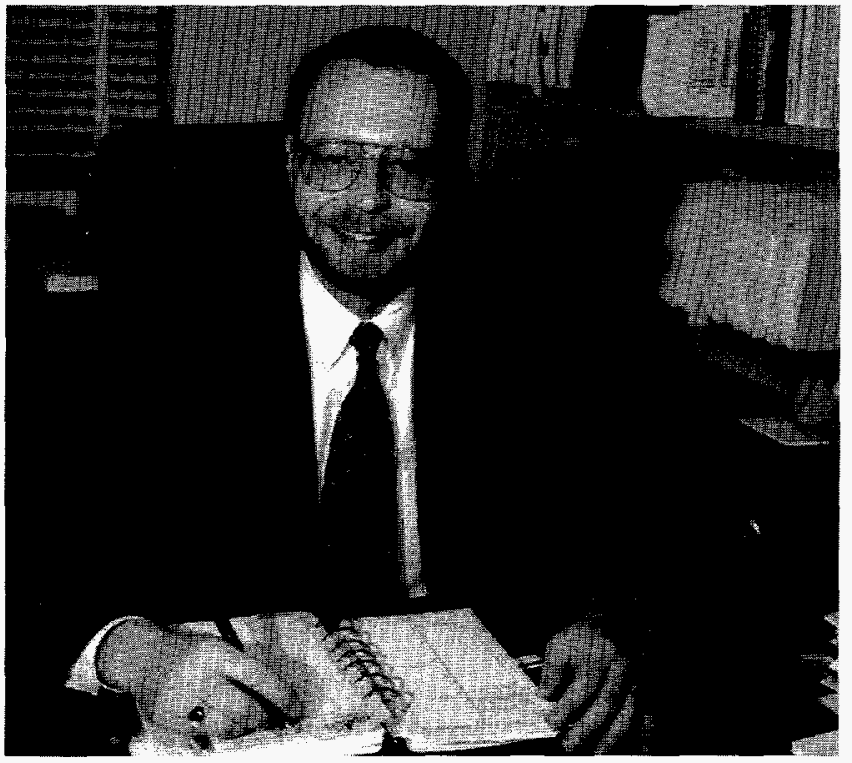

and other research institutions. Our disciplinary diversity and collaborations with other research institutions are among our primary strengths.

\section{ELECTRIC-INDUSTRY POLICY STUDIES}

To reflect the dramatic changes under way in the U.S. electricity industry, the name of the program formerly called Integrated Resource Planning was changed to Electric-Industry Policy Studies. The name change recognizes a significant change in the kinds of projects we conduct. Our work now focuses on several key issues related to electric-industry restructuring. 
Protection of key public-policy functions. Traditionally, utilities have provided many important societal services that go beyond the provision of electricity. These services include support for energy research, promotion of energy efficiency, and acquisition of renewable resources. We are examining these functions to see how they might be implemented in a restructured industry. In particular, we are looking at which functions might be continued easily by a more competitive industry, which might need to be taken over by government, and which might be safely dropped. ${ }^{1}$ We also reviewed recent changes in utility demand-side management (DSM) programs and utility expectations for future changes. ${ }^{2}$

Performance-based regulation. Electric utilities are typically subject to cost-of-service regulation, in which all their prudently incurred costs are reflected dollar-for-dollar in rates. With an emerging competitive marketplace for electricity, policymakers are considering performance-based regulation to give utilities more flexibility in meeting the pricing strategies of their competitors. We are examining the incentives and effects of such regulation. ${ }^{3,4}$

Stranded commitments. As generation markets become more competitive, prices will be determined by the interplay of supply and demand and not by regulators. Utilities with expensive generating units and high-priced purchase-power contracts face substantial earnings losses. We developed initial estimates of the potential losses that utilities might face under different assumptions about market prices and the fraction of utility customers that leave the system (Fig. 4.1). ${ }^{5}$ Our focus is on providing assistance to state and federal regulatory commissions as they review submissions from utilities seeking recovery of these stranded costs. ${ }^{6}$ To that end, we expanded our Oak Ridge Financial Model to include a variety of approaches to calculate stranded costs.

Ancillary services. A key element of efforts to increase competition in wholesale electricity markets is the unbundling of generation and transmission services. Several functions, such as voltage support and spinning

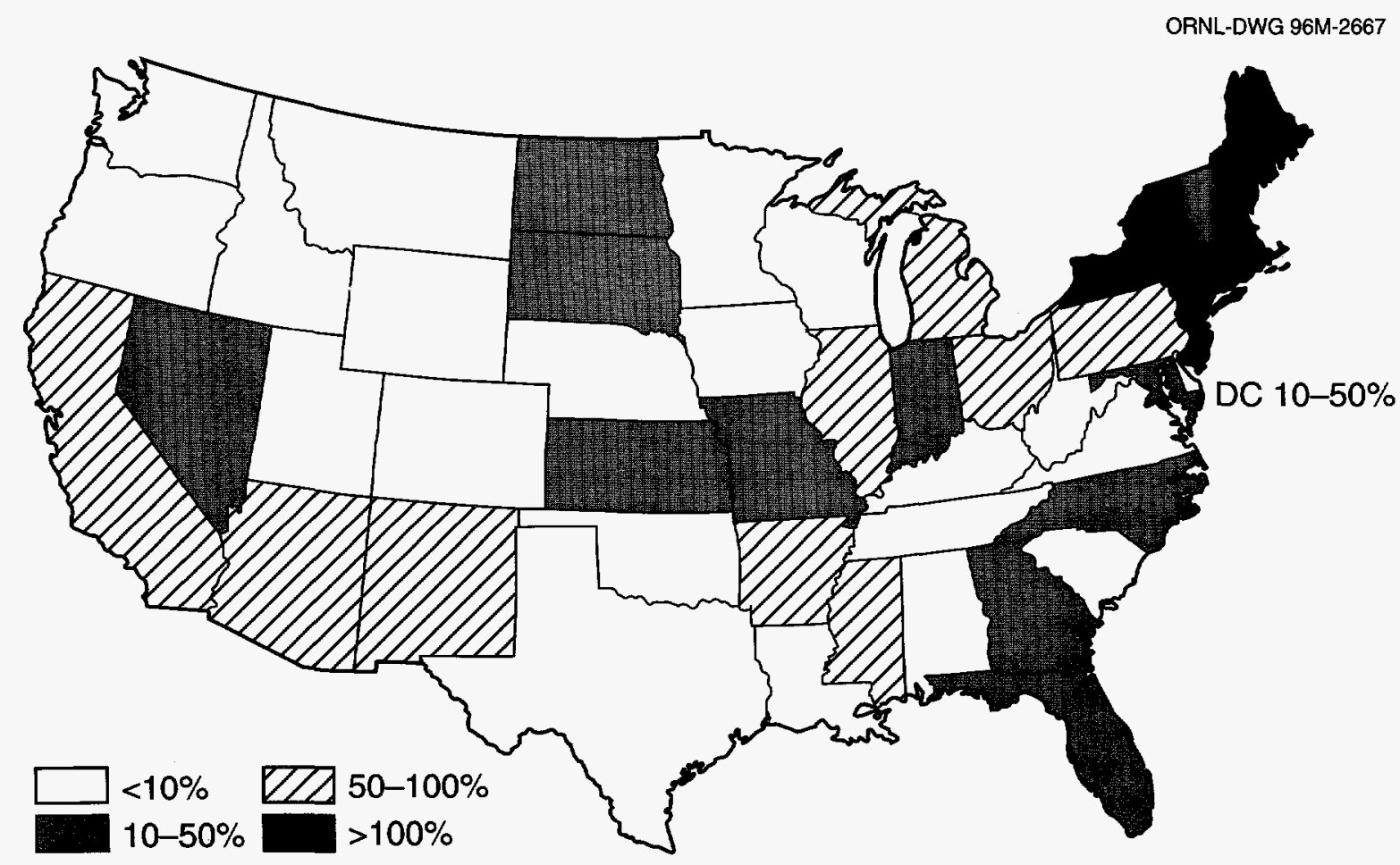

Fig. 4.1. Estimates of potential stranded commitments as a percentage of utility equity for major investor-owned utilities. These estimates assume that $100 \%$ of a utility's customers can choose alternative electricity suppliers and that the wholesale price of electricity is based on the cost of a combined-cycle gas turbine. 
reserves, are called ancillary services because they are essential to the reliable delivery of electricity from generators to customers. We are analyzing ancillary services, seeking to define a set of services that is exhaustive and mutually exclusive. We are also analyzing utility data to develop estimates of the costs of these services, in aggregate and individually, and we are examining various costing and pricing methods for these services. ${ }^{7}$

Outreach. In addition to conducting research, the program is active in using research results in outreach to state policymakers. Larry Hill is a visiting fellow at the National Conference of State Legislatures, working with state legislators and their staffs on various issues dealing with electric-industry restructuring. Doug Bauer is the executive secretary of the National Council of Competition in the Electric Industry, a consortium of state legislators and regulators providing assistance to states on restructuring issues.

\section{DEVELOPING COUNTRIES AND INTERNATIONAL STUDIES}

ORNL played a uniquely central role in Secretary O'Leary's missions to India, China, and South Africa. Besides helping to conceive the first India mission and developing a DOE action plan for following up the trip that became the model for other missions, the Laboratory was also heavily involved in the China and South Africa initiatives.

Tom Wilbanks accompanied the Secretary on her Presidential Mission to India, served as executive secretary of the DOE effort to develop and implement an action plan based on that visit, and was one of a very small number of individuals to accompany the Secretary on her return trip to India in February 1995 (Fig. 4.2). Sujit Das also contributed to the process of defining DOE's roles in Indo-U.S. cooperation.

In another activity, EGCAS conducted a workshop in August 1995 on electric-power planning in Moscow, Russia, for 50 staff members of Russian electric utilities. The workshop covered such topics as the difference between financial and economic analysis, electric-industry regulation, resource evaluation, and integrated resource planning. Larry Hill and Stan Hadley organized and conducted the workshop.

The Energy Division and EGCAS have substantially expanded activities in support of the U.S. Agency for International Development (USAID). One major thrust

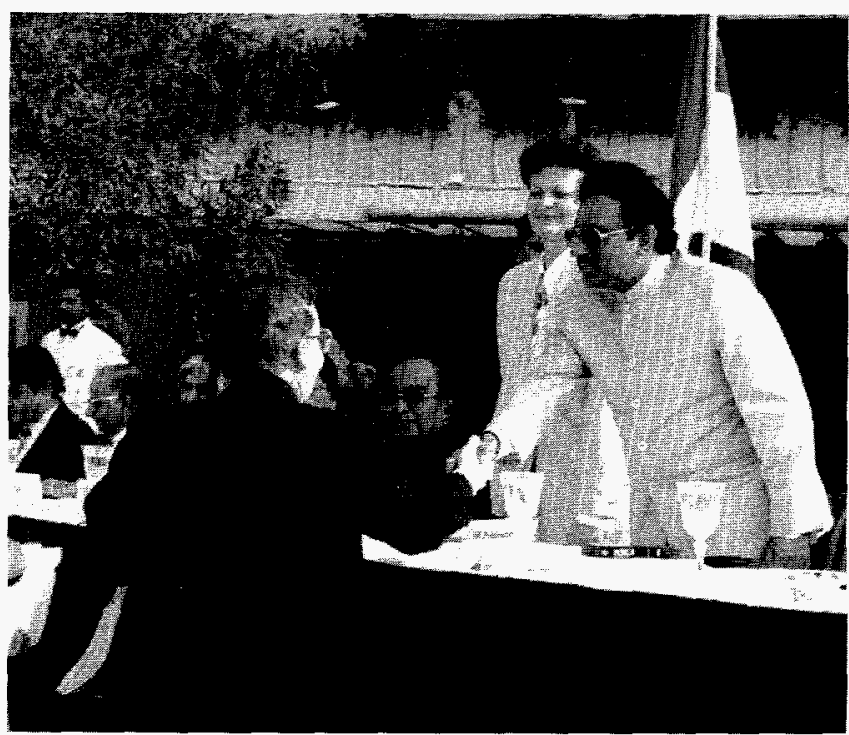

Fig. 4.2. Tom Wilbanks is greeted by Indian Minister of Nonconventional Energy Sources Krishna Kumar and DOE Secretary Hazel O'Leary after the signing of Memorandum of Understanding (MOU) between ORNL and the Energy Management Centre, Government of India, to promote technical collaboration in energy efficiency improvement.

was in Central America, where two long-standing projects proceeded successfully. Since 1991, ORNL has supported USAID and counterpart Guatemalan institutions in establishing a major biosphere preserve in the Peten region of Guatemala (Fig. 4.3). This effort, led by Keith Kline, is being extended to the year 2000 , along with increased OR'NL assistance to strategic planning by USAID in the region. In addition, in the period 1987-95, ORNL provided project monitoring and evaluation assistance for a major regional rural electrification support project, led by John Shonder, developing a new approach to USAID project evaluation in the process.

A second major thrust was in India, where ORNL led an effort to design a new multiyear Environmental Protection Initiative (EPI) for USAID. EPI is intended to address new industrial capital stock decisions in an economy where $70 \%$ of the national industrial capital that will exist a decade from now will be built during this decade. This project design process is part of a larger commitment by USAID to contribute to energy and environmental decision making in this key country; ORNL is expected to play a central role in these activities. 

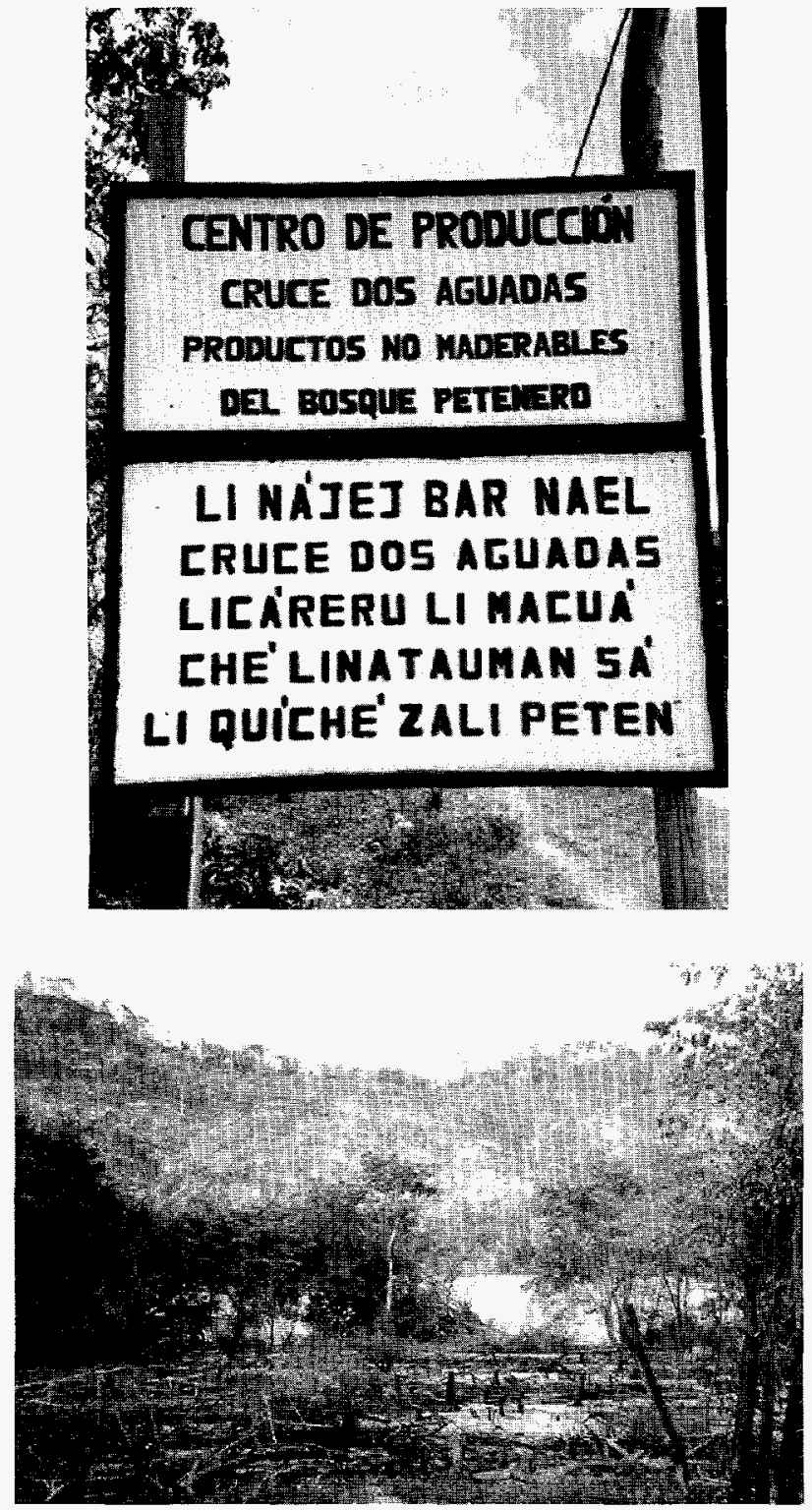

Fig. 4.3. The Maya Biosphere Project, led by EGCAS staff member Keith Kline, is addressing problems of deforestation in the Peten region of Guatemala. The project works with villages in the Peten, such as Cruce Dos Aguadas, to develop economic activities that replace slash-and-burn agriculture with businesses that preserve the forest.

\section{GLOBAL CLIMATE CHANGE}

Many of the section's research activities are relevant to global climate change. Two particular efforts have (1) extended a well-known integrated model of global climate change to allow more detailed analysis of energy and environmental issues, and (2) applied irreversible investment theory to understand why and how businesses and households may or may not invest in technologies that would reduce emissions that contribute to global climate change.

The modeling work in EGCAS has centered largely on modifications to the Nordhaus DICE model, a relatively compact, yet comprehensive model of economic and global environmental interactions. ${ }^{8}$ Russell Lee and Sujit Das have developed significant modifications to the DICE model, replacing the original Cobb-Douglas specification of production with a nested constant elasticity of substitution (CES) specification to develop an energy sector for the model. This in turn permits calculation of emissions by sector and further analysis of policies to reduce emissions. Numerical calculations indicate the revised model retains comparability with the original DICE while permitting greater detail for policy analysis.

Work in investment analysis and global climate change builds upon recent advances in the theory of irreversible investment by applying the methodology of experimental economics. ${ }^{9}$ The importance of this theory lies in the relationship between new technologies and the timing of the investment decision. The theory predicts that under uncertainty and the inability to recover sunk costs, agents with the opportunity to postpone a decision to invest will rationally wait until the cost of waiting is overcome by new information that reduces uncertainty. This view challenges the commonly held view that agents who fail to invest when expected returns exceed expected costs are subject to market failure that justifies government intervention, predicting that "inertia" within the system is rational. Data gathered through laboratory experimental economics supports the major predictions of the theory. ${ }^{10}$ Additional work is exploring the implications of these findings for policy options that would encourage investments in new technologies.

\section{ENVIRONMENTAL AND HEALTH STUDIES}

Environmental and health studies in EGCAS integrate economics and social science with natural science and engineering. Frequently, our studies are related to some planning or policy issue. Examples are the U.S. DOE-European Community (EC) study on the externalities of fuel cycles, several follow-ups to that study, a study of the health costs at Superfund sites, and an ongoing study on communicating the risks associated with consumption 
of contaminated fish and wildlife by low-income and minority populations.

The DOE-EC study covered several years' research and involved more than 50 people at ORNL, Resources for the Future, and elsewhere. Its primary purpose was to develop a methodology to estimate the externalities of fuel cycles. A fuel cycle is a sequence of activities and industrial processes that lead to the generation of electric power. Externalities are changes in individuals' well-being that producers and consumers do not explicitly take into account in their decisions. Individuals affected are those who neither produce nor consume the product.

The damage function approach developed by this study and by other major recently completed studies now stands as the standard for estimating the externalities associated with electric power generation. The study found that the magnitude of the externalities can vary greatly, depending on a number of factors: the type of technology and fuel cycle and the nature of its residual effects, the quantity of emissions, the proximity of highly valued ecological resources, the geographic distribution of nearby populations, the degree of internalization, background levels of pollutants and atmospheric chemistry, and meteorology. Results of the study are published by McGraw-Hill/Utility Data Institute ${ }^{11}$ and are also discussed in two papers by Lee. ${ }^{12,13}$

There have been several follow-ups to that study. A draft study for the Energy Information Administration (EIA) compiled the status of state regulations that require investor-owned utilities to consider externalities in integrated resource planning; the initial assessment of this study was that these regulations have had a negligible effect on actual resource decisions. Another draft study for EIA probed this issue in more detail in three states (Massachusetts, Wisconsin, and California) and confirmed the previous finding. ${ }^{14}$ As the debate about industry restructuring swelled, our environmental and health studies turned more to identifying efficient ways of preserving some of the environmental benefits of existing regulations. This most recent analysis argues that in the arena of real-world policy, second-best solutions are frequently first-best options.

The theme of using an integrated approach that combines science, engineering, economics, and social science is also evident in our study for the Agency for Toxic Substances and Disease Registry (ATSDR). This study estimated the health burden associated with contamination by volatile organic compounds at Superfund sites. Although the state of the science does not support any causal relationship, the study suggests that a sizable burden exists at many of these sites, perhaps $\$ 400$ million nationwide in some past years, and perhaps the same order of magnitude at present. Our study also developed a general methodological framework for estimating the benefits of ATSDR's public health programs at individual Superfund sites. The study introduced a pathways concept similar to the one used in health risk assessments, except that our pathway concept includes economic valuation of health conditions and the economic benefits of intervention by public health agencies.

In addition to providing public health services at hazardous waste sites in an economically efficient way, environmental justice is also a major policy issue. An ongoing study is developing a prototype risk communication program directed at low-income and minority populations who may consume contaminated fish and wildlife.

\section{ENVIRONMENTAL RESOURCE VALUATION}

Environmental resource valuation is a family of analytical methods that seek to estimate the priorities and values of parties impacted by government policies that affect the environment. EGCAS is pursuing means to provide more effective public input to the environmental policy process through several ongoing projects and is teaming with other ORNL staff members to propose new approaches to these difficult questions.

Current projects in this area deal with a range of topics. In one recently completed effort, section staff members organized a workshop intended to summarize the state of the art in contingent valuation analysis and provide suggestions for a research agenda to push forward. A book containing these papers and the research agenda was published in late $1995 .{ }^{15} \mathrm{~A}$ second activity in this area seeks to identify cross-cultural determinants of willingness to pay for reduced impacts on the global environment. In this activity, ORNL has teamed with Georgia State University to develop and test an approach based on the contingent valuation methodology that will provide data describing preferences for environmental protection in different nations of the world. A third and different approach is contained in the noneconomic valuation methodology, which section staff have proposed through a conceptual framework for a Social Perspectives and Responses Module being developed for the National Acid Precipitation Assessment Program. Within this approach, we are developing a system for identifying likely responses among different population groups to alternative acid precipitation-related policies and effects. Additional ongoing activities include examining conjoint analysis, 
which involves utilizing multidimensional discrete choice techniques to measure the value of environmental changes and explorations into benefits transfer.

Determining the appropriate cases whereby estimates of environmental values calculated through nonmarket methods may be transferred from one region to another presents a difficult challenge, with large potential payoff. In an article to be published in the Journal of Environmental Economics and Management in March 1996, Mark Downing and Teofilo Ozuna examine the results of testing the reliability of the benefit function transfer approach using contingent valuation methods. ${ }^{16}$ Results indicate that the benefit function transfer approach tends to overestimate benefits, implying that, at least for the application studied, such an approach was not reliable.

\section{BIOMASS FOR ENERGY}

EGCAS is actively involved in exploring the potential of biomass energy both in the United States and abroad (see the highlight "Potential U.S. Biomass Energy Supply"). Section staff provide research and programmatic support to the Biofuels Feedstock Development Program (BFDP)-a national program whose goal is to develop and demonstrate environmentally acceptable cropping systems for producing low-cost, high-quality biomass feedstocks. Section staff contribute expertise in the technical areas of economics, systems integration, and commercialization (scale-up, feasibility, and demonstration). EGCAS staff are also contributing to assessments of biomass energy systems in China and other regions.

\section{ALTERNATIVE FUELS}

DOE is considering the costs and benefits of promoting the replacement of gasoline vehicles with alternative fuel vehicles (AFVs). Initial studies supported by $\mathrm{ORNL}^{17}$ and others considered the possible penetration of alternative fuels and vehicles in the year 2010, assuming that the vehicles and fuels could be widely available at mature scales of production. These earlier studies suggested that some types of AFVs were reasonably attractive and might have a significant market share by 2010. In order for this to occur, however, substantial production and support infrastructure must be developed; and consumers, producers, and retailers must overcome initial uncertainties regarding the attractiveness of alternative fuels and vehicles.

ORNL is now focusing on the transition from the current market to one based more on alternative motor fuels, seeking to identify possible transitional obstacles that may influence the rate of penetration of AFVs. The approach is to build a multiyear dynamic model which seeks to account for

- the effect of AFV incentives and programs on the behavior of vehicle producers (including the diversity of vehicles offered and their price);

- the effect of early AFV incentives and programs on fuel demand patterns and the behavior of fuel distributors (fuel availability and retail price); and - the combined effect of these changes on the time path of adoption of AFVs by consumer households.

Preliminary experiments with this model indicate that if significant scale economies exist in vehicle and fuel production, and if consumers attach a high cost to the initial low availability of alternative fuel, then it could be difficult for the pieces of the AFV market to come together through normal economic processes. Conversely, without these conditions the market for some fuels and AFVs may develop smoothly. Through further data-gathering and modeling, the project will explore the degree to which these transitional factors may exist, and their importance.

\section{OIL IMPORTS: AN ASSESSMENT OF THE COSTS AND BENEFITS}

U.S. oil imports have grown substantially over the last decade and are expected to climb to $60 \%$ of consumption by 2010 . ORNL conducted a study to assess whether the current level of oil importation is efficient from the perspective of society as a whole. In policy terms, the question is whether a reduction of oil imports by reducing consumption or increasing domestic production-taking into account any social costs of these efforts-would improve the economic well-being of the nation.

The study sought to identify the possible social costs of oil imports that are not included in the price paid by consumers, to discuss the possible size of these costs, and to highlight the reasons for differences in published cost estimates. It concluded that there may be a difference between the market price of imported oil and the total costs to the nation; that is, there may be marginal costs not included in the price consumers pay for imported oil. This difference is called the "oil import premium" in this study. The sizes of the components of the oil import premium are highly dependent on assumptions involving the likelihood and size of oil disruptions and the economic response to various events. These assumptions include the extent of cartel power and noncompetitive pricing in oil markets; the nature of producer and consumer responses 
to U.S. policies; the likelihood of disruptions of different sizes; the extent to which oil consumers have hedged against oil price shocks through future markets and flexible technologies; and the response of monetary and fiscal policies to change in oil prices.

\section{ENERGY PROGRAM EVALUATION}

The energy program evaluation effort in the EGCAS section focuses on the design and implementation of quantitative assessments of energy efficiency and renewable energy programs sponsored by DOE. Core research issues and expertise covered in this area include the following:

- market transformation and the adoption of new energy technologies-including the evaluation of technology commercialization, technology transfer, energy education, and energy information programs;

- program design and policy analysis - including the assessment of alternative program design features and public policies, often through quasi-experimental and survey research; and

- program evaluation methodologies-including the measurement of energy savings persistence, control group methodologies, and valuation of hard-to-quantify program impacts.

Weatherization Assistance Program. In 1994, an assessment of the cost-effectiveness of the nation's largest conservation program-DOE's Low-Income Weatherization Assistance Program-was completed. Based on a sample of almost 15,000 dwellings weatherized by nearly 400 local agencies and a matched sample of approximately 5,000 control homes, the evaluation estimated that during 1989 , the program saved 17.6 MBtus per weatherized dwelling, or $18.2 \%$ of the energy used for space heating. The net present value of this conserved energy is more than the cost of weatherization, resulting in a benefit-cost ratio of 1.09 , which is one of the many measures of program performance developed in the evaluation. The evaluation also characterized the population of clients remaining to be served and the potential for saving more energy in participating homes.

Two new evaluation efforts began in FY 1995. The first is the warm climate weatherization initiative. It is designed to provide state and local weatherization officials with better tools for improving the weatherization program in warm climates. ORNL is designing single-family audits and is evaluating cooling measures that can be used under the weatherization program along with their cost-effectiveness. The second evaluation involves leveraging resources. It will provide state weatherization officials with information necessary to aid their participation in regulatory and market-based activities by enabling them to access nonfederal resources. The primary focus is on the restructuring of the electric utility industry and its implications for utility-financed low-income energy efficiency programs.

Energy-Related Inventions Program. For well over a decade, ORNL has been involved in a longitudinal evaluation of the Energy-Related Inventions Program (ERIP), tracing the program's economic impacts since its inception in 1976, characterizing the innovation process as it pertains to small business energy innovations, and recommending ways of improving the program. In 1994, ORNL completed its most recent ERIP evaluation, investigating such questions as the commercial progress of ERIP inventions and spinoff technologies; employment, tax-revenue, and exports effects; energy savings; and environmental benefits. Table 4.1 quantifies some of the ERIP benefits in 1992 dollars. In 1995, ORNL began the next ERIP evaluation, which will be completed in FY 1996.

\section{REGIONAL STUDIES}

The section continued its long research relationship with the Army National Guard to assist the Guard in recruiting and retention of personnel. In 1994, the EGCAS Regional Studies Program conducted a review of the National Guard's demographic analysis requirements and found that because labor markets continue to change, the Guard is increasingly dependent on demographic analysis tools developed by ORNL during recent years (Fig. 4.4).

As a result, in 1995, the National Guard Bureau (NGB) and ORNL scheduled several workshops to help states identify analysis approaches that can help them choose the best "targets of opportunity" for recruiting new personnel and identify "high-payoff" strategies for their labor markets. More than 50 Guard members from 31 states attended the workshops.

Participants were trained on the Regional Recruiting Potential Model (RRPM), which has been developed and maintained by ORNL and by the National Guard since 1988. States can use the demographic support provided by the section's Regional Studies Program on at least three levels, which correspond to organizational and planning horizons:

1. Basic RRPM support-support staff run analyses; recruiter managers use the results. 


\section{HighLight}

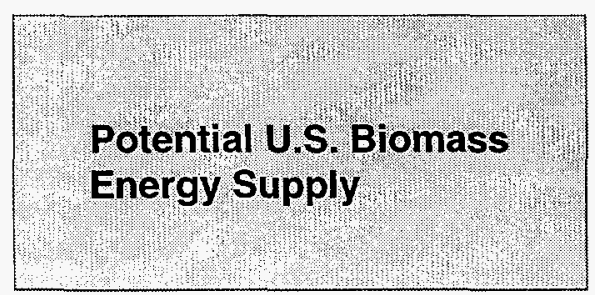

Biomass energy systems are viewed as a means to

- mitigate greenhouse gases;

- decrease dependence on foreign oil supplies;

- provide alternative, environmentally friendly crops for agriculture; and

- enhance rural development opportunities.

Successful commercialization depends on energy crop prices that are low enough to be competitive with alternative energy feedstocks, yet high enough to provide a profit to farmers comparable to what could be earned in alternative land uses. Marie Walsh, of EGCAS, has estimated the full economic costs of producing hybrid poplar and switchgrass in six U.S. regions. The production costs are used to construct national supply curves. If we assume average annual U.S. yields of 5 dry tons per acre, approximately 250 million dry tons of wood chips could be supplied from 37 million acres of land at farm-gate prices of less than $\$ 40$ per dry ton, or approximately 300 million tons of switchgrass bales from about 50 million acres at farm-gate prices of less than $\$ 30$ per dry ton. Transportation costs would add an additional $\$ 10$ per dry ton. These biomass quantities are sufficient to produce an estimated 20 to 33 billion gallons of ethanol with a feedstock cost of only $\$ 0.36$ to $\$ 0.60$ per gallon (depending on conversion efficiency) or 550 billion $\mathrm{kWh}$ of electricity at a price of $\$ 0.04$ to $\$ 0.05$ per $\mathrm{kWh}$ (assuming gasification technology). These supply curves were developed for a multiagency working group to evaluate the economic potential of biomass energy as a means to meet U.S. agreements in the Climate Change Action Plan.

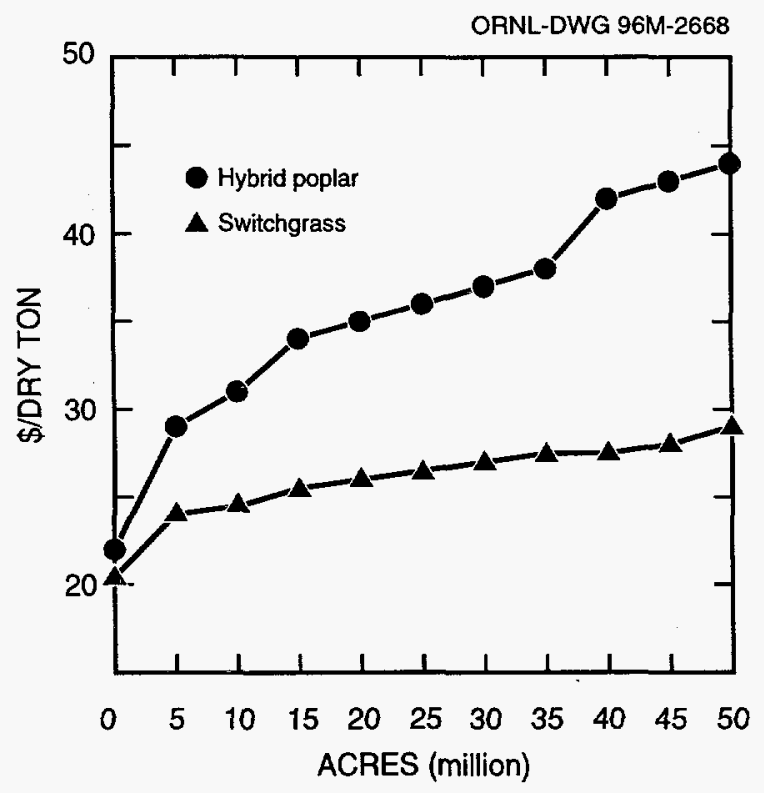

Potential U.S. biomass supply. 


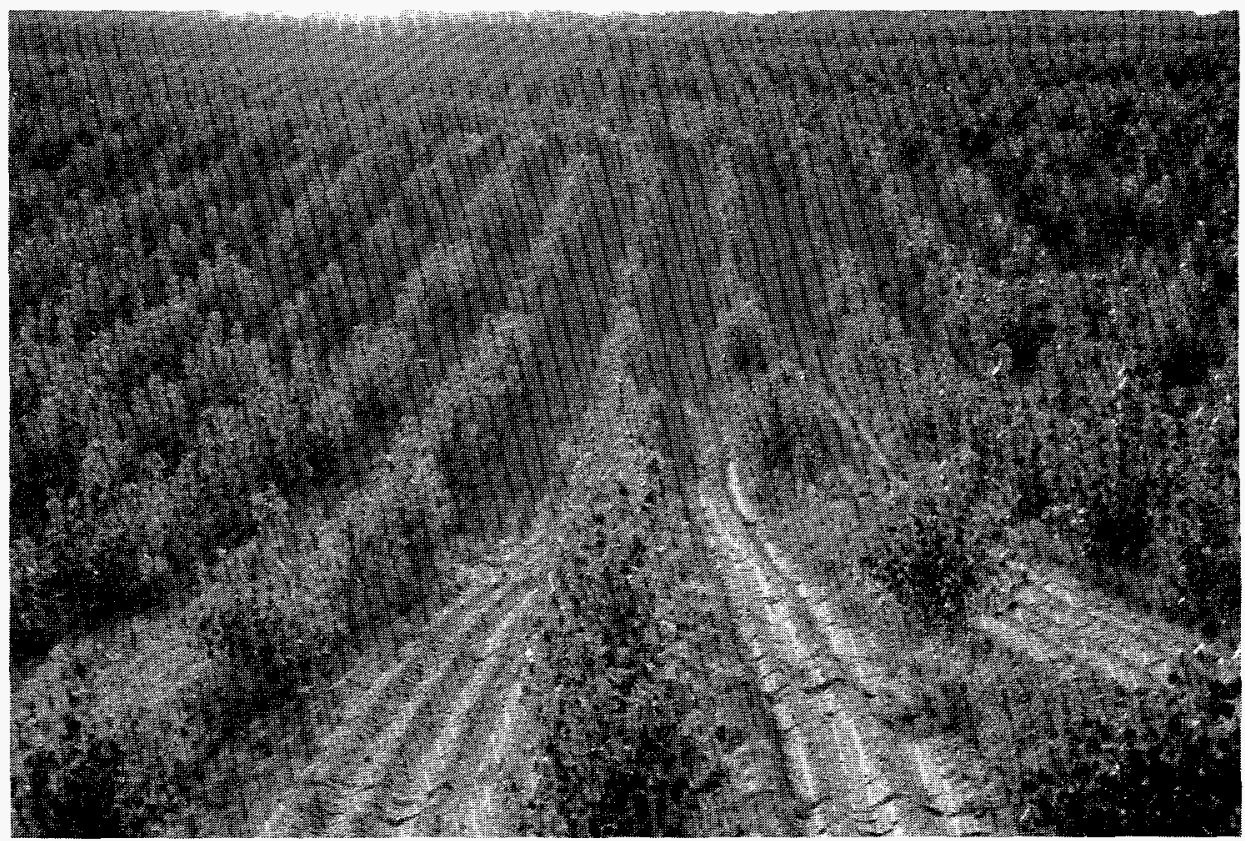

Hybrid poplar plantings on conservation program lands in Minnesota.
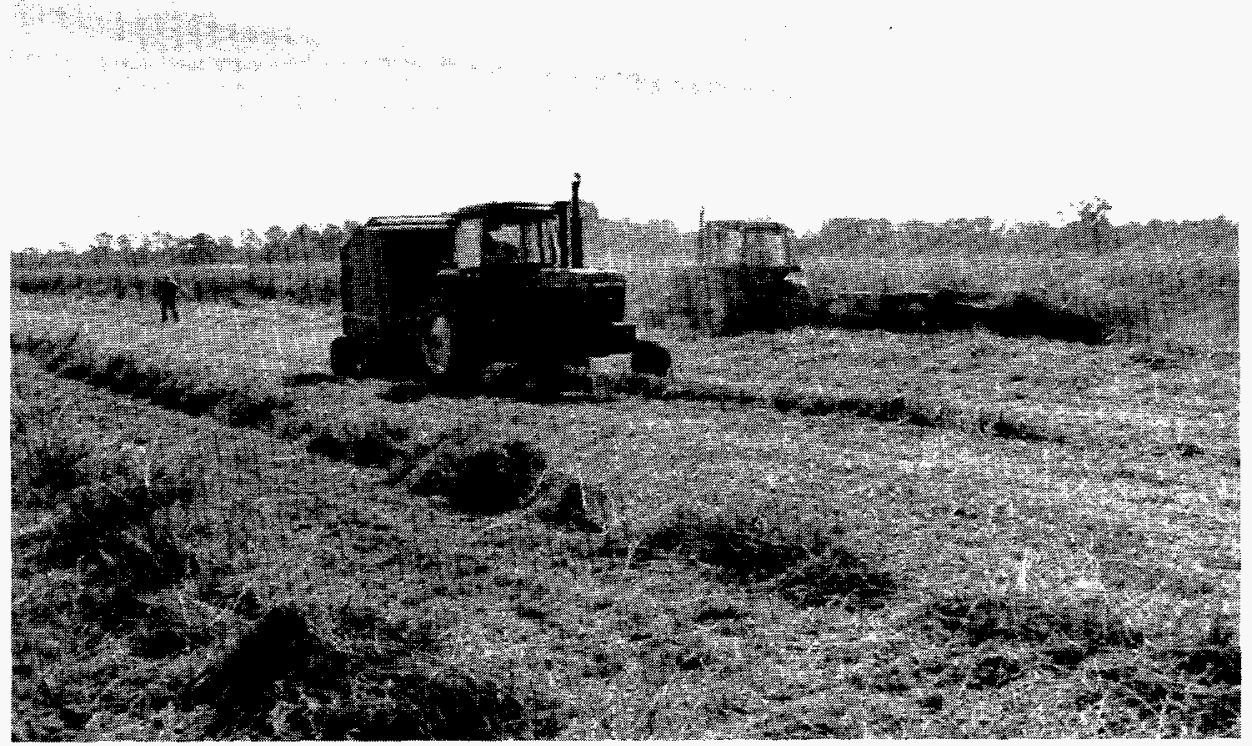

Demonstration of switchgrass harvest operations in lowa. 
Table 4.1. Impacts of the Energy-Related Inventions Program

\begin{tabular}{|c|c|}
\hline Category of benefit & Indicator of program impact \\
\hline Market entries & $\begin{array}{l}\text { At least } 129 \text { ERIP technologies commercialized, representing a } 23 \% \\
\text { commercialization rate }\end{array}$ \\
\hline Sales & $\$ 763$ million of sales generated by these 129 technologies through 1992 \\
\hline Licensing revenues & $\$ 18.6$ million for licensed sales of ERIP technologies through 1992 \\
\hline Spinoffs & An additional $\$ 63$ million in sales generated by 36 spin-off technologies \\
\hline Funds raised & $\begin{array}{l}\$ 2.01 \text { raised by inventors after receipt of ERIP grant for every ERIP } \\
\text { grant dollar }\end{array}$ \\
\hline Jobs & $\begin{array}{l}668 \text { full-time equivalent jobs directly supported by ERIP technologies } \\
\text { in } 1992\end{array}$ \\
\hline Taxes & $\begin{array}{l}\$ 2.7 \text { million in ERIP-related tax revenues returned to the U.S. Treasury } \\
\text { through } 1992\end{array}$ \\
\hline Energy savings & \$531 million of energy expenditures saved by three ERIP technologies \\
\hline Environmental benefits & $\begin{array}{l}\text { Carbon emissions reduced by almost } 1.0 \text { million metric tons, as the } \\
\text { result of three ERIP technologies }\end{array}$ \\
\hline
\end{tabular}

2. Extended analysis-for short-term marketing, evaluating markets, etc.; marketing noncommissioned officers use or would like to use this product.

3. Statewide planning, 5- and 10-year plans-recruiter managers use or would like to use this product to develop long-range plans and incorporate demographics in the planning stage.

Several states now routinely use the RRPM's demographic analysis for their marketing studies and related purposes.

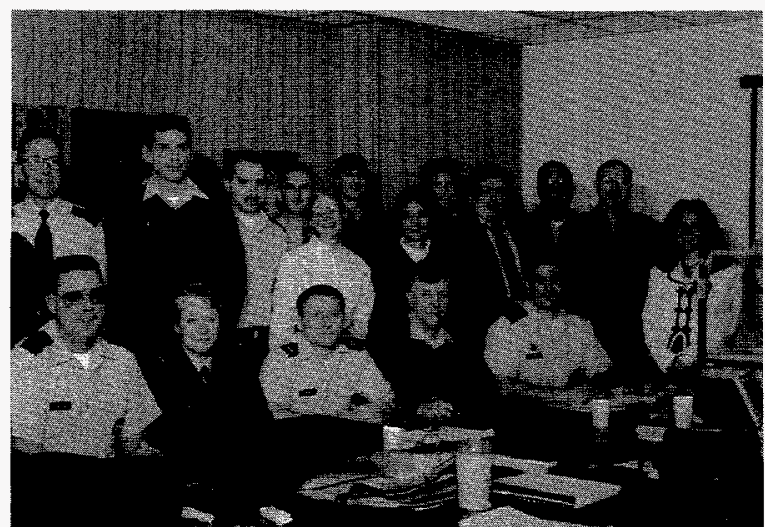

Fig. 4.4. Members from the EGCAS

Regional Studies Program and the Army National Guard conduct a review of the National Guard's demographic analysis tools as developed by ORNL.

\section{ASSET AND WASTE MANAGEMENT}

In FY 1995, EGCAS, in collaboration with other Energy Division sections and ORNL divisions, completed a life-cycle analysis (LCA) of recycling metals at the now-retired K-25 uranium enrichment facility in Oak Ridge. LCA is the process of identifying and assessing all categories of benefits and costs that result from a course of action over the entire period of time affected by the action, quantifying those benefits and costs where possible, and providing results that promote sound decision making. ${ }^{18} \mathrm{~A}$ financial analysis and an analysis of external impacts both point in favor of recycling contaminated metals from K-25 as opposed to the disposal of those metals in a DOE low-level-waste facility. Under the option being considered, contaminated metals would be used to manufacture containers for low-level radioactive waste disposal.

The section was also involved in several other projects that address the social and economic aspects of waste management. For example, several staff members, in collaboration with staff from the University of Tennessee, completed and published a major study on the social and economic viability of municipal waste-to-energy (WTE) facilities in the United States. ${ }^{19}$ The study identified social and economic factors that may have contributed to the recent downturn in the growth of WTE facilities in the United States.

EGCAS also completed a study of recent trends in automobile recycling in the United States, focusing 
specifically on the energy and economic implications of changes in automobile material composition and the development of new technologies for recycling. ${ }^{20}$ This work is now shifting to focus on the effects that material changes being considered by the PNGV may have on the energy, environmental, and economic viability of automobile recycling.

\section{REFERENCES}

1. B. E. Tonn, E. A. Hirst, and D. C. Bauer, Public Policy Responsibilities in a Restructured Electricity Industry, ORNL/CON-420, Oak Ridge National Laboratory, Oak Ridge, Tenn., June 1995.

2. M. Schweitzer and M. Pye, Key Factors Responsible for Changes in Electric-Utility DSM Usage, ORNL/CON-421, Oak Ridge National Laboratory, Oak Ridge, Tenn., September 1995.

3. L. J. Hill, A Primer on Incentive Regulation for Electric Utilities, ORNL/CON-422, Oak Ridge National Laboratory, Oak Ridge, Tenn., October 1995.

4. A. G. Comnes et al., Performance-Based Ratemaking for Electric Utilities: Review of Plans and Analysis of Economic and Resource-Planning Issues, LBL-37577, Lawrence Berkeley National Laboratory, Berkeley, Calif., November 1995.

5. L. W. Baxter and E. A. Hirst, Estimating Potential Stranded Commitments for U.S. Investor-Owned Electric Utilities, ORNL/CON-406, Oak Ridge National Laboratory, Oak Ridge, Tenn., January 1995.

6. L. W. Baxter, Different Approaches to Estimating Transition Costs in the Electric-Utility Industry, ORNL/CON-423, Oak Ridge National Laboratory, Oak Ridge, Tenn., October 1995.

7. B. J. Kirby, E. A. Hirst, and J. VanCoevering, Identification and Definition of Unbundled Electric Generation and Transmission Services, ORNL/CON-415, Oak Ridge National Laboratory, Oak Ridge, Tenn., March 1995.

8. Foundation documentation is contained in W. D. Nordhaus, The "DICE" Model: Background and Structure of a Dynamic Integrated Climate-Economy Model of the Economics of Global Warming, Cowles Foundation Discussion Paper No. 1009, Cowles Foundation, Yale University, New Haven, Conn., 1992.

9. This theory is summarized in A. K. Dixit and R. S. Pindyck, Investment Under Uncertainty, Princeton University Press, Princeton, N.J., 1994.
10. D. J. Bjornstad, P. Brewer, and R. Cummings, "The Option Theory of Investment: A Behavior Exploration," Quarterly Journal of Economics, forthcoming.

11. Oak Ridge National Laboratory and Resources for the Future, External Costs and Benefits of Fuel Cycles, McGraw Hill/Utility Data Institute, Washington, D.C., 1994-95.

12. R. M. Lee, "The U.S.-EC Fuel Cycle Externalities Study: The U.S. Research Team's Methodology, Results, and Conclusions," prepared for the European Commission, International Energy Agency, and Organization for Economic Cooperation and Development Workshop, "The External Costs of Energy," Brussels, Belgium, January 30-31, 1995.

13. R. M. Lee, "Externalities Studies: Why Are the Numbers Different?" prepared for the Third International Workshop on Externality Costs, Ladenburg, Germany (to be published in a book edited by $\mathrm{O}$. Hohmeyer and R. Ottinger, published by Springer-Verlag), May 27-30, 1995.

14. Energy Information Administration, Electricity Generation and Environmental Externalities: Case Studies, DOE/EIA-0598, Energy Information Administration, Washington, D.C., 1995.

15. D. J. Bjornstad and J. R. Kahn, The Contingent Valuation of Environmental Resources: Methodological Issues and Research Needs, Edward Elgar Publishing, Aldershot, England, 1995.

16. M. E. Downing and T. Ozuna, "Testing the Reliability of the Benefit Function Transfer Approach," Journal of Environmental Economics and Management forthcoming (March 1996).

17. P. N. Leiby, A Methodology for Assessing the Market Benefits of Alternative Motor Fuels, ORNL-6771, Oak Ridge National Laboratory, Oak Ridge, Tenn., 1993.

18. The full conceptual process flow model and specific assumptions used in the analyses can be found in the report Preliminary Life Cycle Analysis for a Recycling Program for Metals from Building $K-31$ at the Oak Ridge K-25 Site, ORNL/ER-346, Vol. 2, Oak Ridge National Laboratory, Oak Ridge, Tenn., October 1995.

19. T. R. Curlee et al., Waste-to-Energy in the United States: A Social and Economic Assessment, Quorum Books, Westport, Conn., 1994.

20. S. Das et al., "Automobile Recycling in the United States: Energy Impacts and Waste Generation," Resources, Conservation, and Recycling 14, 265-84 (1995). 


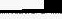




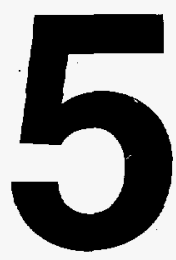

\section{Environmental Analysis and Assessment Section}

Robert M. Reed Section Head
The Environmental Analysis and Assessment Section (EAAS) conducts applied research in the physical and social sciences and performs integrated assessments that provide decision makers with critical information on and analyses of challenging issues that affect the human environment at local, regional, and global scales. A major activity in the section for many years has been providing support to federal agencies by performing environmental impact analyses and preparing EISs and EAs in compliance with NEPA. This activity has allowed us to develop special expertise in emergency management, radioactive waste management, siting and characterization

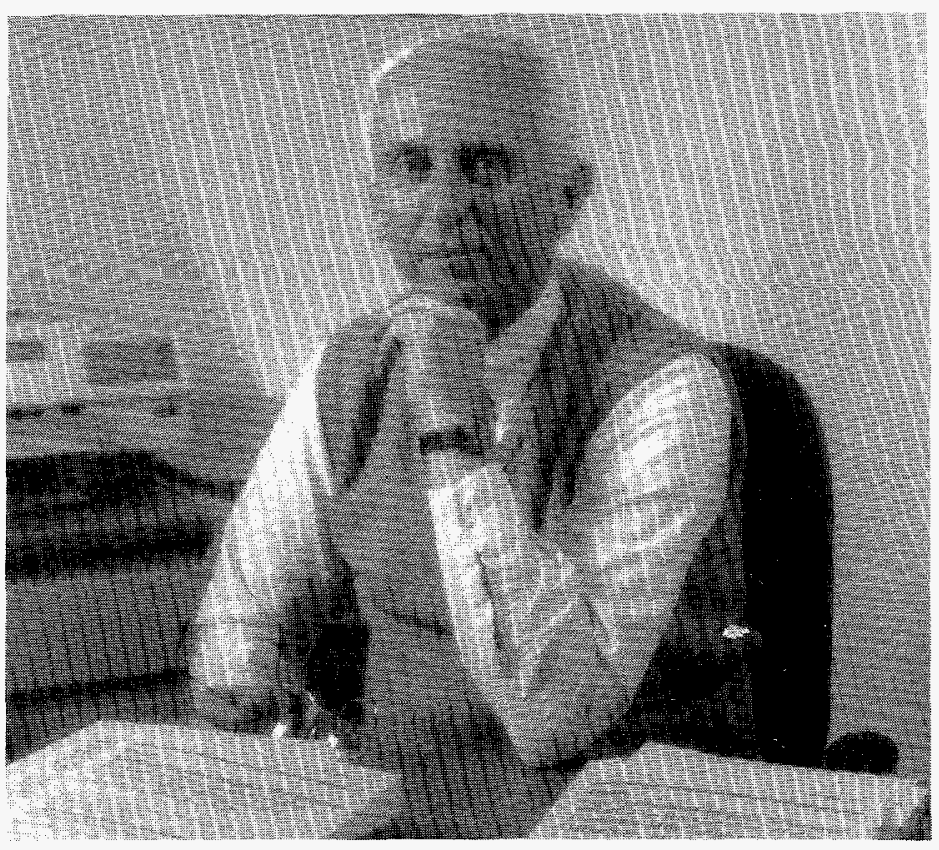

of geohydrologic systems for waste disposal facilities, contaminant transport modeling in atmospheric and aqueous systems, public acceptance of hazardous technologies, institutional mechanisms for managing complex technologies, analysis of socioeconomic impacts of technological change on communities, and environmental decision making on a global scale. One of our major strengths is organizing and leading interdisciplinary teams drawn from one to several ORNL divisions that can provide a sponsor with the necessary information and analysis to assist in the decision-making process. 
Further information about EAAS is available on the Internet at our World Wide Web home page, at http://www.ornl.gov/eaas/home.html.

\section{NEPA SUPPORT TO FEDERAL AGENCIES}

EAAS continues to provide significant support to DOE and other federal agencies in coordinating environmental impact analyses and preparing NEPA documents. Our sponsors in FYs 1994 and 1995 include DOE, the Federal Energy Regulatory Commission (FERC), the U.S. Army, the Nuclear Regulatory Commission (NRC), the National Science Foundation, and the National Park Service (NPS).

\section{NEPA Support to DOE}

EAAS provides NEPA support to DOE programs and sites. In FYs 1994 and 1995, we continued to support the DOE Clean Coal Technology Program by finalizing the EIS on the Healy Clean Coal Project ${ }^{1}$ (see discussion below) and preparing several EAs on innovative clean coal technologies, including EAs on the Warren Station externally fired combined cycle demonstration project in Pennsylvania, ${ }^{2}$ the proposed Gasification Product Improvement Facility at the Fort Martin Power Station in West Virginia, ${ }^{3}$ and the proposed Four Rivers project to demonstrate pressurized circulating fluidized bed technology in Calvert City, Kentucky (Fig. 5.1). EAAS staff continued to support the Rocky Flats Environmental Technology Site in Colorado by conducting an environmental review of the Solid Residue Stabilization Program. When DOE decided not to continue preparation of an EIS on the Hawaii Geothermal Project in May 1994, we initiated activities to archive the extensive database that had been developed for this project. We have published seven reports ${ }^{4-10}$ on the environmental resources of the study area and are completing several others involving cultural resources. We prepared an EA for the DOE Oak Ridge Operations Office on the transfer of funds to the state of Texas to construct a Regional Medical Technology Center at the former site of the Superconducting Super Collider. ${ }^{11}$ We continued to support ORNL site programs by preparing environmental analyses on proposed projects, including the reracking of spent fuel assemblies at the High Flux Isotope Reactor, ${ }^{12}$ construction and operation of Class III/IV Solid Low-Level Waste Storage at Solid Waste Storage Area $7,{ }^{13}$ and movement of spent fuel from ORNL to Savannah River or Idaho National Engineering Laboratory. ${ }^{14}$

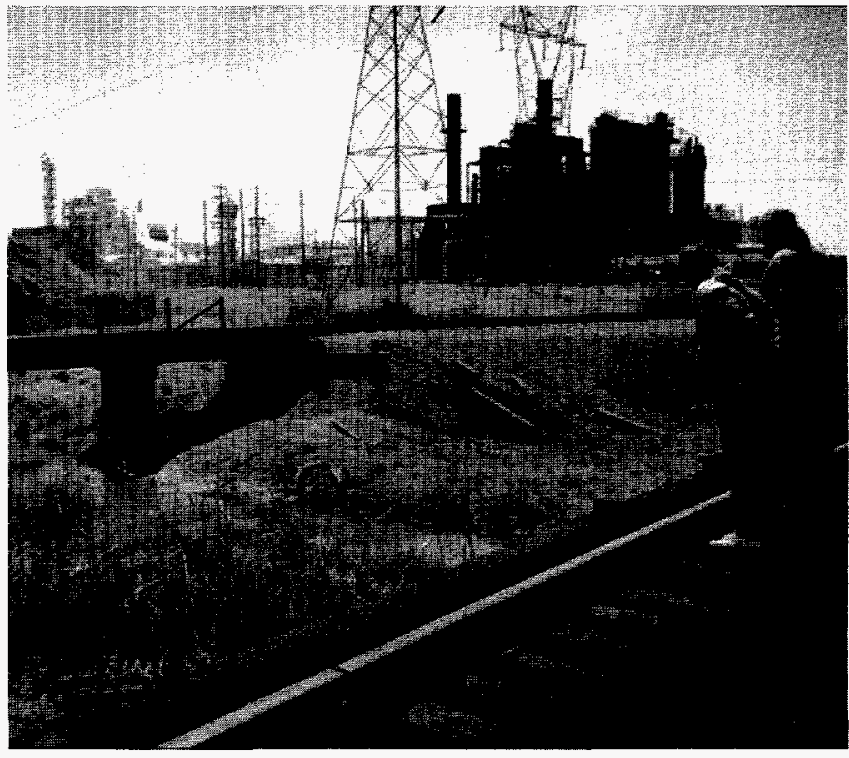

Fig. 5.1. EAAS staff looking over wetland area at the proposed Four Rivers project site in Calvert City, Kentucky.

\section{Environmental Impact Statement on the Healy Clean Coal Project}

In December 1993, ORNL staff completed preparation of an EIS for the Healy Clean Coal Project (HCCP), a proposed coal-fired power plant to be built in Healy, Alaska, about $6 \mathrm{~km}$ (3.8 miles) north of Denali National Park and Preserve (DNNP). ${ }^{1}$ HCCP was selected by DOE in December 1989 for cost-shared funding in the third round of the Clean Coal Technology Program. HCCP will demonstrate novel technologies for removal of sulfur dioxide $\left(\mathrm{SO}_{2}\right), \mathrm{NO}_{x}$, and particulate matter using a new 50-MW coal-fired power generating facility to be built adjacent to the existing 25-MW Healy Unit No. 1, a conventional pulverized-coal unit owned and operated by Golden Valley Electric Association, Inc., in Healy, Alaska (Fig. 5.2). The key issue addressed in this EIS was the potential for HCCP's emissions to cause visibility impairment in DNNP.

Because of the relative proximity of the HCCP site to DNNP - considered by NPS to be a "crown jewel" of the park system, with pristine air quality-the potential for the project's emissions to degrade visibility within the park was of great concern. Although there have been no known visibility impacts associated with the existing Healy Unit No. 1, NPS was concerned that the simultaneous operation of HCCP and Unit No. 1 might result in emissions above a threshold that would trigger perceptible effects. The 
ORNL-DWG 91M-13334R2

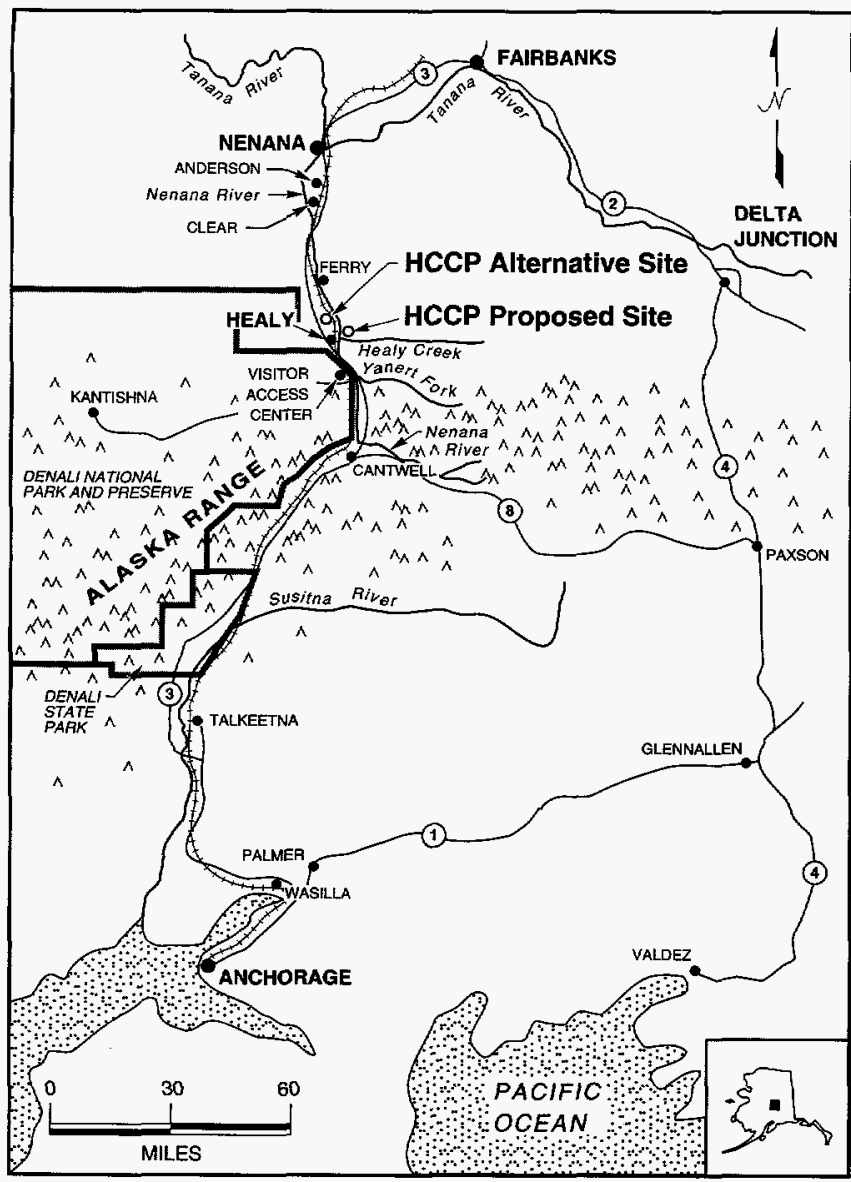

Fig. 5.2. Location of the proposed Healy Clean

\section{Coal Project.}

goal of the visibility analysis, therefore, was to generate predictions which would form an upper bound of expected results, while not being so conservative that they were unrealistic.

Because EPA's regulatory visibility model (PLUVUE II) was not entirely applicable for the proposed site, an innovative approach was developed for the visibility analysis. The PLUVUE I visibility model was used to calculate the ambient concentrations of pollutants in the plume that have the potential to cause visible effects. These calculations used the plume rise, plume transport, plume diffusion, and plume chemistry modules in PLUVUE I (which are the same as in PLUVUE II), but they did not use the optical module, which is not applicable when the sun is within about $10^{\circ}$ of the horizon-typically the case in winter, when visibility impairment is most likely. The optical effects were determined with separate calculations.
The visibility analysis focused on the perceptibility of a plume as viewed from the DNNP Visitor Access Center, located about $14 \mathrm{~km}$ (8.7 miles) south of HCCP (Fig. 5.2). These views were expected to be most susceptible to the effects of the emissions from Healy Unit No. 1 and HCCP. The primary views are to the north (down the Nenana River Valley toward the HCCP site) for $8 \mathrm{~km}$ (5 miles) to the park boundary and to the south (up the Nenana River Valley away from the HCCP site) for $15 \mathrm{~km}$ (9.3 miles) to the boundary.

Initial results indicated that almost all of the potential visibility impacts would be caused by $\mathrm{NO}_{x}$ emissions. As the $\mathrm{NO}_{x}$ emissions exit the stack, they would be primarily in the form of nitric oxide (NO), a colorless gas. Therefore, a visible nitrogen dioxide $\left(\mathrm{NO}_{2}\right)$ plume is not expected at the stack. However, NO is rapidly oxidized by natural ozone $\left(\mathrm{O}_{3}\right)$ in the atmosphere to form $\mathrm{NO}_{2}$, a reddish-brown gas. Given a sufficiently long segment of an $\mathrm{NO}_{2}$ plume, the plume would be visible as a yellow or brown ribbon. The visual effects of particles in the plume, including sulfate particles formed from $\mathrm{SO}_{2}$, were considered, and it was determined that in almost all cases, any reasonable concentration of particles in the emissions would counteract and diminish the visual effects of $\mathrm{NO}_{2}$ and cause the plume to be less visible because particles scatter light to effectively brighten the plume.

$\mathrm{NO}_{2}$ plume burdens were calculated by integrating the $\mathrm{NO}_{2}$ concentrations in the plume predicted by PLUVUE I along each sight path. Burdens typically are given in units of ppbv $\cdot \mathrm{km}$, the multiplicative product of (1) concentration in parts per billion by volume and (2) distance in kilometers. Burdens were calculated each hour for view elevation angles that ranged from $0^{\circ}$ (horizontal sight path) to $20^{\circ}$ above the horizontal in steps of $0.2^{\circ}$ for both the north and south sight paths. A review of the literature found that, for a broad range of geometries, the threshold for plume perceptibility was an $\mathrm{NO}_{2}$ burden of about $150 \mathrm{ppbv} \cdot \mathrm{km}$. Therefore, all plume simulations in which the maximum burden each hour was predicted to be at least $150 \mathrm{ppbv} \cdot \mathrm{km}$ were assumed to have a perceptible plume.

Table 5.1 summarizes results from the analysis of the number of daytime hours per year that the HCCP plume is predicted to be perceptible from the Visitor Access Center for views to the north and south and the total number of hours. The predicted number of hours is extremely low: 2 hours for the north sight path, 2 hours for the south sight path, and a total of 2 hours. Cumulative visibility impacts of air emissions resulting from the simultaneous operation of HCCP and Healy Unit No. 1 also were evaluated. Although the estimates are greater than for the HCCP 
Table 5.1. Number of daytime hours during the year that a plume from Unit No. 1 and the Healy Clean Coal Project (HCCP) is predicted to be perceptible

\begin{tabular}{|c|c|c|c|}
\hline Emission source & $\begin{array}{c}\text { North sight } \\
\text { path }\end{array}$ & $\begin{array}{c}\text { South sight } \\
\text { path }\end{array}$ & Total $^{a}$ \\
\hline$\overline{\mathrm{HCCP}}$ & 2 & 2 & 2 \\
\hline Unit No. 1 & 5 & 5 & 6 \\
\hline Unit No. 1 plus $\mathrm{HCCP}^{b}$ & 8 & 13 & 15 \\
\hline
\end{tabular}

alone, the number of hours is still small: 8 hours annually for the north sight path, 13 hours for the south sight path, and a total of 15 hours. For Unit No. 1 alone, the analysis predicts a perceptible plume for 5 hours for each of the north and south sight paths, and a total of 6 hours.

There have been no published sightings from or within the park of a visible $\mathrm{NO}_{2}$ plume from Unit No. 1, suggesting that currently, Unit No. 1 is not causing a visibility problem of concern to the park service or its visitors. As further evidence, time-lapse cameras operating for 16 months within and adjacent to DNNP did not detect any $\mathrm{NO}_{2}$ plumes in the Nenana River Valley. Therefore, the EIS visibility analysis provided an upper-bound estimate of actual visibility impacts from Unit No. 1 and expected impacts during the simultaneous operation of Unit No. 1 and HCCP. The methodology developed in this visibility analysis should be useful for other cases when the optical calculations in the PLUVUE I and PLUVUE II models are unreliable because the sun is close to the horizon.

\section{Environmental Assessment of the Regional Medical Technology Center}

Public Law 103-126 mandated the termination of the Superconducting Super Collider (SSC) project located in Ellis County, Texas. A provision of the law required DOE to utilize the SSC assets to maximize the return to the nation from its investment in the former SSC project. As part of a settlement agreement between DOE and the state of Texas, DOE was required to transfer $\$ 65$ million for the construction of a Regional Medical Technology Center at Waxahachie, Texas. To be located at the site of the linear accelerator that was to have been the source of protons for SSC, the center would use the first stages of the accelerator to supply protons for cancer therapy. In preparing an EA on the project, ${ }^{11}$ EAAS staff determined that the maximally exposed member of the public could receive less than $0.1 \%$ of the maximum regulatory radiation exposure limit and that the expected worker exposure was to be kept below $10 \%$ of the annual regulatory limit. Through extensive interactions with designers, the potential for activation of surface water and groundwater was reduced to acceptable levels by incorporation of additional radiation shielding. The final EA and a Finding of No Significant Impact were published on May 16, 1995.

\section{Environmental Assessment of the High Flux Isotope Reactor at ORNL}

EAAS staff led an interdisciplinary team that analyzed the potential environmental impacts of reracking spent fuel assemblies in ORNL's High Flux Isotope Reactor (HFIR) pool to increase the storage capacity from 62 to 250 assemblies. HFIR, which is a reactor used to produce transuranic isotopes, is the world's sole provider of palladium-103, a radioisotope used in the treatment of prostate cancer, and is a primary provider of iridium-192, a highly important industrial radioisotope used for nondestructive examination of welds. The foreseeable impacts of reracking the spent fuel assemblies were worker exposures to radiation, exposures during a potential accident, and management of radioactive wastes. The assessment showed that worker radiation exposures could increase by up to $10 \%$, which still would be well below regulatory limits. Radiation exposures during potential accidents were shown to be inconsequential. Finally, the proposed action would increase liquid low-level radioactive waste by about only $1 \%$ of the total amount of liquid low-level radioactive wastes generated at ORNL. Based on the resulting $\mathrm{EA}^{12}$ and other information, Assistant 
Secretary of Energy Tara O'Toole approved a Finding of No Significant Impact for the proposed reracking on August 23, 1994. As a result of this approval, the HFIR spent fuel was reconfigured and the reactor was allowed to continue operation.

\section{Federal Energy Regulatory Commlssion Projects}

ORNL continues to provide technical support to the Office of Hydropower Licensing at FERC in the area of NEPA compliance and related activities. In FYs 1994 and 1995, the ORNL team-consisting of staff from the Environmental Sciences Division and the Energy Division-has participated in a number of important projects. We finalized two draft EISs and an EA on proposed hydroelectric developments in the Skagit and Nooksack river basins that were published by FERC after extensive interactions with federal, state, and local resource agencies. ${ }^{15=17}$ The final EIS on proposed modifications to the Lower Mokelumne River Project in California was published in November $1993 .{ }^{18}$ A preliminary draft EIS on the New Don Pedro Project on California's Tuolumne River and a study of environmental issues associated with water resources in the Bay-Delta Area were submitted to FERC in FY 1995. Neither of these studies has been finalized because of continuing negotiations on the issues involved between state and federal agencies. In FY 1995, we initiated a new EIS on relicensing of nine dams on the Missouri and Madison Rivers in Montana and began work on scoping studies involving a number of hydroelectric projects on the Snake River in Idaho and Washington. An EA was finalized on retrofitting a navigation dam for power generation at the New Cumberland site on the Ohio River, ${ }^{19}$ and another EA was finalized on a consent agreement related to the construction and operation of fish passage facilities at three hydroelectric projects on the Susquehanna River in Pennsylvania. ${ }^{20} \mathrm{~A}$ new study of calculation methods for headwater benefits was also initiated at the end of FY 1995.

\section{NEPA Support to Other Federal Agencles}

We continue to support the U.S. Army in preparing NEPA documentation for the demilitarization of chemical weapons at eight depots within the conterminous United States. NEPA documentation has been finalized for two of these sites-Tooele, Utah, and Anniston, Alabama. In FY 1995, the draft EIS for the Pine Bluff Arsenal in Arkansas was published, ${ }^{21}$ and the final EIS for the Umatilla, Oregon, site will be published shortly. Draft
EISs for the depots at Pueblo, Colorado; Aberdeen, Maryland; Bluegrass, Kentucky; and Newport, Indiana, are currently being prepared by ORNL.

We continue to support NRC with revising the EIS on the relicensing of nuclear power plants throughout the United States. We have prepared several revisions to the EIS published in November 1991 following policy decisions from NRC. The EIS should be published by NRC in CY 1996.

Since FY 1993, we have assisted the NRC Office of Nuclear Material Safety and Safeguards (NMSS) with its NEPA documents. In August 1993, we provided a final EIS on the licensing of the Envirocare of Utah, Inc., facility to dispose of uranium and thorium by-product material for publication by NRC. ${ }^{22}$ In FY 1994, we began preparing a draft EIS on the reclamation of the uranium mill tailings pile in Moab, Utah (Fig. 5.3). The draft EIS is scheduled for publication in early CY 1996 . We are currently assisting NMSS with the preparation of three additional EISs-the Shieldalloy facility in Cambridge, Ohio; the Parks Township facility near Pittsburgh, Pennsylvania; and the Crownpoint uranium mining project near Crownpoint, New Mexico-and an EA on the Nuclear Metals, Inc., facility in Concord, Massachusetts. These projects include a mix of licensing actions that range from decommissioning a site to construction and operation of a new facility.

The U.S. Antarctic Program (USAP) is managed by the National Science Foundation, Office of Polar Programs. As part of a 5-year safety, environment, and health initiative, and under the environmental impact

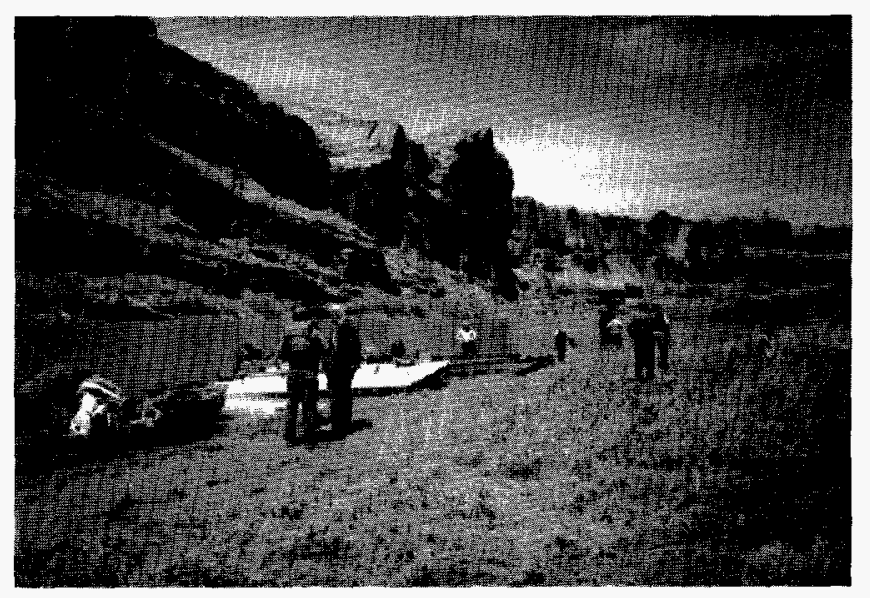

Fig. 5.3. EAAS staff members participate in a presampling survey along the Colorado River to investigate possible contamination from uranium mill tailings plle in Moab, Utah. 
assessment requirements of NEPA and the Protocol on Environmental Protection to the Antarctic Treaty, our interdisciplinary teams have assisted USAP in assessing the potential impacts of its operations and research activities on the environment of Antarctica. Most recently we have published a series of environmental reports on potential environmental effects of three activities involving both research and logistic support components of USAP: (1) ice and geological drilling, (2) management and detonation of explosives, and (3) release of weather and research balloons. ${ }^{23-25}$ All three of these activities are essential to the conduct of USAP research, but they require careful management to avoid long-term, deleterious impacts to the harsh yet fragile antarctic environment and to future research opportunities. The information contained in the ORNL reports will be used by USAP in preparing appropriate environmental assessment documentation for planned activities and in selecting the best methods to avoid adverse impacts.

Since 1989, the Energy Division, the Environmental Sciences Division, and a number of subcontractor staff have supported NPS by collecting field data and preparing analyses of impacts from the proposed construction and operation of sections of the Foothills Parkway bordering the Great Smoky Mountains National Park. Field studies have been conducted on geology, soils, water quality, and terrestrial and aquatic biota. In addition, existing data-supplemented in some cases with limited collection of field data and modeling - have been compiled on air quality, socioeconomics, and traffic. In FY 1995, NPS published a draft EIS on Section 8D of the Foothills Parkway, ${ }^{26}$ based in large part on the ORNL environmental report. We also began a new project to collect similar data for Section 8B of the Foothills Parkway, between Pittman Center and Cosby. Our final report on the affected environment will be submitted in FY 1996. An analysis of impacts will be prepared subject to decisions by NPS on the future of the parkway.

\section{EMERGENCY PREPAREDNESS AND RESPONSE}

\section{Chemical Stockpile Emergency Preparedness Program (CSEPP)}

ORNL continues to provide technical support to the Federal Emergency Management Agency (FEMA) and the U.S. Army for the Chemical Stockpile Emergency Preparedness Program (CSEPP). In FYs 1994 and 1995, the ORNL team met a number of major milestones. Our work includes activities in three areas-training, planning, and modeling. Examples of our accomplishments in these areas are (1) development of such training materials as the Technical Planning and Evaluation (TPE) course, a risk communications sourcebook, and a protective action decision video; ${ }^{27}$ (2) publication of the program planning guidance and the development of a GIS-based demographic analysis capability; and (3) completion of OREMS, an evacuation model, and Protective Action Dose Reduction Estimator (PADRE), a protective action model.

An accident involving chemical agents could be a rapidly occurring event with no time for detailed analysis-it would require an immediate emergency response reaction. In order to achieve such a reaction, as much decision making as possible should be completed during the planning phase so that the decisions made can be implemented immediately in the case of an accident. A primary function of the TPE course is to help the planner organize the information and concepts discussed in the CSEPP Planning Guidance and Standards into a practical framework for developing local protective action plans. The objectives of the TPE course are

- to identify the physical and chemical properties of chemical agents that are important to the protective action decision-making process and how these relate to developing protective action strategies;

- to identify the potential human health effects of chemical agents that are important for the protective action decision-making process and how these relate to developing protective action strategies;

- to define and illustrate the concepts of exposure, dose, and risk, and show how these relate to the protective action decision-making process;

- to list the basic functions of models and describe their use in planning;

- to list and describe the specific planning tools developed within CSEPP for protective action planning; and

- to define evacuation and sheltering as protective actions for CSEPP.

Figure 5.4 shows the form used in TPE to organize planning assumptions.

The risk communications sourcebook ${ }^{28}$ is a fairly comprehensive sourcebook on risk, risk management, risk communication research, and recommended risk communication practices. The sourcebook was developed for CSEPP in support of the training module on risk communications. Although the examples provided are specific to CSEPP, its use could extend beyond CSEPP 


\begin{tabular}{|c|c|c|c|}
\hline & Description & $\begin{array}{c}\text { Suburban } \\
\text { Houses } 25 \text { yrs old }\end{array}$ & \multirow{4}{*}{$\begin{array}{l}\text { If source of } \\
\text { Average Evac. } \\
\text { Speed is } \\
\text { ORMES, you } \\
\text { must complete } \\
\text { the OREMS } \\
\text { Assumptions } \\
\text { forms }\end{array}$} \\
\hline & $\begin{array}{c}\text { Direction } \\
\text { Range in "s } \\
\end{array}$ & $40^{\circ}$ to $120^{\circ}$ & \\
\hline $\mathrm{A} 2$ & Distance & $5000 \mathrm{~m}$ & \\
\hline A3 & $\begin{array}{l}\text { Air Exchange } \\
\text { Rate } \\
\end{array}$ & 1.5 & \\
\hline \multirow{2}{*}{ L1 } & \multirow{2}{*}{$\begin{array}{c}\text { Average } \\
\text { Evac. Speed }\end{array}$} & \multirow{2}{*}{$20 \mathrm{mi} / \mathrm{h}$} & Source \\
\hline & & & OREMS \\
\hline
\end{tabular}

\begin{tabular}{|c|c|c|c|c|c|c|c|}
\hline & & & Number of & Air Exchange & $\begin{array}{r}\text { Public } \\
\text { Si }\end{array}$ & $\begin{array}{l}\text { Ise Tim } \\
\text { point }\end{array}$ & \\
\hline & & & People & Rate & Evac & Shelter & Implementation Start \\
\hline $\begin{array}{l}\text { Population } \\
\text { Subgroup }\end{array}$ & A5 & $\begin{array}{c}\text { Normal Day } \\
\text { Population }\end{array}$ & 1000 & 1.5 & & & \\
\hline & $\overline{A 6}$ & $\begin{array}{c}\text { Normal Night } \\
\text { Population }\end{array}$ & & & & & \\
\hline & A7 & $\begin{array}{l}\text { Population } \\
\text { Subgroup } 1\end{array}$ & 2 & 1.5 & & & $\begin{array}{c}30 \text { minute delay for } \\
\text { evacuation }\end{array}$ \\
\hline & A8 & $\begin{array}{l}\text { Population } \\
\text { Subgroup } 2\end{array}$ & 50 & 0.0 & & & \\
\hline & A9 & $\begin{array}{l}\text { Population } \\
\text { Subgroup } 3\end{array}$ & & & & & \\
\hline & A10 & $\begin{array}{l}\text { Population } \\
\text { Subgroup } 4\end{array}$ & & & & & \\
\hline
\end{tabular}

Population Subgroups are defined as groupings of identified special populations with similar evacuation time estimates or other population groups who have sheltering differences from the predominant sheltering characteristics, should be listed in the order of the length of time it takes to evaluate the population, from the shortest time to the longest.

Fig. 5.4. Form used in the Technical Planning and Evaluation course to organize planning assumptions.

because the findings apply to a broad spectrum of risk communication topics. While the emphasis is on communication in emergency preparedness and response specific to CSEPP, the materials cover other nonemergency communication settings as well.

The CSEPP planning guide developed for the Army and FEMA $^{29}$ is intended to assist state, local, and Army installation planners in formulating and coordinating plans for chemical events that may occur at the chemical agent stockpile storage locations in the continental United States. Broad planning guidance is provided for use by both on-post and off-post agencies and organizations in the development of a coordinated plan for responding to chemical events. It contains checklists to assist in ensuring that all important aspects are included in the plans and procedures developed at each Chemical Stockpile Disposal Program (CSDP) location. The checklists are supplemented by planning guidelines in the appendices, which provide more detailed guidance regarding some issues.

The methodology for conducting demographic analyses for CSEPP using GIS tools is easily replicated and provides a basis for comparison among units. A GIS is composed of three basic components: a database for storing attribute information, a user interface for accessing and displaying information, and a set of tools or functions for manipulating and analyzing data. For this effort we chose MapInfo- a commercially available GIS product-on the basis of cost, functionality, and ease of use. Other GIS packages could also be used to conduct 
the analyses performed. Some of the areas in which EAAS can perform analyses include

- demographic analysis of the population structure and characteristics within an impact area;

- screening and assessment of environmental justice issues; $^{30}$

- estimates of population and resources within an emergency planning zone;

- identification of sensitive populations;

- integrated health risk analysis;

- assessment of housing characteristics, including occupancy, vacancies, age, and value;

- development of base maps and mapping the results of analyses on the base map (e.g., thematic maps of the percentage of minority populations).

Where data permit, the system supports such analyses at a variety of geographic scales, including the block (the smallest census unit), the block group, the census tract, or the county level.

As shown in Fig. 5.5, the population at risk from a release of hazardous materials from a point source is estimated for a $10-\mathrm{km}$ radius and for a specific plume with a downwind hazard distance of $10 \mathrm{~km}$. Where the radius or the plume intersects a block, the population is portioned out according to the area of the block inside the object.
PADRE is a software program developed by ORNL for FEMA. This interactive program for emergency planners in CSEPP simulates an emergency response to airborne releases of chemical agent and is designed to assist in the evaluation of protective actions for chemical emergencies. It iteratively presents the user with dialog screens designed to set accident parameters and to specify the emergency response and the protective actions employed. PADRE then graphically presents the results of the analysis. The results are portrayed as the accumulation of out-of-doors dosage of a chemical agent over time for someone with no protection and for the accumulated dosage given the chosen emergency system and protective action. Planners are provided with summary data such as plume arrival time, portion of the population protected when the plume arrives, and expected exposure reduction. PADRE allows the user to change scenarios (i.e., different scale of accident, different protective actions) and to analyze the change in exposure to chemical agents. Imbedded in PADRE are the D2PC dispersion model and PARDOS code developed by the Army. PADRE has evolved from an earlier model called Protective Action Evaluator for Chemical Emergencies (PAECE), a research tool developed to analyze protective action strategies.

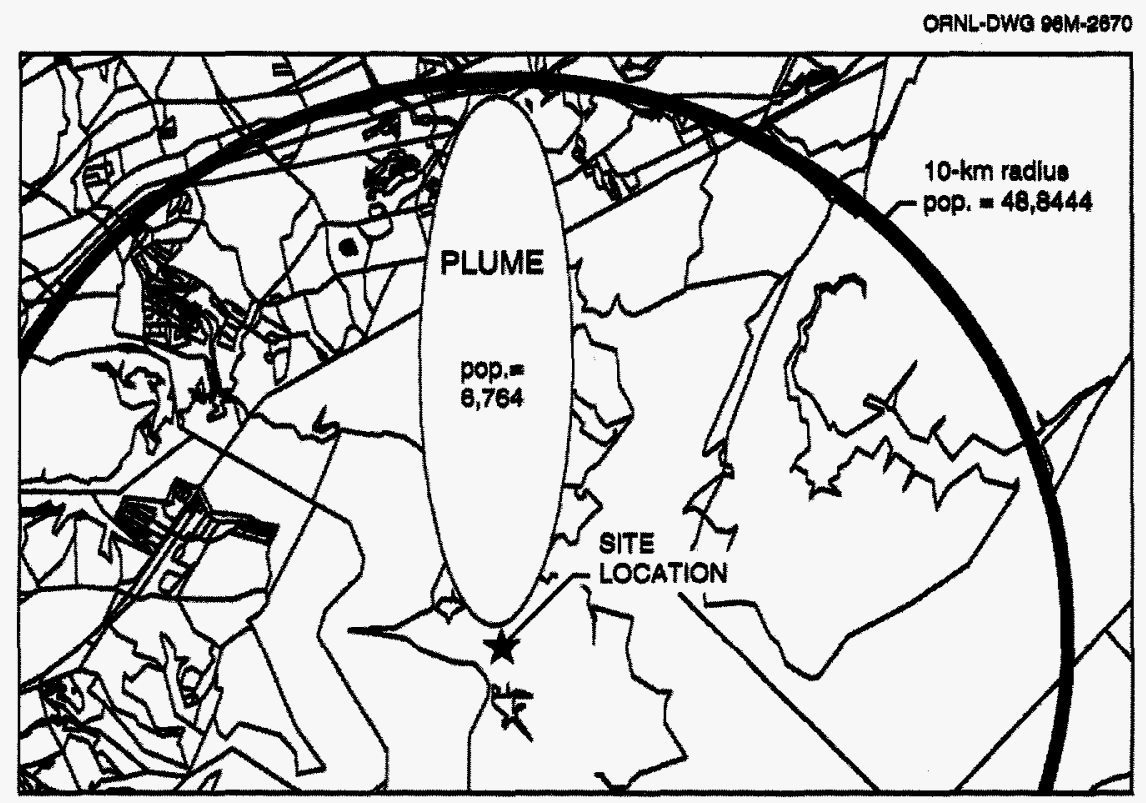

Fig. 5.5. Use of a plume overlay on a block-level census data map to provide an estimate of the population at risk from a release of hazardous materials from a point source. 


\section{Emergency Preparedness Support for DOE's Office of Defense Programs}

DOE orders require that DOE facilities conduct full-scale exercises to demonstrate and improve the readiness of their incident response capabilities. Tribal, state, and local jurisdictions have the opportunity to participate in these exercises.

EAAS staff have participated in some of these exercises as Defense Program members of a DOE Headquarters evaluation team. The Headquarters teams not only evaluate the response, but also consider how well the facility planned and conducted the exercise. An EAAS staff member evaluated the Albuquerque Operations Center Emergency Operations Center during a May 1995 exercise at Sandia National Laboratory. The exercise scenario involved an explosion and building collapse, with many casualties and small releases of radiological and other toxic materials. In July 1995, the EAAS representative was assigned to evaluate on-scene incident command at the Los Alamos National Laboratory exercise. The Los Alamos scenario focused on hostage negotiation, but there was an initiating automobile accident with a wounded man who was contaminated with radioactive iodine. The fall exercise at the Amarillo, Texas, Pantex Plant dealt with an explosion in a handling cell that produced casualties and dispersed plutonium across the facility and into nearby areas. The EAAS staff member evaluated the incident command group.

A written report was prepared after each exercise. In some cases the Headquarters evaluation team prepared a report, while at other times this evaluation was combined with other DOE evaluations for one report. The facilities then use their exercise experience, information from critiques, and exercise reports to improve their response capabilities.

\section{WASTE MANAGEMENT, ENVIRONMENTAL RESTORATION, AND SAFETY ANALYSIS UPGRADE PROGRAM SUPPORT}

EAAS continues to provide support to Lockheed Martin-managed DOE sites and other sites in the DOE system in the areas of waste management, environmental restoration, and the safety analysis upgrade program. One of the more challenging activities during this reporting period has been a cooperative effort with Sandia National Laboratory in preparing a performance evaluation for disposal of mixed, low-level waste at 15 DOE sites (see the highlight "Performance Evaluation for Disposal of Mixed, Low-Level Waste").

\section{Performance Assessment for Solid Waste Storage Area 6 (SWSA 6)}

The only low-level radioactive waste disposal facility in Oak Ridge is located at SWSA 6 in Melton Valley. For each low-level radioactive waste disposal facility that accepts waste, a site-specific performance assessment is required by DOE Order $5820.2 \mathrm{~A}$. The effort to develop a performance assessment for SWSA 6 is led by EAAS staff and was initiated in 1989. A draft performance assessment was prepared in 1990 and submitted to the DOE Peer Review Panel for review. While the review was largely favorable, substantial efforts were required to revise the performance assessment, which was completed in February 1994. The revised performance assessment was submitted to the DOE Peer Review Panel for acceptance in March 1994. ${ }^{31}$ The review included the preparation of responses to several information requests and was concluded in January 1995. The Peer Review Panel concluded that the performance assessment for SWSA 6 was technically acceptable, and DOE Headquarters subsequently concurred. Several recommendations were included in the letter of acceptance, the most important of which was the need to revise the performance assessment to be consistent with actions that have occurred to improve operations at SWSA 6. Current activities are directed towards responding to the recommendations of DOE Headquarters and responding to the additional requirements imposed on performance assessments for DOE by the Defense Nuclear Safety Board in Recommendation 94-2.

\section{Pinellas Plant Dose Assessment}

DOE's Pinellas Plant, in Largo, Florida, proposed shipping hazardous sludge containing radioactive tritium to the U.S. Pollution Control, Inc. (USPCI), hazardous waste landfill in Tooele County, Utah, for disposal. For this waste to be approved for shipment and disposal, a radiological dose assessment is required to ensure the protection of workers and the public from radiation hazards. The radiological dose assessment is also necessary before DOE will allow an exemption from the Department's moratorium on the off-site shipment of radioactively contaminated wastes.

Pinellas solicited assistance from EAAS staff in August 1995 to prepare the required radiological dose assessment because there was an opportunity to transfer 


\section{Highlight}

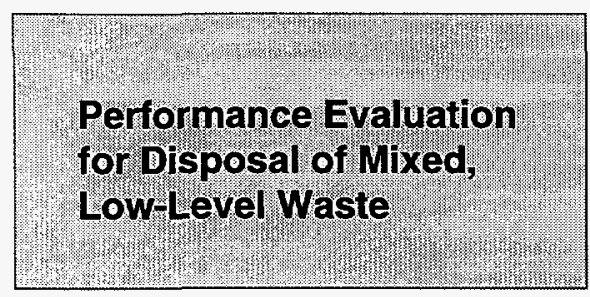

The Federal Facilities Compliance Act (FFCA) of 1992 requires DOE to work with its regulators and with members of the public to establish plans for the treatment of DOE's mixed low-level waste (MLLW). Along with other radioactive and hazardous waste, MLLW has been generated for more than 50 years through DOE activities related to the production of materials for nuclear weapons and research with nuclear materials. DOE currently generates, stores, or expects to generate (over the next 5 years) about $650,000 \mathrm{~m}^{3}\left(877,500 \mathrm{yd}^{3}\right)$ of MLLW at 41 sites in 20 states. Although FFCA does not specifically address disposal of treated MLLW, both DOE and the states recognize that disposal issues are an integral part of any treatment discussions.

In a collaborative effort sponsored by DOE's Office of Environmental Management, EAAS and Sandia National Laboratory staff have prepared a study that will allow DOE to make informed decisions about the fate of radioactive wastes. The study is the first of its kind in comparing radioactive waste disposal sites within the DOE complex. Fifteen such sites, in thirteen different states, were selected for detailed evaluation; and a comprehensive, three-volume draft report is being published.

The findings of the study are summarized in graphical format in the figure. All fifteen candidate disposal sites were found to be capable of disposing of each radionuclide in some concentration; however, the numerical concentrations varied by up to four orders of magnitude among sites. The sites west of the Mississippi River, also generally characterized as arid sites, were found to have few radionuclides controlled by the water and atmospheric pathways, while the water pathway played a more controlling role at the eastern sites. The abundance of water-controlled pathways for the eastern sites suggests that the western sites are better suited for permanent mixed-waste disposal facilities.

The performance evaluation-along with the findings from the FFCA's Site Treatment Plans and DOE's draft Waste Management Programmatic Environmental Impact Statement-will be used in further discussions between DOE and the states regarding the siting and configuration of future radioactive waste disposal facilities. 


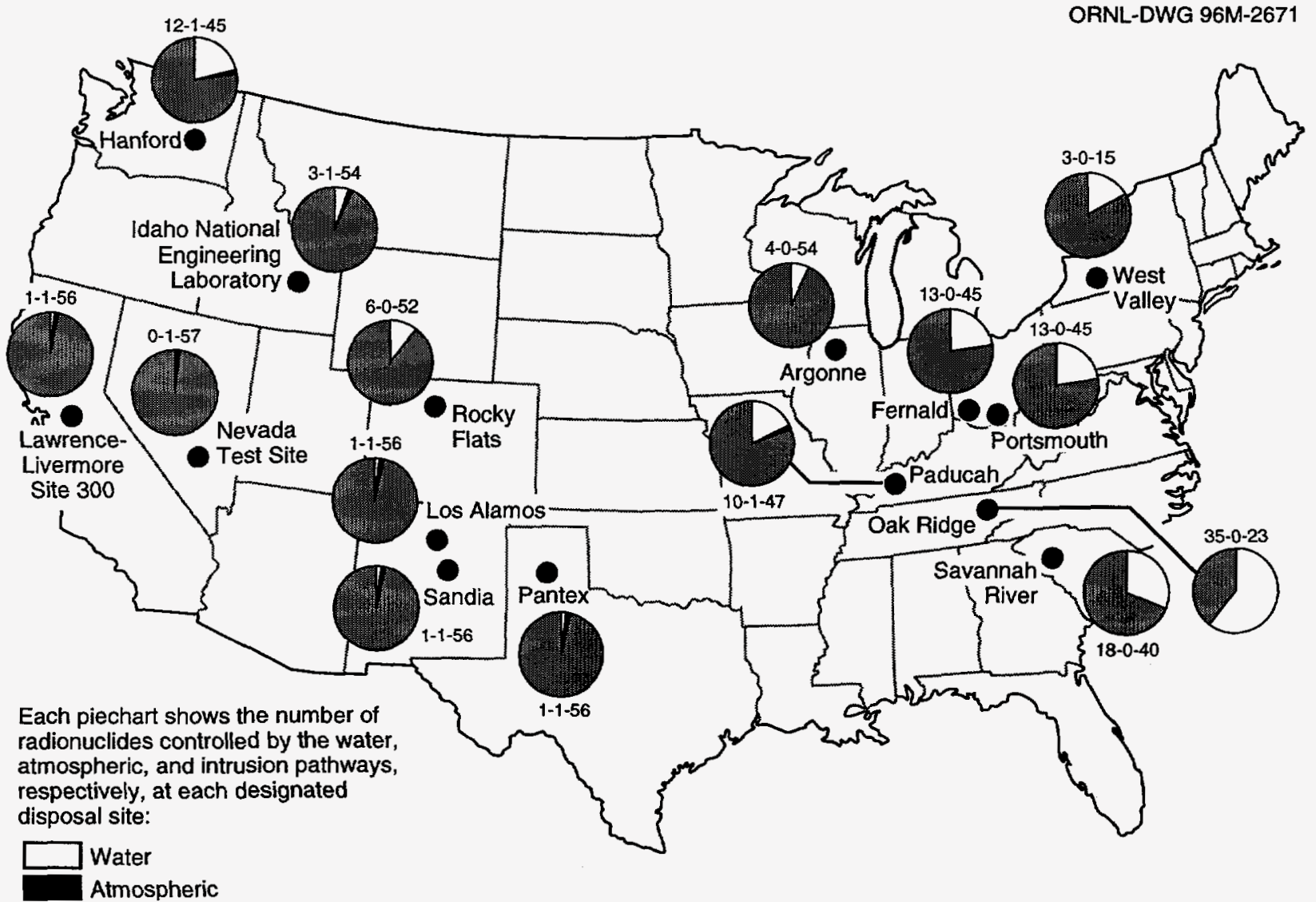

General trend of radionuclides whose disposed concentrations are limited by the water, atmospheric, and direct intrusion pathways at 15 candidate disposal sites. 
the Pinellas sludge to USPCI in October 1995. EAAS staff responded quickly and were able to meet Pinellas's needs by preparing the initial draft assessment by the end of September. The objective of the study was to assess the possible radiological impact to workers at the USPCI facility and members of the public due to the handling, processing, and burial of the DOE waste. The potential off-site public dose was calculated as an upper bound for the hypothetical maximally exposed off-site individual. The predicted doses were compared to background radiation levels and applicable federal regulatory limits.

The highly conservative dose assessment predicted extremely low worker and public doses from tritium exposure. The estimated doses from inhalation of tritium were all far below the natural background levels and the applicable regulatory limits. For example, the worker doses from waste operations were predicted to be 310,000 to 50 million times less than radiation doses from natural sources and 5.1 million to 830 million times less than DOE's regulatory limit.

\section{Groundwater Contaminant Plume Interception and Treatment}

EAAS's Applied Geology Group has played a major role in DOE's Environmental Restoration Program activities at ORNL through participation in groundwater contaminant plume control projects. Groundwater contaminant plumes have formed in the vicinity of contaminant release sites in the radioisotopes production area and at several low-level radioactive waste shallow land burial sites at ORNL. These sites are being regulated and remediated under the Comprehensive Environmental Response, Compensation, and Liability Act (CERCLA). One component of the site management and remediation strategy at ORNL is to take early actions to control releases to the environment to substantially reduce the potential human health and environmental risk from relatively high-priority contaminant source areas.

Because of the hydrogeologic conditions at ORNL, most groundwater contaminants from shallow sources, such as pipeline leak sites and shallow buried waste, migrate through shallow groundwater flow pathways to local surface streams. These routes of groundwater transport cause contamination of springs and seeps. Additionally, in areas where infrastructure elements such as buried storm sewers and other underground facilities lie in the groundwater flow zone, the infrastructure becomes the groundwater contaminant transport pathway. During 1994 and 1995 three projects were constructed at ORNL to reduce strontium- 90 release to the local surface water system. Two of the projects intercept strontium-bearing groundwater near a shallow land burial site and treat the water on-site with discharge of treated water to the local stream, and the third project intercepts groundwater seeping into a storm drain and routes the collected water to the main wastewater treatment facility at ORNL. Geologists from the Applied Geology Group were instrumental in scoping these projects, assisting in design and performance estimation, and providing on-site decisions regarding construction details during the installation of groundwater collectors.

\section{Use of Groundwater Models in Remedial Action Performance Assessment}

Mathematical models for groundwater flow, coupled flow, and solute transport have been applied at ORNL to support three ER projects within the past year. In Waste Area Grouping (WAG) 1, groundwater flow and solute transport modeling was performed to support risk assessments and feasibility studies for the Surface Water Impoundments Operable Unit and the Gunite and Associated Tanks project. For the WAG 4 Seeps project, groundwater flow was modeled and the potential effectiveness of several design alternatives was assessed.

The WAG 1 model was used to evaluate the performance for various source stabilization options at the Surface Water Impoundment Operable Unit and the Gunnite and Associated Tanks project. Contaminant source leaching models were used to produce a solute concentration for the FTWORK model. Retardation values based on soil testing performed in the WAG 1 remedial investigation were used in the contaminant transport analysis. The potential effects on contaminant concentrations in White Oak Creek were based on dilutional mixing of the groundwater seepage flux of specific contaminants in the average flow volume in the creek at the southern edge of WAG 1 . The use of this model has provided a realistic assessment of contaminant release behavior in the complex groundwater flow system of WAG 1.

In WAG 4 the PFEM model was used to analyze the groundwater flow system of Haw Ridge and WAG 4 in support of the WAG 4 Seeps project. The WAG 4 Seeps project is being performed to reduce the release of strontium-90 from WAG 4. The PFEM model was used to analyze the potential benefits of several remedial alternatives at the site, including construction of interceptor drains to divert uncontaminated groundwater, construction 
of various caps, and solidification of portions of trenches. The model analyses led to the following conclusions:

- At WAG 4, hillslope hydrology is likely to cause problems for capping as a source control measure because of lateral underflow of caps.

- Small area caps over sources combined with vertical groundwater seepage cutoff walls may be a successful control measure in the western portion of the site, but near the center of the site, upwelling artesian groundwater may produce a continuous source of groundwater beneath a cap.

- Solidification of contaminant sources provides the best in situ source control option.

\section{Solid Waste Landfill Operating Limit Evaluation at the Paducah Gaseous Diffusion Plant}

The solid waste landfill at the Paducah Gaseous Diffusion Plant (PGDP) reached its capacity limit in FY 1995. A new solid waste landfill was proposed, but the justification for a new landfill required that wastes other than conventional solid wastes from administrative areas of the plant be accepted for disposal. Other waste materials at PGDP have the potential to become incidentally contaminated from uranium enrichment operations. Managing these incidentally contaminated wastes as low-level radioactive wastes would be costly, while disposing of these wastes in an industrial landfill could result in substantial liabilities to DOE. EAAS undertook an operating limit study for the new solid waste landfill, with the objective of determining a limit for allowable contamination in wastes that would be protective of public health and the environment. ${ }^{32}$ This analysis established radionuclide contamination limits for waste materials at the landfill. It also established that the combined potential traces of uranium and all other radionuclides in the landfill waste stream were less than the calculated concentration limits for the landfill.

The operating limit proposed for the new solid waste landfill and the supporting analysis was presented to the Commonwealth of Kentucky for approval. The operating limit was accepted and will become a condition placed on the operating permit for the new solid waste landfill. The acceptance of the operating limit by the Commonwealth of Kentucky results in savings to DOE of $\$ 160$ million over the next 10 years from the disposal of wastes with incidental contamination from PGDP operations.
OTHER EAAS ACTIVITIES

\section{DOE Materials Inventory}

In keeping with the Secretary of Energy's promise to realign functions with current program priorities, the Office for National Security and Environmental Restoration Policy was directed in August 1994 to develop a report on assets and other materials for which the Department is responsible. EAAS staff assigned to the ORNL Washington Office supported DOE in the development of the first detailed inventory of the assets and liabilities the Department and its predecessor agencies have accumulated over the past 50 years. These materials range from precious metals to surplus equipment to high-level radioactive wastes. The Baseline Asset Inventory Report provides the analytic foundation for determining what assets can be transferred to other agencies or sold to the private sector without adversely affecting DOE missions and programs. The report also establishes a policy framework that will ensure that materials are divested in an environmentally sound manner and makes recommendations as to what types of programmatic enhancements are required to increase the overall efficiency and effectiveness of the assets management system.

EAAS staff responsibilities included assisting in the development of the overall analytic approach to assessing material disposition activities, helping to articulate strategic-level disposition paths for approximately 30 categories of material assets and wastes, identifying barriers to effective assets divestiture through field interviews, distilling lessons learned from the development of disposition pathways, and supporting development of the final report. The final report is to be published in early 1996.

The Baseline Asset Inventory Report identifies barriers to the timely disposition and/or divestiture of surplus assets and outlines an asset management strategy that stresses reclamation and reuse of surplus materials. The report also stresses that DOE will have continuing custodial responsibilities for contaminated lands and facilities. At the core of the report is a strong commitment to disposition strategies that reduce amounts of materials that eventually become wastes, that generate revenues that can be used to support DOE missions and/or reduce the deficit, and that promote local economic development. In sum, the Baseline Asset Inventory Report presents a new paradigm for managing material assets across the entire DOE complex. 


\section{Life Cycle Analysis Study for the Army}

Working with staff in ORNL's Metals and Ceramics Division, the Space and Defense Technologies Program Office, and the Health Sciences Research Division, EAAS staff are leading an interdisciplinary study for the U.S. Army to evaluate the environmental consequences of adopting alternatives to depleted uranium (DU) for kinetic energy penetrator (KEPs). KEPs with large length-to-diameter ratios are used in Army M1A2 tanks to penetrate and disable enemy tanks. Although DU alloys have provided the highest performance of any high-density metal alloy in deployment against enemy armor, long-term use of DU poses a number of environmental risks arising out of the low-level radioactivity of DU. These risks include exposures to military and civilian populations from inhalation, ingestion, and injection of particles that are transported directly by air and water, and indirectly through plant and animal uptake and subsequent transfer to humans. High-performance alternatives to DU would achieve performance objectives equal to DU and remove the risks and low-level radioactive waste management costs associated with DU. However, other metal substitutes may present alternative environmental consequences that should be evaluated before decisions are made to manufacture KEPs made of alternative materials. This study has been designed to evaluate the environmental consequences that are likely to be associated with the leading base material, tungsten, in various stages of the military life cycle of KEPs. Modeling of environmental pathways, physiological behavior of tungsten, and atmospheric transport has been completed, and a draft report has been delivered to the Army.

\section{Key Factors Responsible for Changes in Electric-Utility DSM Usage}

Researchers at ORNL and the American Council for an Energy-Efficient Economy recently surveyed staff at 37 electric utilities and 22 state regulatory commissions for the purpose of identifying how utilities' use of DSM resources is changing in the increasingly competitive electric-utility industry and the key factors responsible for this. ${ }^{33}$ We chose a collection of states and utilities that provided a mix of those where DSM use was increasing most rapidly and those where reliance on DSM resources was declining most precipitously or growing most slowly. This work was sponsored by DOE's Competitive Resources Strategy Program, Office of Utility
Technologies, Office of Energy Efficiency and Renewable Energy.

Between 1992 and 1994, the median annual growth rate for utility DSM expenditures was $16 \%$ for the utilities studied and $11 \%$ for the states (Fig. 5.6). In contrast, the median utility projected an annual decline in DSM expenditures of 3\% for 1994-98, while the median state growth rate was projected to be $1.5 \%$ annually. The growth rate in cumulative energy savings also is expected to be substantially less in the near-term future than it was in the recent past, but the decline in growth will not be as dramatic as for DSM expenditures. In contrast, the projected growth rate in cumulative peak demand reductions will come much closer to matching the recent historical record than will either DSM expenditures or energy savings. In general, utilities reported that their programs will change over the next few years in ways designed to make them more cost-effective and service-oriented. Specifically, utilities will put less

ORNL-DWG 95M-8739R

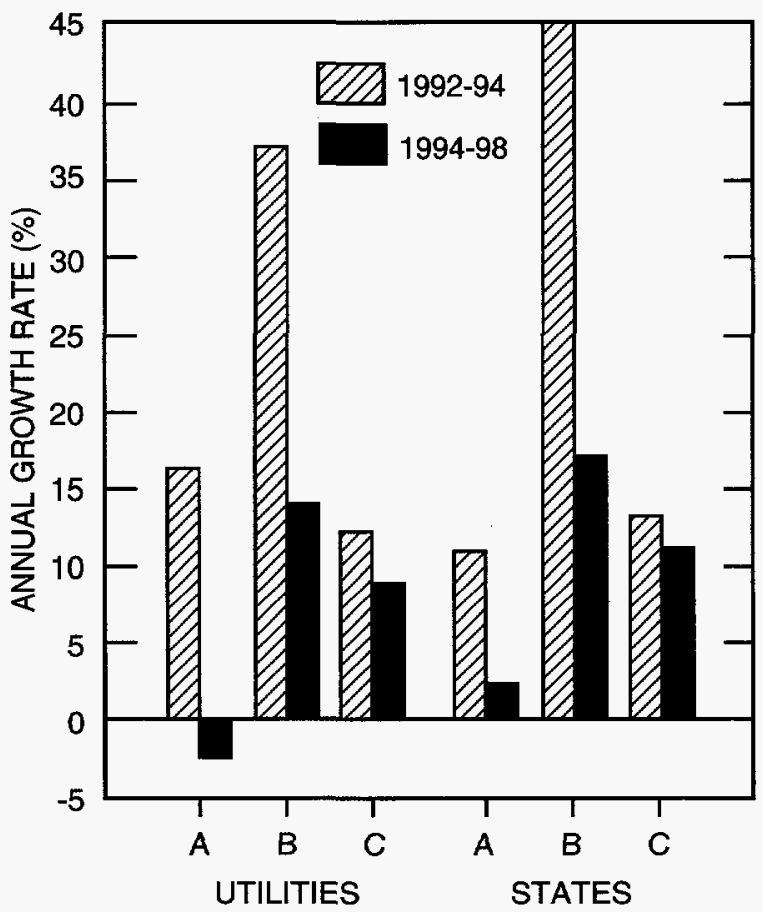

$$
\begin{aligned}
& A=\text { Annual DSM expenditures } \\
& B=\text { Cumulative energy savings } \\
& C=\text { Cumulative peak-demand reduction }
\end{aligned}
$$

Fig. 5.6. Annualized median change in demand-side management usage by utilities and states. 
emphasis on rebates and direct installation of DSM measures and more emphasis on a variety of other approaches, including recovery of program costs from participants, financing, shared savings programs, and market transformation.

Utilities and states anticipating minimal growth in the use of DSM resources very frequently attributed this to their anticipation of increased competition. We found that the actual or threatened loss of customers to a variety of competitive pressures frequently was related to lower rates of growth in DSM usage. However, it appears that the loss of customers could, in some instances, stimulate utilities to spend more on DSM in order to induce remaining customers to stay on the system. Utilities with a history of aggressive DSM usage tended to have less growth in their use of DSM resources in the recent past and near-term future than did later entrants into the DSM arena, indicating that utilities with well-established DSM portfolios may be peaking out in their use of these resources.

\section{REFERENCES}

1. U.S. Department of Energy, Final Environmental Impact Statement for the Proposed Healy Clean Coal Project, DOE/EIS-0186, Pittsburgh Energy Technology Center, Pittsburgh, December 1993.

2. U.S. Department of Energy, Environmental Assessment for the Warren Station Externally Fired Combined Cycle Demonstration Project, DOE/EA-1007, Morgantown Energy Technology Center, Morgantown, W.Va., April 1995.

3. U.S. Department of Energy, Environmental Assessment: Proposed Gasification Product Improvement Facility at the Fort Martin Power Station, Maidsville, West Virginia, DOE/EA-0905, Morgantown Energy Technology Center, Morgantown, W.Va., March 1994.

4. F. M. Glenn et al., Bibliography of Documents and Related Materials Collected for the Hawaii Geothermal Project Environmental Impact Statement, ORNLTM-12862, Oak Ridge National Laboratory, Oak Ridge, Tenn., March 1995.

5. D. A. Lombardi et al., Environmental Resources of Selected Areas of Hawaii: Climate, Ambient Air Quality, and Noise, ORNL/TM-12861, Oak Ridge National Laboratory, Oak Ridge, Tenn., March 1995.

6. J. W. Saulsbury et al., Environmental Resources of Selected Areas of Hawaii: Socioeconomics, ORNL/TM-12860, Oak Ridge National Laboratory, Oak Ridge, Tenn., March 1995.
7. W. P. Staub and R. M. Reed, Environmental Resources of Selected Areas of Hawaii: Groundwater in the Puna District of the Island of Hawaii, ORNL/TM-12858, Oak Ridge National Laboratory, Oak Ridge, Tenn., March 1995.

8. W. P. Staub and R. M. Reed, Environmental Resources of Selected Areas of Hawaii: Geological Hazards, ORNL/TM-12857, Oak Ridge National Laboratory, Oak Ridge, Tenn., March 1995.

9. C. C. Trettin et al., Environmental Resources of Selected Areas of Hawaii: Ecological Resources, ORNL/TM-12863, Oak Ridge National Laboratory, Oak Ridge, Tenn., March 1995.

10. G. C. Burtchard and P. Moblo, Archaeology in the Killauea East Rift Zone, Part I: Land-Use Model and Research Design, Kapoho, Kamāili, and Kïlauea Geothermal Subzones, Puna District, Hawai ' $i$ Island, ORNL/Sub/94-SN150/1, Oak Ridge National Laboratory, Oak Ridge, Tenn., July 1994.

11. U.S. Department of Energy, Environmental Assessment: Regional Medical Technology Center at Waxahachie, Texas, Superconducting Super Collider Project Office, Waxahachie, Texas, May 1995.

12. U.S. Department of Energy, Environmental Assessment: Reracking of High-Flux Isotope Reactor (HFIR) Spent Fuel Assemblies, DOE/EA-0935, Office of Nuclear Energy, Washington, D.C., September 1994.

13. U.S. Department of Energy, Environmental Assessment: Class III/IV Solid Low-Level Waste Storage at Solid Waste Storage Area 7 at the Oak Ridge National Laboratory, Oak Ridge Operations, Oak Ridge, Tenn., October 1995.

14. M. L. Socolof et al., Environmental Data and Analyses for the Proposed Management of Spent Nuclear Fuel on the DOE Oak Ridge Reservation, ORNL/TM-13065, Oak Ridge National Laboratory, Oak Ridge, Tenn., August 1995.

15. Federal Energy Regulatory Commission, Draft Environmental Impact Statement: Nine Proposed Hydroelectric Projects in the Skagit River Basin, Washington, FERC/EIS-0083-D, Office of Hydropower Licensing, Washington, D.C., November 1994.

16. Federal Energy Regulatory Commission, Draft Environmental Impact Statement: Nooksack River Basin Hydroelectric Projects, Washington, FERC/EIS-0069-D, Office of Hydropower Licensing, Washington, D.C., November 1994.

17. Federal Energy Regulatory Commission, Environmental Assessment for Hydropower License, 
Skagit River Hydroelectric Project, Washington, FERC Project No. 553, Office of Hydropower Licensing, Washington, D.C., May 1995.

18. Federal Energy Regulatory Commission, Final Environmental Impact Statement: Proposed Modifications to the Lower Mokelumne River Project, California, FERC/FEIS-0067, Office of Hydropower Licensing, Washington, D.C., November 1993.

19. Federal Energy Regulatory Commission, License Amendment to Modify Spill Flow Requirements at the New Cumberland Project on the Ohio River, FERC Project No. 6901-026, Office of Hydropower Licensing, Washington, D.C., September 1995.

20. Federal Energy Regulatory Commission, Environmental Assessment: The Construction and Operation of Fish Passage Facilities at Three Hydroelectric Projects on the Susquehanna River, Federal Energy Regulatory Commission, Washington, D.C., January 1994.

21. U.S. Army, Draft Environmental Impact Statement for the Disposal of Chemical Agents and Munitions Stored at Pine Bluff Arsenal, Arkansas, prepared for Program Manager for Chemical Demilitarization, Aberdeen Proving Ground, Aberdeen, Md., July 1995.

22. U.S. Nuclear Regulatory Commission, Final Environmental Impact Statement to Construct and Operate a Facility to Receive, Store, and Dispose of 1le.(2) Byproduct Material near Clive, Utah, NUREG-1476, Office of Nuclear Material, Safety, and Safeguards, Washington, D.C., August 1993.

23. M. C. Wade, J. W. Webb, and W. H. Hedberg, Technical Emvironmental Report: The Use of Drilling by the U.S. Antarctic Program, ORNL/TM-12809, Oak Ridge National Laboratory, Oak Ridge, Tenn., August 1994.

24. J. T. Ensminger and T. J. Blasing, Environmental Report: The Use of Explosives by the U.S. Antarctic Program, ORNL/TM-13031, Oak Ridge National Laboratory, Oak Ridge, Tenn., July 1995.
25. L. N. McCold, G. K. Eddlemon, and T. J. Blasing, Environmental Effects of the U.S. Antarctic Program's Use of Balloons in Antarctica, ORNL/TM-13032, Oak Ridge National Laboratory, Oak Ridge, Tenn., August 1995.

26. National Park Service, Draft Environmental Impact Statement: Foothills Parkway, Section 8D, Great Smoky Mountains National Park, Tennessee, Denver Service Center, Denver, November 1994.

27. C. J. Coomer et al., An Introduction to Protective Action Decision Making, video for the Federal Emergency Management Agency, April 1995.

28. B. M. Vogt and J. Sorensen, Risk Communication and the Chemical Stockpile Emergency Preparedness Program, ORNL-6824, Oak Ridge National Laboratory, Oak Ridge, Tenn., September 1994.

29. B. L. Shumpert et al., Planning Guidance for the Chemical Stockpile Emergency Preparedness Program, ORNL-6764, Oak Ridge National Laboratory, Oak Ridge, Tenn., October 1995.

30. B. M. Vogt, J. H. Sorensen, and H. Hardee, Environmental Assessment and Social Justice, ORNL/TM-12919, Oak Ridge National Laboratory, Oak Ridge, Tenn., March 1995.

31. D. W. Lee et al., Performance Assessment for Continuing and Future Operations at Solid Waste Storage Area 6, ORNL-6783, Oak Ridge National Laboratory, Oak Ridge, Tenn., February 1994.

32. D. W. Lee, J. C. Wang, and D. C. Kocher, Operating Limit Study for the Proposed Solid Waste Landfill at Paducah Gaseous Diffusion Plant, ORNL/TM-13008, Oak Ridge National Laboratory, Oak Ridge, Tenn., July 1995 .

33. M. Schweitzer and M. Pye, Key Factors Responsible for Changes in Electric-Utility DSM Usage, ORNL/CON-421, Oak Ridge National Laboratory, Oak Ridge, Tenn., September 1995. 


\section{Appendix}

\section{Summary Data, Awards, and Publications}

\section{ENERGY DIVISION ADVISORY COMMITTEE, FY 1994-FY 1995}

Dr. Douglas R. Bohi

Dr. Thomas E. Drabek

Dr. Stephen G. Hildebrand

Mr. Calvin D. MacCracken

Ms. Jacqueline B. Shrago

Mr. George F. Sowers, P.E.

Dr. C. Michael Walton
Director, Energy and Natural Resources Division

Resources for the Future

1616 P Street, N.W.

Washington, DC 20036

Phone: (202) 328-5072

Professor, Department of Sociology

University of Denver

Denver, CO 80208-0209

Phone: (303) 871-2050

Director, Environmental Sciences Division

Oak Ridge National Laboratory

P.O. Box 2008

Oak Ridge, TN 37831-6037

Phone: (423) 574-7374

President, Calmac Manufacturing Corporation

101 West Sheffield Avenue

P.O. Box 710

Englewood, NJ 07631

Phone: (201) 569-0420

Vice-Chancellor, Information Technologies

Tennessee Board of Regents

1415 Murfreesboro Road, Suite 350

Nashville, TN 37217

Phone: (615) 366-4485

Senior Vice President

Law Companies Group, Inc.

114 Townpark Drive, Suite 250

Kennesaw, GA 30144-5599

Phone: (404) 421-3460

Ernest H. Cockrell Centennial Chair

in Engineering and Chairman

Department of Civil Engineering

University of Texas at Austin

Austin, TX 78712-1076

Phone: (512) 471-1414 
ENERGY DIVISION SPONSORS, EXPENDITURES, AND COMMITMENTS OF SCIENTIFIC STAFF FOR FY 1994

\begin{tabular}{|c|c|c|c|c|c|}
\hline \multirow[b]{2}{*}{ Sponsor } & \multirow[b]{2}{*}{ Expenditures $^{a}$} & \multicolumn{2}{|c|}{$\begin{array}{l}\text { Scientific staff } \\
\text { (person-years) }\end{array}$} & \multirow{2}{*}{$\begin{array}{c}\text { Direct } \\
\text { person-year } \\
\text { costs }^{a} \\
\end{array}$} & \multirow[b]{2}{*}{$\begin{array}{c}\text { Subcontract } \\
\text { costs }^{a}\end{array}$} \\
\hline & & $\begin{array}{c}\text { Energy } \\
\text { Division } \\
\end{array}$ & $\begin{array}{c}\text { Other } \\
\text { divisions }\end{array}$ & & \\
\hline \multicolumn{6}{|c|}{ Department of Energy work } \\
\hline $\begin{array}{l}\text { Assistant Secretary for Energy } \\
\text { Efficiency and Renewable Energy }\end{array}$ & $\$ 20,674$ & 57.4 & 3.4 & $\$ 8,651$ & $\$ 8,484$ \\
\hline $\begin{array}{l}\text { Office of Environmental Restoration } \\
\text { and Waste Management }\end{array}$ & 282 & 1.1 & 0.3 & 193 & 12 \\
\hline Energy Information Administration & 321 & 0.7 & 0.0 & 58 & 194 \\
\hline Office of Energy Research & 668 & 2.7 & 0.1 & 430 & 49 \\
\hline Federal Energy Regulatory Commission & 574 & 1.3 & 1.7 & 440 & 91 \\
\hline Assistant Secretary for Fossil Energy & 723 & 3.3 & 0.4 & 571 & 4 \\
\hline $\begin{array}{l}\text { Assistant Secretary for Defense } \\
\text { Programs }\end{array}$ & 119 & 0.6 & 0.0 & 94 & 0 \\
\hline Assistant Secretary for Nuclear Energy & 100 & 0.2 & 0.0 & 24 & 22 \\
\hline $\begin{array}{l}\text { Assistant Secretary for Policy, } \\
\text { Planning, and Program Evaluation }\end{array}$ & 2,120 & 6.4 & 0.4 & 946 & 888 \\
\hline DOE-related & 1,156 & 5.0 & 1.0 & 902 & 77 \\
\hline Other Assistant Secretaries & 57 & 0.3 & 0.0 & 21 & 30 \\
\hline Total DOE & 26,794 & 79.0 & $\overline{7.3}$ & 12,330 & 9,851 \\
\hline \multicolumn{6}{|c|}{ Work for other federal agencies } \\
\hline Department of Defense & 7,683 & 15.4 & 7.0 & 3,171 & 3,612 \\
\hline Department of Transportation & 5,272 & 12.7 & 3.2 & 2,263 & 2,035 \\
\hline $\begin{array}{l}\text { Federal Emergency Management } \\
\text { Agency }\end{array}$ & 1,404 & 4.1 & 0.4 & 513 & 604 \\
\hline Department of State-USAID & 430 & 1.2 & 0.0 & 165 & 55 \\
\hline National Science Foundation & 205 & 1.0 & 0.3 & 177 & 0 \\
\hline National Park Service & 208 & 0.5 & 0.3 & 120 & 63 \\
\hline Environmental Protection Agency & 136 & 0.5 & 0.0 & 70 & 56 \\
\hline Nuclear Regulatory Commission & 1,112 & 4.6 & 1.7 & 936 & 25 \\
\hline Other & 268 & 0.9 & 0.0 & 119 & 356 \\
\hline Total other federal agencies & 16,718 & 40.9 & 12.9 & 7,534 & 6,806 \\
\hline \multicolumn{6}{|c|}{ Work for private organizations } \\
\hline CRADAS & 97 & 0.1 & 0.0 & 27 & 0 \\
\hline Other & 492 & 2.2 & 0.3 & 324 & 75 \\
\hline Total private organization work & $\overline{589}$ & $\overline{2.3}$ & $\overline{0.3}$ & $\overline{351}$ & $\overline{75}$ \\
\hline Total Energy Division & $\$ 44,101$ & 122.2 & 20.5 & $\$ 20,215$ & $\$ 16,732$ \\
\hline
\end{tabular}

${ }^{a}$ Dollars expressed in thousands. 


\section{ENERGY DIVISION SPONSORS, EXPENDITURES, AND COMMITMENTS OF SCIENTIFIC} STAFF FOR FY 1995

\begin{tabular}{|c|c|c|c|c|c|}
\hline \multirow[b]{2}{*}{ Sponsor } & \multirow[b]{2}{*}{ Expenditures $^{a}$} & \multicolumn{2}{|c|}{$\begin{array}{l}\text { Scientific staff } \\
\text { (person-years) }\end{array}$} & \multirow{2}{*}{$\begin{array}{c}\text { Direct } \\
\text { person-year } \\
\text { costs }^{a} \\
\end{array}$} & \multirow[b]{2}{*}{$\begin{array}{c}\text { Subcontract } \\
\text { costs }^{a}\end{array}$} \\
\hline & & $\begin{array}{l}\text { Energy } \\
\text { Division }\end{array}$ & $\begin{array}{c}\text { Other } \\
\text { divisions }\end{array}$ & & \\
\hline \multicolumn{6}{|c|}{ Department of Energy work } \\
\hline $\begin{array}{l}\text { Assistant Secretary for Energy } \\
\text { Efficiency and Renewable Energy }\end{array}$ & $\$ 21,911$ & 54.3 & 2.0 & $\$ 8,282$ & $\$ 9,730$ \\
\hline $\begin{array}{l}\text { Office of Environmental Restoration } \\
\text { and Waste Management }\end{array}$ & 361 & 1.4 & 0.5 & 284 & 22 \\
\hline Energy Information Administration & 249 & 1.3 & 0.0 & 145 & 79 \\
\hline Office of Energy Research & 445 & 2.0 & 0.1 & 317 & 59 \\
\hline Federal Energy Regulatory Commission & 619 & 1.9 & 1.3 & 474 & 91 \\
\hline Assistant Secretary for Fossil Energy & 285 & 1.5 & 0.0 & 229 & 9 \\
\hline $\begin{array}{l}\text { Assistant Secretary for Defense } \\
\text { Programs }\end{array}$ & 0 & 0.3 & 0.0 & 45 & 0 \\
\hline Assistant Secretary for Nuclear Energy & 39 & 0.0 & 0.0 & 1 & 10 \\
\hline $\begin{array}{l}\text { Assistant Secretary for Policy, } \\
\text { Planning, and Program Evaluation }\end{array}$ & 1,595 & 4.8 & 0.0 & 719 & 642 \\
\hline DOE-related & 1,132 & 4.9 & 0.9 & 873 & 51 \\
\hline Other Assistant Secretaries & 87 & 0.0 & 0.0 & 4 & 20 \\
\hline Total DOE & 26,723 & $\overline{72.4}$ & 4.8 & $\overline{11,373}$ & 10,713 \\
\hline \multicolumn{6}{|c|}{ Work for other federal agencies } \\
\hline Department of Defense & 6,929 & 15.5 & 6.4 & 3,855 & 2,933 \\
\hline Department of Transportation & 7,093 & 16.1 & 2.8 & 2,858 & 3,070 \\
\hline $\begin{array}{l}\text { Federal Emergency Management } \\
\text { Agency }\end{array}$ & 1,362 & 3.3 & 0.1 & 325 & 624 \\
\hline Department of State—USAID & 192 & 1.2 & 0.0 & 132 & 0 \\
\hline National Science Foundation & 28 & 0.2 & 0.0 & 28 & 0 \\
\hline National Park Service & 0 & 1.1 & 0.3 & 214 & 111 \\
\hline Environmental Protection Agency & 91 & 0.2 & 0.0 & 22 & 110 \\
\hline Nuclear Regulatory Commission & 1,476 & 6.7 & 1.7 & 1,229 & 37 \\
\hline Other & 644 & 1.0 & 0.0 & 141 & 17 \\
\hline Total other federal agencies & 17,815 & 45.3 & 11.3 & 8,804 & 6,902 \\
\hline \multicolumn{6}{|c|}{ Work for private organizations } \\
\hline CRADAS & 80 & 0.3 & 0.0 & 48 & 25 \\
\hline Other & 290 & 1.4 & 0.0 & 215 & $\underline{0}$ \\
\hline Total private organization work & 370 & 1.7 & 0.0 & 263 & 25 \\
\hline Total Energy Division & $\$ 44,908$ & 119.4 & 16.1 & $\mathbf{2 0 , 4 4 0}$ & $\$ 17,640$ \\
\hline
\end{tabular}

\footnotetext{
${ }^{a}$ Dollars expressed in thousands.
} 


\section{INDUSTRIAL AND UNIVERSITY PARTNERS OF THE ENERGY DIVISION}

A. J. Devaney Associates

Advanced Traffic

AFES

Ahlstrom, Inc.

Alliance to Save Energy

ALK Associates

Alternative Fluorocarbons

Environmental Acceptability Study

(AFEAS) consortium

American Society of Heating,

Refrigerating, and Air-Conditioning

Engineers, Inc. (ASHRAE)

American Gas Cooling Center (AGCC)

American Iron and Steel Institute

Americold Compressors

Analysas Corp.

Applied Management Science

Aspen Systems Corp.

Association of Home Appliance

Manufacturers (AHAM)

Astronautics Corporation of America

Atlantic Research Corp.

Automated Sciences Group, Inc.

Boston University

Bonneville Power Administration

Bowater Company

Brand Consulting Group

Buhler and Abraham

Carrier/United Technologies

Central United States Earthquake Consortium

Circuit City

Clayton Homes

Climate Master Inc.

Data Support Service

Dow Chemical Co.

Dow Corning

DynEco

E.I. duPont de Nemours amp; Co.

Eaton

Economic Opportunity Research Institute

Electric Power Research Institute (EPRI)

Empire State Electric Energy Research Corp.

Energy and Environmental Analysis

Energy Management Association
Enermodel

Engineering Science Inc.

Environmental Consulting Engineers, Inc.

Farradyne Systems

Florida Solar Energy

Gas Research Institute (GRI)

Geophex, Ltd.

Georgia State University Policy

Research Center

Geothermal Heat Pump Consortium, Inc.

H\&R Technical Associates

Hobe Corp.

Home Energy Magazine

Housing Allowance Project

Iapitus Co.

Incentives Research Inc.

Industry Council on Energy

Information International Association

International Archaeological Research Institute, Inc.

International Institute for Energy

Conservation

International Technology Corp.

IT Environmental Programs, Inc.

J. M. Morales \& Associates

Jaycor

Jerry Jackson \& Associates

Joint Institute for Energy and the Environment

KLD Associates

Lawrence Berkeley Laboratory

Lazer Graphics

LeRoy Landers Associates

Manhattan Data Systems

Manville Corp.

Massachusetts Institute of Technology

Material \& Electrochemical Research Corp.

Maxima Corp.

Microcomputer System

MITRE Corporation, MITREK

Division

Montana Department of Natural Resources

Montgomery Ward

NASA - Jet Propulsion Laboratory
National Association for State

Community Services Programs

National Association of Energy Service Companies (NAESCO)

National Association of Home Builders

National Low-Income Energy Consortium

National Roofing Contractors Association

Naval Postgraduate School

New York State Electric and Gas Co.

New York State Energy Research and Development Adminstration

North Carolina State University

Opus One

Oak Ridge Institute for Science and Education

PAI Corp.

PEI Associates

Pennsylvania State University, Center for Logistics Research

Phase Change Technologies, Inc.

Polyiosocyanurate Insulation Manufacturers Association

Polysteel

Princeton University

R. D. Mingo \& Associates

Ramsey Action Program

RANA Solutions

Rankin International

Resources for the Future

RJO

ROH, Inc.

Roof Consultants Institute

Rowland Productions, Inc.

Sabra, Halkias, \& Associates

Saturn Resource Management

Science and Technology

Science Applications International Corp. (SAIC)

Sears Merchandising Group

Seattle City Light, Tampa Electric, Pacific Gas \& Electric, and other electric and water utilities in the THELMA (high-efficiency laundry appliances) collaborative

SEMCO Inc. 
Single-Ply Roofing Industry Society for the Plastics Industry Softeach Corp.

Synergy South Inc.

Synertech Systems Corp.

SYSCON

Systems Research App.

T. J. Murphy \& Associates

TATA Energy Institute

Techmatics, Inc.

Tennessee Valley Authority (TVA)

Texas A\&M University, Texas

Transportation Institute

ThermShield

Thomason and Associates

Total Quality, Inc.
Trane Co.

Trantek, Inc.

U.S. Department of Housing and

Urban Development

U.S. Export Council for Renewable Energy

University of California

University of California, Los Angeles

University of Colorado

University of Florida

University of Idaho

University of Iowa

University of Massachusetts

University of Mississippi

University of New Mexico

University of Oklahoma
University of Southern California University of Southern California,

Economics Dept.

University of Tennessee

University of Tennessee, College of Business

University of Texas at Austin

Vanderbilt University

VIGGEN Corp.

VSE Corp.

Washington State Energy Office

Western Area Power Administration

Witten Technologies

Wolverine Tube, Inc.

York International 


\section{WORKSHOPS AND SYMPOSIA ORGANIZED BY ENERGY DIVISION STAFF}

American Society of Heating, Refrigerating, and Air-Conditioning Engineers (ASHRAE) Symposium,

"Refrigerator-Freezer Energy Performance: Model and Laboratory Evaluations," New Orleans, Louisiana, January

1994, organized and chaired by E. A. Vineyard.

American Society of Heating, Refrigerating, and Air-Conditioning Engineers (ASHRAE) Symposium, "Advanced Framing: Measurements and Modeling," San Diego, California, June 1995, organized and chaired by J. E. Christian.

"Another Mayday: A Multidisciplinary Forum on Common Ground in Energy, Education, and Information," Knoxville, Tennessee, May 5, 1994, organized and chaired by D. L. White.

Biomass Planning Meeting, Oak Ridge, Tennessee, December 10, 1993, chaired by T. D. Anderson.

Chemical Stockpile Emergency Preparedness Program (CSEPP) National Conference, Indianapolis, Indiana, July 19-21, 1994, J. H. Sorensen, member, organizing committee.

Chemical Stockpile Emergency Preparedness Program (CSEPP) National Conference, Lexington, Kentucky, June 12-15, 1995 , J. H. Sorensen, member, organizing committee.

Climate Change Action Plan (CCAP) Workshop on Chillers, Chicago, November 10, 1994, chaired by J. J. Tomlinson.

Commercial HVAC and Refrigeration Workshop, Washington, D.C., December 8, 1993, chaired by J. J. Tomlinson.

"Comparison of Utility Experiences in Using Measurement and Evaluation Results in Program Planning," Folsom, California, June 16-17, 1994, chaired by L. W. Baxter.

Dessicant Cooling and Dehumidification Technology Conference, Chicago, February 9, 1995, chaired by J. R. Sand.

DOE/EPA Contingent Valuation Workshop, Herndon, Virginia, May 18-20, 1994, chaired by D. J. Bjornstad.

"The Energy Efficiency and Renewable Energy Network (EREN) Semi-annual Program Review," Oak Ridge, Tennessee, September 27-28, 1994, organized and chaired by D. L. White.

Forest Products Industries Workshop, Oak Ridge, Tennessee, November 22, 1994, chaired by T. D. Anderson.

Fuel Cell Workshop, Alexandria, Virginia, March 1-3, 1995, co-chaired by F. C. Chen and J. A. Shonder.

"Information Technology, K-12 Education, and the Issue of Sustainability," Chattanooga, Tennessee, September 24-25, 1995, chaired by B. E. Tonn.

"IRP and the Electric Industry of the Future," Chicago, July 19-20, 1994, co-organized by B. E. Tonn, E. A. Hirst, and D. C. Bauer.

ITS Education and Training Strategic Planning Workshop, Reston, Virginia, June 12-14, 1995, chaired by M. S. Bronzini. IVHS America Workshop, Knoxville, Tennessee, September 12-13, 1994, chaired by S. R. Gordon.

Lighting Systems and Equipment, Washington, D.C., December 2, 1993, chaired by E. A. Vineyard.

Major Appliance and Water Heating Workshop, Washington, D.C., November 18, 1993, chaired by E. A. Vineyard.

Measuring the Full Social Costs and Benefits of Transportation Conference, Irvine, California, July 6-8, 1995, chaired by D. L. Greene.

"Public Policy Responsibilities and Electric Industry Restructuring: Shaping the Research Agenda," Chicago, April 3-4, 1995, co-organized by B. E. Tonn, E. A. Hirst, and D. C. Bauer.

Research Immersion Building Science Workshop for Science Teachers, Oak Ridge, Tennessee, July 1995, presented by J. E. Christian.

Residential HVAC Equipment Workshop, Washington, D.C., November 23, 1993, chaired by V. D. Baxter.

"Roundtable on U.S. Department of Energy Best (Business) Practices Network," Arlington, Virginia, July 12-13, 1995, organized and co-chaired by D. L. White.

Tech Commercialization Evaluation, Washington, D.C., June 15, 1994, chaired by M. A. Brown.

Uncertainty and Global Climate Change Research Meeting, Knoxville, Tennessee, March 22-23, 1994, organized by B. E. Tonn.

United Nations Environmental Programme Workshop "Non-CFC Technologies for Domestic Manufacturing Industries in the Latin American Region," São Paulo, Brazil, May 1995, organized by E. A. Vineyard.

U.S./Russia Collaborative Demonstration Project for Energy-Efficient Building Technologies Workshop, San Diego, California, June 18-23, 1995, co-chaired by R. B. Shelton and P. D. Fairchild.

U.S./Russia Electric Power Planning Workshop, Moscow, August 1-3, 1995, co-chaired by L. J. Hill and S. W. Hadley.

U.S./Russia Workshop "Developing Financing Packages for Energy Projects," Gatlinburg, Tennessee, April 4-8, 1994, co-chaired by R. B. Shelton and D. C. Bauer. 


\section{ENERGY DIVISION PROFESSIONAL HONORS AND AWARDS, FY 1994-FY 1995}

Adcock, P. W., was chosen National Membership Committee chairperson for the Society of Women Engineers.

Adcock, P. W., was elected treasurer for WATTec, Inc., which organizes the annual WATTec Conference and Exhibition.

Baxter, V. D., was elected to the Research and Technical Committee of the American Society of Heating, Refrigerating, and Air-Conditioning Engineers, Inc. (ASHRAE).

Braid, R. B., and members of the Service Rate Management Committee received the Energy Systems President's Award for Continuous Improvement for managing significant reductions in the Hazardous Waste Remedial Actions Program overhead rate.

Chen, F. C., received U.S. Patent No. 5,293,130 for the Proportional Counter Device for Detecting Electronegative Species in an Air Sample.

Chen, F. C., was appointed an associate editor of the Journal of Energy Resources Technology for 1995-97.

Chen, F. C., was elected chair of the Advanced Energy Systems Division of the American Society of Mechanical Engineers (ASME) for 1995-96.

Chen, F. C., and V. C. Mei received an Energy Systems Invention Award at the 1994 Awards Night Ceremony and the Sixth Annual Awards Ceremony at ORNL for the development of an air conditioner system modification with significant energy efficiency.

Chen, F. C., and V. C. Mei received an Advanced Technology Award from the International Hall of Fame for their invention, Liquid Over-Feeding (LOF) Air Conditioning System and Method.

Christian, J. E., A. O. Desjarlais, and R. Graves won the Best Paper award for "A Five-Year Validation of an Accelerated Aging Procedure for Estimating the Lifetime Thermal Conductivity of Polyisocyanurate Laminated Board Insulation" at the Polyurethanes ' 95 Conference.

Desjarlais, A. O., D. M. Counce, P. Wolff, L. D. Gilliam, and C. I. Moser received an Award of Excellence in the East Tennessee Chapter of the Society for Technical Communications competition for Proceedings of the Low-Slope Reroofing Workshop.

DeVault, R. C., received a Certificate of Recognition for the filing of a patent application for Hermetically Sealed Superconducting Magnet Motors.

Fairchild, P. D., and members of the CFC Replacement Program Team received an Environmental Excellence Award and a related Certificate of Recognition from DOE.

Fischer, S. K., J. R. Sand, and V. D. Baxter received a Certificate of Recognition for the filing of a patent application for Nonazeotropic Refrigerant Blends as Replacements for R-22.

Hadder, G. R., received an Energy Systems Research and Development Accomplishment Award at the 1995 Awards Night Ceremony for developing an innovative and practical method for calculating cost-effective $\mathrm{NO}_{x}$ emission reduction standards.

Lee, R., C. E. Easterly, C. T. Hunsaker, and G. E. Michaels received an Energy Systems Research and Development Accomplishment Award at the 1994 Awards Night Ceremony and the Sixth Annual Awards Ceremony at ORNL for completion of the joint DOE/European Community study on fuel cycle externalities.

Lee, R., received an honors award for Best Report in Applied Geography from the Association of American Geographers for Estimating Externalities of Coal Fuel Cycles in March 1995.

Mei, V. C., and F. C. Chen received the International Hall of Fame Advanced Technology Award in May 1995.

Mei, V. C., and F. C. Chen received a Certificate of Recognition for the filing of a patent application for the Integrated/Accumulator/Expander Heat Exchanger in January 1995.

Mei, V. C., and F. C. Chen received a Certificate of Recognition for the filing of a patent application for the Liquid Overfeeding Refrigeration System and Methods with Integrated Accumulator Expander Heat Exchange.

Middendorf, D. P., and M. S. Bronzini received an award for Best Paper on Cost Analysis for "Effect of Longer Combination Vehicles on the Total Logistics Costs of Truckload Shippers" at the 36th Annual Meeting of the Transportation Research Forum.

Murphy, R. W., received a Letter of Appreciation from ORNL for expertise and active involvement in the successful construction of the magnetic cryocooler in February 1995. 
Sand, J. R., E. A. Vineyard, and V. D. Baxter received the Best Paper Award from American Society of Heating, Refrigerating, and Air-Conditioning Engineers, Inc. (ASHRAE) for "Laboratory Evaluation of an Ozone-Safe Zeotropic Refrigerant Mixture in a Lorenz-Meutzner Refrigerator" at the Society's 1994 Annual Meeting.

Sand, J. R., and S. Labinov received U.S. Patent No. 5,392,606 for the Self-Contained Small Utility System.

Shelton, R. L., was selected to serve on the Technical Handbook Committee of the American Society of Heating, Refrigerating, and Air-Conditioning Engineers, Inc. (ASHRAE).

Tomlinson, J. J., received a Certificate of Recognition for the filing of a patent application for System for Energy Load Management for Heating and Cooling of Buildings.

Vineyard, E. A., was selected to serve on the United Nations Environmental Programme (UNEP) Technical Options Committee for Refrigeration, Air-Conditioning, and Heat Pumps as part of UNEP's reassessment of the Montreal Protocol.

Wilbanks, T. J., received the James B. Anderson Medal of Honor in Applied Geography at the Association of American Geographers' annual awards ceremony in March 1995. 


\section{ENERGY DIVISION PUBLICATIONS, FY 1994-FY 1995}

Abraham, M. M., and J. M. MacDonald, Energy Conservation Opportunities in Small Commercial Buildings, ORNL/CON-414, Oak Ridge National Laboratory, Oak Ridge, Tenn., August 1995.

Abraham, M. M., J. M. MacDonald, and H. A. McClain, Impact Evaluation of the Energy Retrofits Installed in the Margolis High-Rise Apartment Building, Chelsea Housing Authority, ORNL/CON-413, Oak Ridge National Laboratory, Oak Ridge, Tenn., March 1995.

Adcock, P. W., "Component Modeling and Preliminary Optimization of $\mathrm{LiBr} / \mathrm{H}_{2} \mathrm{O}$ Absorption Cycles," M.S. thesis, University of Tennessee, Knoxville, 1995.

Adcock, P. W., "From Fire to Ice," pp. 79-84 in Engineering-Revolutionizing Our Lives, Proceedings of the 1995 National Conference of the Society of Women Engineers, Boston, June 27-July 1, 1995.

Adler, M. V., and K. S. Gant, Chemical Stockpile Emergency Preparedness Program Exercises, prepared by Oak Ridge National Laboratory, Oak Ridge, Tenn., for FEMA and the U.S. Army, February 1994.

Adler, M. V., K. S. Gant, and E. E. Weinstein, Guidance for a Large Tabletop Exercise for a Nuclear Power Plant, NUREG-1514, Oak Ridge National Laboratory, Oak Ridge, Tenn., December 1994.

Arthur D. Little, Inc., The Market Potential for SMEs in Electric Utility Applications, ORNL/Sub/85-SL889/1, Oak Ridge National Laboratory, Oak Ridge, Tenn., June 1994.

Bansai, P. K., and C. K. Rice, "Thermodynamic Model for R-12 Alternatives in Domestic Refrigerator/Freezers: Initial Analysis," pp. 95-104 in Proceedings of "Cold Chain Refrigeration Equipment by Design," Palmerston North, New Zealand, 1994.

Barnes, P. R., W. P. Dykas, and B. J. Kirby, The Integration of Renewable Energy Sources into Electric Power Transmission Systems, ORNL-6827, Oak Ridge National Laboratory, Oak Ridge, Tenn., July 1995.

Barnes, P. R., D. T. Rizy, and F. M. Tesche, "MHD-EMP and Electric Power Systems," Journal of Radiation Effects, Research, and Engineering 12(1A), 79-85 (January 1994).

Barnes, P. R., and E. F. Vance, "MHD-EMP Protection Guidelines," Journal of Radiation Effects, Research, and Engineering 12(1), 30-33 (January 1994).

Barnes, P. R., J. W. Van Dyke, and F. M. Tesche, The Integration of Renewable Energy Sources into Electric Power Distribution Systems, vol. 1, ORNL-6775/V1, Oak Ridge National Laboratory, Oak Ridge, Tenn., June 1994. (For vol. 2, see Zaininger, Ellis, and Schaefer.)

Baxter, L. W., Application of DSM Evaluation Studies to Utility Forecasting and Planning, ORNL/CON-409, Oak Ridge National Laboratory, Oak Ridge, Tenn., February 1995.

Baxter, L. W., “Applying DSM Evaluation Results to Utility Planning," pp. 701-7 in Energy Program Evaluation: Uses, Methods, and Results, Proceedings of the National Energy Program Evaluation Conference, Chicago, Ill., 1995.

Baxter, L. W., Assessment of Net Lost Revenue Adjustment Mechanisms for Utility DSM Programs, ORNL/CON-408, Oak Ridge National Laboratory, Oak Ridge, Tenn., January 1995.

Baxter, L. W., "Net Lost Revenue from DSM: State Policies That Work," pp. 130-37 in Proceedings of the Seventh National DSM Conference, Dallas, Texas, 1995.

Baxter, L. W., and E. A. Hirst, Estimating Potential Stranded Commitments for U.S. Investor-Owned Electric Utilities, ORNL/CON-406, Oak Ridge National Laboratory, Oak Ridge, Tenn., January 1995.

Baxter, L. W., and D. K. Schultz, "Recent Program Evaluations: Implications for Long-Run Planning," pp. 22-33 in Resource Planning Methodologies, vol. 7 of Proceedings of the ACEEE 1994 Summer Study on Energy Efficiency in Buildings, Washington, D.C., 1994.

Baxter, V. D., P. Fairchild, and C. K. Rice, The DOE-ORNL Heat Pump Design Model: Efficiency by Design, M95-76726, ORNL/DOE information brochure, Oak Ridge National Laboratory, Oak Ridge, Tenn., 1994.

Bernard, D. P., D. B. Hunsaker, and D. R. Marmorek, "Tools for Improving Predictive Capabilities of Environmental Impact Assessments: Structured Hypotheses, Audits, and Monitoring," pp. 547-64 in Environmental Analysis: The NEPA Experience, Lewis Publishers, Boca Raton, Fla., 1993.

Bernow, S., et al., Modeling Renewable Electric Resources: A Case Study of Wind, ORNL/Sub/93-03370, prepared by Tellus Institute, Boston, October 1994.

Berry, L. G., Progress in the Standardization of DSM Terminology, Reporting Formats, and Evaluation Protocols, ORNL/TM-12855, Oak Ridge National Laboratory, Oak Ridge, Tenn., October 1994. 
Berry, L. G., and M. A. Brown, "Energy-Efficiency Improvements and Remaining Opportunities in the DOE Low-Income Weatherization Program," pp. 19-28 in Proceedings of the 1994 ACEEE Summer Study on Energy Efficiency in Buildings, vol. 6, Pacific Grove, Calif., 1994.

Berry, L. G., and M. A. Brown, Patterns of Impact in the Weatherization Assistance Program: A Closer Look, ORNL/CON-331, Oak Ridge National Laboratory, Oak Ridge, Tenn., June 1994.

Blasing, T. J., R. J. Miller, and L. N. McCold, Potential Effects of Clean Coal Technologies on Acid Precipitation, Greenhouse Gases, and Solid Waste, ORNL/TM-12633, Oak Ridge National Laboratory, Oak Ridge, Tenn., November 1993.

Boston, C. R., G. D. Kerr, and R. L. Kroodsma, Environmental Assessment-Operation of Army Pulse Radiation Facility at U.S. Army Combat Systems Test Activity, Aberdeen Proving Ground, Maryland, ORNL/M-3338, Oak Ridge National Laboratory, Oak Ridge, Tenn., March 1994.

Brinch, J., and J. O. Kolb, Evaluation of Training Workshops on Performance Contracting for Public Housing Agencies in HUD Regions I, IX, and X, ORNL/CF-94/18, Oak Ridge National Laboratory, Oak Ridge, Tenn., February 1994.

Broders, M. A., J. A. Shaver, and M. K. Voss, Energy Efficiency and Conservation Measures and Practices Applied to the Food and Beverage Industry in the Asia Pacific Region, ORNL/TM-12709; APEC 94-RE-01.1, prepared for the Asia-Pacific Economic Cooperation (APEC) by Oak Ridge National Laboratory, Oak Ridge, Tenn., December 1994.

Bronzini, M. S., "Panama Canal Capacity Analysis," pp. 25-40 in The New Panama Canal-Another Path Between the Seas, Proceedings ASCE and ICE, American Society of Civil Engineers, New York, 1995.

Brown, M. A., L. G. Berry, and J. O. Kolb, Keys to Success: Ten Case Studies of Effective Weatherization Programs, ORNL/CON-328, Oak Ridge National Laboratory, Oak Ridge, Tenn., November 1993.

Brown, M. A., L. G. Berry, and L. B. Kinney, Weatherization Works: An Interim Report of the National Weatherization Evaluation, ORNL/CON-373, Oak Ridge National Laboratory, Oak Ridge, Tenn., November 1993.

Brown, M. A., P. Brandis, and B. Cody, "Promoting Energy-Efficient Home Construction: The Impacts of Alternative Policy Instruments," pp. 27-40 in Energizing the Energy Policy Process: The Impact of Evaluation, ed. J. Heilman and R. Walsh, Quorum Books, Westport, Conn., 1994.

Brown, M. A., and L. J. Hill, Low-Income DSM Programs: Methodological Approach to Determining the Cost-Effectiveness of Coordinated Partnerships, ORNL/CON-375, Oak Ridge National Laboratory, Oak Ridge, Tenn., May 1994.

Brown, M. A., and J. Johnson, "Program Design," pp. xi-xiv in Proceedings of the ACEEE 1994 Summer Study on Energy Efficiency in Buildings, vol. 10, Pacific Grove, Calif., 1994.

Brown, M. A., and P. Mihlmester, Summary of California DSM Impact Evaluation Studies, ORNLCON-403, Oak Ridge National Laboratory, Oak Ridge, Tenn., October 1994.

Brown, M. A., and C. R. Wilson, "R\&D Spinoffs: Serendipity vs. a Managed Process," Journal of Technology Transfer 18(3-4), 5-15 (Summer-Fall 1993).

Brown, M. A., C. R. Wilson, and C. A. Franchuk, The Economic, Energy, and Environmental Impacts of the Energy-Related Inventions Program, ORNL/CON-381, Oak Ridge National Laboratory, Oak Ridge, Tenn., July 1994.

Buescher, B. A., EMFRapid Implementation Plan for Communication, ORNL/M-4282, Oak Ridge National Laboratory, Oak Ridge, Tenn., May 1995.

Buescher, B. A., Questions \& Answers About Electric and Magnetic Fields Associated with the Use of Electric Power (brochure), ORNL/M-4280, Oak Ridge National Laboratory, Oak Ridge, Tenn., May 1995.

Buescher, B. A., et al., Research Agenda and Communication Plan-EMFRapid Program, ORNL/M-4283, Oak Ridge National Laboratory, Oak Ridge, Tenn., May 1995.

Carnes, S. A., "Negotiating Equity for Management of DOE Wastes," pp. 1-8 in Proceedings of the Fifth Annual International Conference on High-Level Radioactive Waste Management, Las Vegas, Nevada, May 22-26, 1994, vol. 1, American Nuclear Society and American Society of Civil Engineers, 1994.

Carnes, S. A., "Social Impact Assessment and Public Involvement Introduction and Summary," pp. 223-27 in Environmental Analysis: The NEPA Experience, Lewis Publishers, Boca Raton, Fla., 1993.

Carnes, S. A., and A. K. Wolfe, "Toward Integrated Design of Waste Management Technologies," pp. 267-74 in Proceedings of the Fifth Annual International Conference on High-Level Radioactive Waste Management, Las Vegas, Nevada, May 22-26, 1994, vol. 1, American Nuclear Society and American Society of Civil Engineers, 1994. 
Appendix: Summary Data, Awards, and Publications

Chen, F. C., S. L. Allman, and C. H. Chen, "New Concepts for Refrigerant Leak Detection and Mixture Measurement," pp. 211-17 in Proceedings of the International CFC (Chlorofluorocarbon) and Halon Alternatives Conference, October 20-23, 1993, Washington, D.C., 1993.

Chen, D. T., R. W. Murphy, and V. C. Mei, Performance Analysis of Reciprocating Regenerative Magnetic Heat Pumping, ORNL/TM-12630, Oak Ridge National Laboratory, Oak Ridge, Tenn., February 1994.

Chester, C. V., "Eugene Wigner's Contribution to Civil Defense: An Annotated Selection of His Papers," in Collected Works of Eugene P. Wigner, vol. 6, Springer-Verlag, New York, 1992.

Chin, S. M., et al., "How Well Does It Work?," pp. 71-100 in Bureau of Transportation Statistics Annual Report to Congress, U.S. Department of Transportation, Bureau of Transportation Statistics, Washington, D.C., January 1994.

Christian, J. E., "Introduction: Welcome," pp. ix-xi in Proceedings of the Low-Slope Reroofing Workshop: A Review of the Alternatives, CONF-9405206, compiled by A. O. Desjarlais, Oak Ridge National Laboratory, Oak Ridge, Tenn., September 1994.

Christian, J. E., "Moisture Sources," pp. 176-84 in Manual on Moisture Control in Buildings, ed. H. R. Trechsel, ASTM Manual Series MNL 18, American Society for Testing and Materials, February 1994.

Christian, J. E., et al., Building Thermal Envelope Systems and Materials (BTESM) Update 3(9-11), 4(1-11), 5(1-6), October 1993-June 1995.

Copenhaver, E. D., Response Phase Decontamination for CSEPP: Training Guide, ORNL/M-3081, Oak Ridge National Laboratory, Oak Ridge, Tenn., March 1994.

Copenhaver, E. D., Use of Auto-Injectors by Civilian Emergency Medical Personnel to Treat Civilians Exposed to Nerve Agent: Instructor's Guide, ORNL/M-3320, Oak Ridge National Laboratory, Oak Ridge, Tenn., May 1994.

Copenhaver, E. D., Use of Auto-Injectors by Civilian Emergency Medical Personnel to Treat Civilians Exposed to Nerve Agent: Study Guide, ORNL/M-3319, Oak Ridge National Laboratory, Oak Ridge, Tenn., May 1994.

Courville, G. E., A Guidebook for Insulated Low-Slope Roof Systems, IEA Annex 19, Oak Ridge National Laboratory, Oak Ridge, Tenn., February 1994.

Curlee, T. R., "Polymer Recycling," pp. 307-14 in Encyclopedia of Advanced Materials, Pergamon Press, Oxford, 1993.

Curlee, T. R., "The Socioeconomics of Waste-to-Energy in the United States," pp. 11.173-78 in Handbook of Integrated Solid Waste Management, ed. F. Krieth, McGraw-Hill, New York, 1994.

Curlee, T. R., et al., Recent Trends in Automobile Recycling: An Energy and Economic Assessment, ORNL/TM-12628, Oak Ridge National Laboratory, Oak Ridge, Tenn., March 1994.

Curlee, T. R., et al., Waste-to-Energy in the United States: A Social and Economic Assessment, Quorum Books, New York, 1994.

Curlee, T. R., et al., Waste-to-Energy in the United States: Socioeconomic Factors and the Decision-Making Process, NREL/TP-430-5694, National Renewable Energy Laboratory, Golden, Colo., October 1993.

Cushman, R. M., et al., "Global Climate Change and NEPA Analysis," pp. 442-62 in Environmental Analysis: The NEPA Experience, Lewis Publishers, Boca Raton, Fla., 1993.

Das, S., "Democratization and World Petroleum Trade in the Year 2000," Energy-The International Journal 19(7), 783-93 (July 1994).

Das, S., and T. R. Curlee, An Assessment of the Cost of Microwave Sintering Ceramic Tiles for Armor Applications: Phase 2 Report, ORNL/TM-12896, Oak Ridge National Laboratory, Oak Ridge, Tenn., March 1995.

Davis, S. C., Transportation Energy Data Book: Edition 14, ORNL-6798, Oak Ridge National Laboratory, Oak Ridge, Tenn., June 1994.

Davis, S. C., and S. G. Strang, Transportation Energy Data Book: Edition 15, ORNL-6856, Oak Ridge National Laboratory, Oak Ridge, Tenn., May 1995.

Delucchi, M. A., D. L. Greene, and M. Q. Wang, "Motor-Vehicle Fuel Economy: The Forgotten Hydrocarbon Control Strategy?" Transportation Research A 28A(3), 223-44 (1994).

Desjarlais, A. O., comp., Proceedings of the Low-Slope Reroofing Workshop: A Review of the Alternatives, CONF-9405206, Oak Ridge National Laboratory, Oak Ridge, Tenn., September 1994.

Desjarlais, A. O., J. E. Christian, and R. S. Graves, "In Situ Aging of Roof Systems Containing Polyisocyanurate Roof Insulation Foamed with Alternative Blowing Agents," in Third International Workshop on Long-Term Thermal Performance of Cellular Plastics, Proceedings of the Society of Plastics Industry of Canada, Toronto, 1993. 
Desjarlais, A. O., and J. Kosny, "Influence of Wall System Details on the Thermal Performance of Residential Building Envelopes," Journal of Thermal Insulation and Building Envelopes 18, 53-69 (July 1994).

Desjarlais, A. O., et al., "Laboratory Measurements of the Drying Rates of Low-Slope Roofing Systems," pp. 77-88 in Proceedings of the Low-Slope Reroofing Workshop: A Review of the Alternatives, CONF-9405206, Oak Ridge National Laboratory, Oak Ridge, Tenn., September 1994.

Desjarlais, A. O., et al., "A Whole Building Demonstration of Re-Cover over an Existing Wet Roof," pp. 111-19 in Proceedings of the 11th Conference on Roofing Technology, Science, and Technology: The Basis for Improved Roofing, Gaithersburg, Md., September 1995.

Dominguez, N., and V. E. Lynch, Absence of Second Stability in ATF, ORNL/TM-13040, Oak Ridge National Laboratory, Oak Ridge, Tenn., July 1995.

Downing, M. E., S. McLaughlin, and M. E. Walsh, "Energy, Economic, and Environmental Implications of Production of Grasses as Biomass Feedstocks," pp. 288-97 in Proceedings of the Second Biomass Conference of the Americas: Energy, Environment, Agriculture, and Industry, NREL/CP-200-8098, Portland, Ore., August 21-24, 1995.

English, M. R., M. Schweitzer, and S. M. Schexnayder, "Energy Efficiency Advocacy Groups: Factors Affecting Their Influence on DSM and IRP," Utilities Policy 5(1), 55-63 (January 1995).

English, M. R., M. Schweitzer, and J. A. Altman, "Interactive Efforts Between Utilities and Non-Utility Parties: Constraints and Possibilities," Energy-The International Journal 19(10), 1051-60 (1994).

English, M. R., M. Schweitzer, and S. M. Schexnayder, Making a Difference: Ten Case Studies of DSM/IRP Interactive Efforts and Related Advocacy Group Activities, ORNL/CON-378, Oak Ridge National Laboratory, Oak Ridge, Tenn., March 1994.

Ensminger, J. T., Initial Environmental Evaluation, Environmental Assessment: Construction of a Mobile Runway Facility to Support Air Operations at Williams Field and the Sea Ice Runway, McMurdo Station, National Science Foundation, Washington, D.C., February 1994.

Ensminger, J. T., and T. J. Blasing, Environmental Report: The Use of Explosives by the U.S. Antarctic Program, ORNL/TM-13031, Oak Ridge National Laboratory, Oak Ridge, Tenn., July 1995.

Ensminger, J. T., et al., Environmental Assessment: The Construction and Operation of Fish Passage Facilities at Three Hydroelectric Projects on the Susquehanna River, ORNL/M-3284; Federal Energy Regulatory Commission Project Nos. 1881-02, 1025-010, and 1888-01, February 1994.

Fairchild, P. D., and S. K. Fischer, "Using TEWI to Evaluate Climate Change and Energy Efficiency Impacts of CFC/HCFC Alternatives," pp. 237-56 in Proceedings of the International on Conference Climate Change, Building and Energy Efficiency, Washington, D.C., July 28, 1994.

Feldman, D. L., "Adapting to Climate Change: Costs, Benefits, and Risks in Preparing for an Uncertain Future," pp. 2-18 in Global Climate Change and Public Policy, Nelson-Hall, Chicago, 1994.

Feldman, D. L., ed., Global Climate Change and Public Policy, Nelson-Hall, Chicago, 1994.

Feldman, D. L., "Using Planning Scenarios for DOE Radwaste Management: The Case of the Advanced Neutron Source," pp. 1696-1703 in Proceedings of the Fifth Annual Conference on High-Level Radioactive Waste Management, Las Vegas, Nevada, May 22-26, vol. 3, American Nuclear Society, 1994.

Feldman, D. L., J. H. Peretz, and B. D. Jendrucko, "Policy Gridlock in Waste Management: Balancing Federal and State Concerns," p. 10 in Proceedings of the ASPA/CASU 54th National Training Conference, San Francisco, July 17-21, 1993, 1993.

Ferguson, R., "Utilizing ORACLE Tools Within UNIX," paper 22 in Proceedings of the International ORACLE User Group, vol. 1, San Francisco, September 25-30, 1994.

Ferguson, T. D., ed., Energy Division Quarterly Highlights Newsletter 2(2), August 1995.

Ferguson, T. D., ed., The Energy Insider (newsletter) 1(1-2) and 2(1), January and May 1994, April 1995.

Fischer, S. K., "Total Equivalent Warming Impact: A Measure of the Global Warming Impact of CFC Alternatives in Refrigerating Equipment," International Journal of Refrigeration 16, 423-28 (November 1993).

Fischer, S. K., and J. R. Sand, "Screening Analysis for Chlorine-Free Alternative Refrigerants to Replace R-22 in Air Conditioning Applications," ASHRAE Transactions 99(2), 627-36 (1993).

Fischer, S. K., P. J. Hughes, and J. J. Tomlinson, Energy and Global Warming Impacts of Not-in-Kind and Next-Generation CFC and HCFC Alternatives, ORNL/M-3949, Oak Ridge National Laboratory, Oak Ridge, Tenn., December 1994. 
Flanigan, T., and S. W. Hadley, Analysis of Successful Demand-Side Management at Publicly Owned Utilities, ORNL/CON-397, Oak Ridge National Laboratory, Oak Ridge, Tenn., August 1994.

Foust, C. B., C. J. Coomer, and E. D. Copenhaver, Personal Protective Equipment: Instructor's Guide, ORNL/M-3639, Oak Ridge National Laboratory, Oak Ridge, Tenn., August 1994.

Foust, C. B., C. J. Coomer, and E. D. Copenhaver, Personal Protective Equipment: Study Guide, ORNL/M-3638, Oak Ridge National Laboratory, Oak Ridge, Tenn., August 1994.

Glenn, F. M., et al., Bibliography of Documents and Related Materials Collected for the Hawaii Geothermal Project Environmental Impact Statement, ORNL/TM-12862, Oak Ridge National Laboratory, Oak Ridge, Tenn., March 1995.

Greene, D. L., Alternative Fuels and Vehicles Choice Model, ORNL/TM-12738, Oak Ridge National Laboratory, Oak Ridge, Tenn., October 1994.

Greene, D. L., ed., CTA Intersections (newsletter) 2(3-4) and 3(5), February 1994-March 1995.

Greene, D. L., S. M. Chin, and R. Gibson, Aggregate Vehicle Travel Forecasting Model, ORNL-6872, Oak Ridge National Laboratory, Oak Ridge, Tenn., May 1995.

Greene, D. L., and Y. Fan, Transportation Energy Efficiency Trends, 1972-1992, ORNL-6828, Oak Ridge National Laboratory, Oak Ridge, Tenn., December 1994.

Greene, D. L., D. W. Jones, and P. N. Leiby, The Outlook for U.S. Oil Dependence, ORNL-6873, Oak Ridge National Laboratory, Oak Ridge, Tenn., May 1995.

Griffin, G. D., et al., Guidance on Health Effects of Toxic Chemicals, ES/CSET-20, Martin Marietta Energy Systems, Oak Ridge, Tenn., February 1994.

Grossman, G., R. C. DeVault, and F. A. Creswick, "Simulation and Performance Analysis of an Ammonia-Water Absorption Heat Pump Based on the Generator-Absorber Heat Exchange (GAX) Cycle," ASHRAE Transactions 101(1), 1313-23 (February 1995).

Grossman, G., M. Wilk, and R. C. DeVault, "Simulation and Performance Analysis of Triple-Effect Absorption Cycles," ASHRAE Transactions 100(1), 452-62 (January 1995).

Grossman, G., A. Zaltash, and P. W. Adcock, "Simulating a 4-Effect Absorption Chiller," ASHRAE Journal, 45-53 (June 1995).

Grossman, G., A. Zaltash, and R. C. DeVault, "Simulation and Performance Analysis of a 4-Effect Lithium Bromide-Water Absorption Chiller," ASHRAE Transactions 101(1), 1302-12 (February 1995).

Hadder, G. R., Reformulated Gasoline: Costs and Refinery Impacts, ORNL-6747, Oak Ridge National Laboratory, Oak Ridge, Tenn., December 1993.

Hadder, G. R., and S. M. Chin, Rocky Mountain Area Petroleum Product Availability with Reduced PADD IV Refining Capacity, ORNL-6751, Oak Ridge National Laboratory, Oak Ridge, Tenn., February 1994.

Hadley, S. W., "Successful Demand-Side Management," Public Power 53(3), 29-30 (May-June 1995).

Hadley, S. W., L. J. Hill, and R. D. Perlack, Report on the Study of the Tax and Rate Treatment of Renewable Energy Projects, ORNL-6772, Oak Ridge National Laboratory, Oak Ridge, Tenn., December 1993.

Hadley, S. W., and E. L. Hillsman, Electric Retail Market Options: The Customer Perspective, ORNL/CON-418, Oak Ridge National Laboratory, Oak Ridge, Tenn., July 1995.

Hadley, S. W. and E. A. Hirst, "How Integrated Resource Planning for U.S. Electric Utilities Affects Shareholder Interests," Utilities Policy 5(1), 37-45 (August 1995).

Hadley, S. W., and E. A. Hirst, "Regulatory and Tax Treatment of Electric Resources," pp. 85-94 in Resource Planning Methodologies, vol. 7 of Proceedings of the 1994 ACEEE Summer Study on Energy Efficiency in Buildings, Pacific Grove, Calif., August 28-September 3, 1994.

Hadley, S. W., and E. A. Hirst, "The Status of U.S. Electric Utility Demand-Side Management," pp. vii-xxvii in U.S. Electricity Demand-Side Management, 1993, Energy Information Adminstration, U.S. Department of Energy, Washington, D.C., 1995.

Hadley, S. W., and E. A. Hirst, Utility DSM Programs from 1989 Through 1998: Continuation or Cross Roads? ORNL/CON-405, Oak Ridge National Laboratory, Oak Ridge, Tenn., February 1995.

Hake, K. A., "An Overview of High-Speed Networking for Workstations," pp. 934-39 in Proceedings of the Ninth Annual Symposium on Geographic Information Systems '95, Vancouver, British Columbia, March 27-30, 1995, GIS World, Ft. Collins, Colo., 1995. 
Harrison, I. G., T. Thomas, and B. Lester, "DOE's Transportation Management Division's Automation Program," Transactions of the American Nuclear Society 70, 61 (June 1994).

Hill, L. J., "The Challenge of Implementing an IRP Process in Asia: The Case of Hainan Province, China," in Proceedings of the Third International Energy Efficiency and DSM Conference, Vancouver, B.C., November 1994.

Hill, L. J., "Electric Power, Economic Development, and the Environment in Hainan, China," Asian Journal of Environmental Management 1(2), 67-76 (November 1993).

Hill, L. J., Factors Affecting Expanded Electricity Trade in North America, ORNL/TM-12321, Oak Ridge National Laboratory, Oak Ridge, Tenn., January 1994.

Hill, L. J., Financial Comparison of Time-of-Use Pricing with Technical DSM Programs and Generating Plants as Electric-Utility Resource Options, ORNL/CON-352, Oak Ridge National Laboratory, Oak Ridge, Tenn., April 1994.

Hill, L. J., and M. A. Brown, "Estimating the Cost-Effectiveness of Coordinated DSM Programs," Evaluation Review 19(2), 181-96 (April 1995).

Hill, L. J., and M. A. Brown, "Issues in Assessing the Cost-Effectiveness of Coordinated DSM Programs," Utilities Policy 5(1), 47-53 (January 1995).

Hill, L. J., and M. A. Brown, Standard Practice: Estimating the Cost-Effectiveness of Coordinated DSM Programs, ORNL/CON-390, Oak Ridge National Laboratory, Oak Ridge, Tenn., December 1994.

Hill, L. J., R. A. Chronowski, and A. M. Shapiro, An Integrated Assessment of Electric Power Resource Options in the U.S. Virgin Islands, ORNL/TM-12186, Oak Ridge National Laboratory, Oak Ridge, Tenn., February 1994.

Hillsman, E. L., and D. R. Alvic, Interactions Between Energy Efficiency and Emission Trading Under the 1990 Clean Air Act Amendments, ORNL/CON-400, Oak Ridge National Laboratory, Oak Ridge, Tenn., August 1994.

Hillsman, E. L., D. R. Alvic, and J. B. Bennett, "The Bureau of Mines Electric Utility Model," Operations Research 42(6), 998-1009 (1994).

Hirst, E. A., "A Bright Future for Electric-Utility DSM Programs," Environment 36(9), 10-15, 31-36 (November 1994).

Hirst, E. A., Costs and Effects of Electric-Utility DSM Programs: 1989 Through 1997, ORNL/CON-392, Oak Ridge National Laboratory, Oak Ridge, Tenn., June 1994.

Hirst, E. A., "Data and Projections on U.S. Electric-Utility DSM Programs: 1989-1997," pp. 665-71 in Competitive Energy Management and Environmental Technologies, Proceedings of the 17th World Engineering Congress, Association of Energy Engineers, Atlanta, Ga., 1994.

Hirst, E. A., "DSM Today Through 2000," Electric Perspectives 17(6), 65-67 (November/December 1993).

Hirst, E. A., "Effects of Utility Demand-Side Management Programs on Uncertainty," Resource and Energy Economics 16(1), 25-45 (March 1994).

Hirst, E. A., "Electric Utility and Energy Efficiency: Friends or Enemies?" ORNL Review (May 1994).

Hirst, E. A., Electric-Utility DSM Programs in a Competitive Market, ORNL/CON-384, Oak Ridge National Laboratory, Oak Ridge, Tenn., April 1994.

Hirst, E. A., "Energy Efficiency, Challenges and Opportunities for Electric Utilities-Book Review," Forum for Applied Research and Public Policy 10(1), 144-45 (Spring 1995).

Hirst, E. A., "How Competition Might Affect Electric-Utility DSM Programs," Energy-The International Journal 19(12), 1193-1203 (December 1994).

Hirst, E. A., "An Introduction to Integrated Resource Planning," Public Power 51(6), 40-47 (November-December 1993).

Hirst, E. A., "IRP and the Utility of the Future," Edison Times IRP Quarterly 9, 26-30 (April 1994).

Hirst, E. A., "Reforming Electric-Utility Regulation: The Engineer as Anthropologist," Practicing Anthropology 16(2), 27-30 (Spring 1994).

Hirst, E. A., "Regulatory Disincentives for Utility Demand-Side Management Programs," Public Utility Fortnightly 132(13), 45-48 (July 1994).

Hirst, E. A., "Retail Competition May Put DSM Out of Business," Public Utility Fortnightly 132(17), 14-16 (September 1994).

Hirst, E. A., "The Role of Environmental Groups in Electric-Utility Regulation: A Case Study," Electricity Journal 7(2), 66-76 (March 1994).

Hirst, E. A., "Statistical Recoupling: Breaking the Link Between Electric-Utility Sales and Revenues," Energy Sources 16(4), 549-69 (December 1994).

Hirst, E. A., "What Constitutes a Good Integrated Resource Plan?”' Utilities Policy 4(2), 141-53 (April 1994). 
Hirst, E. A., and L. W. Baxter, "How Stranded Will Electric Utilities Be?" Public Utilities Fortnightly 133(4), 30-32 (February 15, 1995).

Hirst, E. A., and E. Blank, "Solutions to Regulatory Disincentives for Utility DSM Programs," Utilities Policy 4(2), 105-12 (April 1994).

Hirst, E. A., E. Blank, and D. Moskovitz, "Alternative Ways to Decouple Electric-Utility Revenues from Sales," Electricity Journal 7(6), 38-47 (July/August 1994).

Hirst, E. A., E. Blank, and D. Moskovitz, "Three Ways to Decouple Electric-Utility Revenues from Sales," pp. 383-94 in Proceedings of NARUC-DOE Fifth National Integrated Resource Planning Conference on Integrated Resource Planning, Kalispel, Mont., May 1994.

Hirst, E. A., and J. Eto, Justification for Electric-Utility Energy-Efficiency Programs, ORNL/CON-419, Oak Ridge National Laboratory, Oak Ridge, Tenn., August 1995.

Hirst, E. A., and S. W. Hadley, "The DSM Sky Hasn't Fallen Yet," Electricity Journal 7(10), 77-79 (December 1994).

Hirst, E. A., and S. W. Hadley, Effects of Resource Acquisitions on Electric-Utility Shareholders, ORNL/CON-387, Oak Ridge National Laboratory, Oak Ridge, Tenn., May 1994.

Hirst, E. A., and S. W. Hadley, "Must DSM Programs Increase Rates?" Public Utilities Fortnightly 133(12), $26-29$ (June 5, 1995).

Hirst, E. A., and S. W. Hadley, Price Impacts of Electric-Utility DSM Programs, ORNL/CON-402, Oak Ridge National Laboratory, Oak Ridge, Tenn., November 1994.

Hirst, E. A., and S. Swanson, "David and the Goliaths: How a Small Environmental Group Helps Reform Electric-Utility Regulation," pp. 107-114 in Program Design, vol. 10 of Proceedings of the 1994 ACEEE Summer Study on Energy Efficiency in Buildings, Pacific Grove, Calif., 1994.

Hirst, E. A., B. Tonn, and D. Bauer, "The Future of IRP and Other 'Public Goods' in a Market-Driven World," Electricity Journal 8(3), 74-84 (April 1995).

Hobbs, B. F., and P. Meier, Integrated Resource Planning and the Environment: A Guide to the Use of Multi-Criteria Decision Methods, ORNL/Sub/94-03371, Oak Ridge National Laboratory, Oak Ridge, Tenn., July 1994.

Hu, P. S., S. C. Davis, and D. L. Greene, Chapters 6 and 7, pp. 133-76 of Bureau of Transportation Statistics Annual Report to Congress, U.S. Department of Transportation, Bureau of Transportation Statistics, Washington, D.C., January 1994.

Hu, P. S., S. C. Davis, and M. Q. Wang, "Preliminary Assessment of Fleets Covered by the Energy Policy Act," pp. 375-83 in Proceedings of the Annual Automotive Technology Development Contractors' Coordination Meeting, Dearborn, Michigan, Oct. 24-27, 1994, Society of Automotive Engineers, 1994.

Hu, P. S., D. Trumble, and A. Lu, Fuel Used for Off-Highway Recreation, ORNL-6794, Oak Ridge National Laboratory, Oak Ridge, Tenn., July 1994.

Hu, P. S., and J. Young, 1990 Nationwide Personal Transportation Survey Data Book: Volume 1, FHWA-PL-94-010B, Federal Highway Administration, Washington, D.C., November 1993.

Hughes, P. J., "Environmental Benefits of Different Types of Heat Pumps, Available and Expected," pp. 3-32 in Proceedings of Second International Conference on Heat Pumps in Cold Climates, Moncton, New Brunswick, Canada, August 16-17, 1993, Caneta Research, Inc., January 1994.

Hughes, P. J., "Gas Heat Pumps Are Coming-But by a Different Name," pp. 97-102 in Proceedings of the 1994 ACEEE Summer Study on Energy Efficiency in Buildings, vol. 3, Pacific Grove, Calif., 1994.

Hughes, P. J., "Residential Gas Heat Pump Assessment: A Market-Based Approach," ASHRAE Transactions 101(2) 1995.

Hughes, P. J., R. L. D. Cane, and S. B. Clemes, "Heat Exchanger Sizing for Vertical Closed-Loop Ground-Source Heat Pumps," pp. 63-68 in Solar Engineering 1995, vol. 1 of Proceedings of the 1995 ASMEJJSMEJJSES International Solar Energy Conference, Maui, Hawaii, March 19-24, 1995, American Society of Mechanical Engineers, New York, 1995.

Hughes, P. J., and S. Laitner, Evaluating the Income and Employment Impacts of Gas Cooling Technologies, ORNL/CON-412, Oak Ridge National Laboratory, Oak Ridge, Tenn., March 1995.

Hunsaker, D. B., "NEPA Follow-up Introduction and Summary," pp. 511-15 in Environmental Analysis: The NEPA Experience, Lewis Publishers, Boca Raton, Fla., 1993.

Janson, B. N., "Most Likely Link Uses from Equilibrium Assignment," Transportation Research 27B, 333-50 (October 1993). 
Jensen, M. K., and B. Shome, Literature Survey of Heat Transfer Enhancement Techniques in Refrigeration Applications, ORNL/Sub/91-85-SK794, Oak Ridge National Laboratory, Oak Ridge, Tenn., May 1994.

Johnson, R. O., "Local Drainage Analyses of the Paducah and Portsmouth Gaseous Diffusion Plants During an Extreme Storm," pp. 431-40 in Proceedings of the Fourth DOE Natural Phenomena Hazards Mitigation Conference, Atlanta, October 19-22, 1993, vol. 1, CONF-9310102, Lawrence Livermore National Laboratory, Livermore, Calif., 1993.

Johnson, R. O., "Nonlinear Adsorption of Uranyl: Analytical Modeling of Liner Migration," Ground Water 32(2), 293-304 (March-April 1994).

Jones, D. W., "Phoenician Unguent Factories in Dark Age Greece: Social Approaches to Evaluating the Archaeological Evidence," Oxford Journal of Archaeology 12(3), 293-303 (November 1993).

Jones, D. W., and R. V. O'Neill, "Development Policies, Urban Unemployment and Deforestation: The Role of Infrastructure and Tax Policy in a Two-Sector Model," Journal of Regional Science 35(1), 135-53 (February 1995).

Jones, D. W., and R. V. O'Neill, "Land Use in the Presence of an Atmosphere Externality, With and Without Corrective Taxes," Journal of Regional Science 33(4), 457-80 (November 1993).

Jones, D. W., and R. V. O'Neill, "A Model of Neotropical Land Use with Endogenous Malaria and Preventive Ecological Measures," Environment and Planning 25A(11), 1677-87 (November 1993).

Jones, D. W., et al., "Farming in Rondonia," Resource and Energy Economics 17(2), 155-88 (August 1995).

Kahn, J. R., and R. B. Buerger, "Valuation and the Consequences of Multiple Sources of Environmental Deterioration: The Case of the New York Striped Bass Fishery," Journal of Environmental Management 40, 257-74 (March 1994).

Kirby, B. J., E. A. Hirst, and J. VanCoevering, Identification and Definition of Unbundled Electric Generation and Transmission Services, ORNL/CON-415, Oak Ridge National Laboratory, Oak Ridge, Tenn., March 1995.

Kosny, J., "Wooden Concrete: High Thermal Efficiency Using Waste Wood," pp. 3.109-16 in Proceedings of the 1994 ACEEE Summer Study on Energy Efficiency in Buildings, Pacific Grove, Calif., 1994.

Kosny, J., and J. E. Christian, "Modified Zone Factors: Method of Clear Wall R-Value Calculations for Steel-Framed Walls" in Thermal Performance of Steel-Framed Walls, National Association of Home Builders, Project No. 1006(2178), November 21, 1994.

Kosny, J., and J. E. Christian, "The Optimum Use of Insulated Masonry Blocks for Building Foundations," Journal of Building Research 2(2), 9-19 (November 1993).

Kosny, J., and J. E. Christian, "Thermal Evaluation of Several Configurations of Insulation and Structural Materials for Some Metal Stud Walls," Energy and Buildings (Switzerland) 22(2), 157-63 (1995).

Kossecka, E., J. Kosny, and J. E. Christian, "A Simple Algorithm for Determining the Thermal Resistance of the Wall Based on Measurements of Surface Heat Flux and Temperature," Journal of Building Research 3(1), 57-66 (1994).

Kyle, D. M., and A. O. Desjarlais, Assessment of Technologies for Constructing Self-Drying Low-Slope Roofs, ORNL/CON-380, Oak Ridge National Laboratory, Oak Ridge, Tenn., May 1994.

Lee, D. W., "Performance Assessment Experience at Oak Ridge National Laboratory," in Proceedings of the 16th Annual U.S. Department of Energy Low-Level Radioactive Waste Management Conference, December 13-15, 1994.

Lee, D. W., "Uncertainty Analysis for Low-Level Radioactive Waste Disposal Performance Assessment at Oak Ridge National Laboratory," in Proceedings of the International Topical Meeting on Nuclear and Hazardous Waste Management, Spectrum '94, August 14-18, 1994.

Lee, D. W., J. C. Wang, and D. C. Kocher, Operating Limit for the Proposed Solid Waste Landfill at Paducah Gaseous Diffusion Plant, ORNL/TM-13008, Oak Ridge National Laboratory, Oak Ridge, Tenn., June 1995.

Lee, D. W., et al., Performance Assessment for Continuing and Future Operations at SWSA 6, ORNL-6783, Oak Ridge National Laboratory, Oak Ridge, Tenn., February 1994.

Lee, R. M., "The Damage Function Approach for Estimating Fuel Cycle Externalities," pp. 35-45 in Proceedings, International Association for Energy Economics 15th Annual North American Conference, IAEE, Washington, D.C., 1993.

Lee, R. M., "Estimating the Impacts, Damages, and Benefits of Fuel Cycles: Insights from an Ongoing Study," pp. 81-97 in Social Costs of Energy: Present Status and Future Trends, ed. R. Ottinger and O. Honmeyer, Springer-Verlag, Berlin, 1994.

Lee, R. M., R. L. Miller, and C. McIlvaine, "Influence of Meteorology in Assessing Energy Externalities: Application of Damage Function Approach," pp. 1086-96 in Proceedings of the 13th International Congress of Biometeorology, Calgary, Alberta, Environment Canada, Downsview, Canada, 1994. 
Lee, R. M., Oak Ridge National Laboratory, and Resources for the Future, Estimating Fuel Cycle Externalities: Analytical Methods and Issues, Report No. 2, McGraw-Hill/Utility Data Institute, Washington, D.C., 1994.

Lee, R. M., Oak Ridge National Laboratory, and Resources for the Future, Estimating Externalities of Coal Fuel Cycles, Report No. 3, McGraw-Hill/Utility Data Institute, Washington, D.C., 1994.

Lee, R. M., Oak Ridge National Laboratory, and Resources for the Future, Estimating Externalities of Hydro Fuel Cycles, Report No. 6, McGraw-Hill/Utility Data Institute, Washington, D.C., 1994.

Lee, R. M., Oak Ridge National Laboratory, and Resources for the Future, Estimating Externalities of Nuclear Fuel Cycles, Report No. 8, McGraw-Hill/Utility Data Institute, Washington, D.C., 1994.

Leiby, P. N., A Methodology for Assessing the Market Benefits of Alternative Motor Fuels, ORNL-6771, Oak Ridge National Laboratory, Oak Ridge, Tenn., September 1993.

Lerner-Lam, E., and A. K. Rathi, "Digital Maps and Spatial Data Bases for IVHS Needs and Opportunities," pp. 560-64 in Proceedings of IVHS America Third Annual Meeting, Washington, D.C., 1993.

Levine, M. D., E. Hirst, and J. Koomey, Energy Efficiency, Market Failures, and Government Policy, ORNL/CON-383 and LBL-35376, Oak Ridge National Laboratory, Oak Ridge, Tenn., March 1994.

Levins, W. P., and M. P. Ternes, "Are Heating-System Retrofit and Tune-Up Programs Really Increasing the Efficiency of Oil-Fired Systems?" pp. 143-52 in Proceedings of the 1994 ACEEE Summer Study on Energy Efficiency in Buildings, vol. 5, Pacific Grove, Calif., 1994.

Levins, W. P., and M. P. Ternes, Energy Efficiency in Military Family Housing: Inspection Results, ORNL/TM-12692, Oak Ridge National Laboratory, Oak Ridge, Tenn., September 1994.

Levins, W. P., and M. P. Ternes, Energy Efficiency in Military Family Housing: Monitoring to Support Revitalization Guidebook, ORNL/TM-12723, Oak Ridge National Laboratory, Oak Ridge, Tenn., November 1994.

Levins, W. P., and M. P. Ternes, Impacts of the Weatherization Assistance Program in Fuel-Oil-Heated Houses, ORNL/CON-327, Oak Ridge National Laboratory, Oak Ridge, Tenn., October 1994.

Levins, W. P., and M. P. Ternes, "Weatherization Assistance Program Evaluation Results in Fuel-Oil-Heated Houses," Energy Exchange Newsletter 4(1), 16-20 (February 1994).

Lewis, P. J., and D. M. Counce, eds., Proceedings of the 1993 Refrigeration and Air-Conditioning Technology Workshop, Breckenridge, Colo., June 23-25, 1993, ORNL-6797, Oak Ridge National Laboratory, Oak Ridge, Tenn., April 1994.

Lewis, P. J., and D. M. Counce, eds., Proceedings of the 1993 Nonfluorocarbon Insulation, Refrigeration, and Air-Conditioning Technology Workshop, Wiesbaden, Germany, September 27-29, 1993, ORNL-6805, Oak Ridge National Laboratory, Oak Ridge, Tenn., November 1994.

Loftis, J. P., and J. Grubb, "Distributed Processing Using ORACLE 7 and SQL*NETV2: An Implementation Story," pp. 1-5 in Proceedings of the 1993 International ORACLE Users' Week, vol. 2, Orlando, Fla., September 26-October 1, 1993.

Loftis, J. P., L. F. Truett, and P. C. Shipe, Standards and Conventions for the Worldwide Port System (WPS) Regional Integrated Cargo Database (ICDB), ORNL/TM-12799, Oak Ridge National Laboratory, Oak Ridge, Tenn., February 1995.

Lombardi, D. A., M. D. Morris, and A. P. Watson, "Using Air Dispersion Modeling as a Key Tool for Reentry Decision Making Following an Accidental Release of Chemical Warfare Agent," in Proceedings of the 86th Annual Meeting of the Air and Waste Management Association, vol. 1, 93-TP-26B.04, Air Modeling Issues, Air and Waste Management Association, Denver, Colo., 1994.

Lombardi, D. A., et al., Environmental Resources of Selected Areas of Hawaii: Climate, Ambient Air Quality, and Noise, ORNL/TM-12861, Oak Ridge National Laboratory, Oak Ridge, Tenn., March 1995.

MacDonald, J. M., "Energy Efficiency Capital Requirements for Buildings in the United States," pp. 121-30 in Proceedings of the 1994 ACEEE Summer Study on Energy Efficiency in Buildings, vol. 7, Pacific Grove, Calif., 1994.

MacGregor, D. G., and R. T. Goeltz, Bonneville Power Administration Communication Alarm Processor (CAP): Final Report, ORNL/TM-12619, Oak Ridge National Laboratory, Oak Ridge, Tenn., January 1995.

McCold, L. N., "Banking on a Better Environment," Forum for Applied Research and Public Policy 9(1), 135 (Spring 1994).

McCold, L. N., G. K. Eddlemon, and T. J. Blasing, Environmental Effects of the U.S. Antarctic Program's Use of Balloons in Antanctica, ORNL/TM-13032, Oak Ridge National Laboratory, Oak Ridge, Tenn., August 1995. 
McCold, L. N., and J. Holman, "Cumulative Impacts in Environmental Assessments: How Well Are They Considered?" The Environmental Professional 17, 2-8 (March 1995).

McConnell, B. W., and R. J. Ferraro, Understanding Superconducting Magnetic Energy Storage: Technology, Applications, and Economics for End-Use Workshop, ORNL/Sub/88-SM362/1, Oak Ridge National Laboratory, Oak Ridge, Tenn., November 1993.

McLain, H. A., S. B. Leigh, and J. M. MacDonald, Analysis of Savings Due to Multiple Energy Retrofits in a Large Office Building, ORNL/CON-363, Oak Ridge National Laboratory, Oak Ridge, Tenn., May 1994.

McLaughlin, S. B., T. J. Blasing, and D. J. Downing, "Two-Hundred-Year Variation of Southern Red Spruce Radial Growth as Estimated by Spectral Analysis: Discussion," Canadian Journal of Forest Research 24, 2299-2304 (November 1994).

McLean, R. B., and T. N. Russo, "Cumulative Impact Assessment-Introduction," p. 335 in Environmental Analysis: The NEPA Experience, Lewis Publishing, Boca Raton, Fla., 1993.

Mei, V. C., and F. C. Chen, A Liquid Over-Feed Military Air Conditioner, ORNL/TM-13027, Oak Ridge National Laboratory, Oak Ridge, Tenn., August 1995.

Mei, V. C., and F. C. Chen, "Study of Solar-Assisted Thermoelectric Technology for Automobile Air Conditioning," ASME Journal of Solar Energy Engineering 115, 200-215 (November 1993).

Mei, V. C., F. C. Chen, and J. Carlstedt, Experimental Analysis of a Window Air Conditioner with R-22 and Zeotropic Mixture of R-32/R-125/R-134a, ORNL/CON-389, Oak Ridge National Laboratory, Oak Ridge, Tenn., August 1995.

Mei, V. C., F. C. Chen, and E. P. Huangfu, "A Recuperative Air Conditioning Cycle," pp. 19-26 in Proceedings of the ASME 1993 Winter Annual Meeting, New Orleans, La., November 28-December 3, 1993, AES vol. 29, ed. K. R. Den Braven and V. C. Mei, December 1993.

Miaou, S. P., 'Discussion on 'Association of Median Width and Highway Accident Rates' by Knuiman, Council, and Reinfurt," Transportation Research Record 1401, 80-81 (1993).

Miaou, S. P., "Factors Associated with Aggregate Car Scrappage Rate in the United States: 1966-1992," Transportation Research Record 1475, 3-9 (1995).

Miaou, S. P., "The Relationship Between Truck Accidents and Geometric Design of Road Sections: Poisson Versus Negative Binomial Regression," Accident Analysis and Prevention 26(4), 471-82 (August 1994).

Miaou, S. P., S. C. Davis, and J. R. Young, Estimating Public Uses of Motor Fuel: Phase II, ORNL/TM-12737, Oak Ridge National Laboratory, Oak Ridge, Tenn., July 1994.

Miaou, S. P., and H. Lum, "Modeling Vehicle Accidents and Highway Geometric Design Relationships," Accident Analysis and Prevention 25(6), 689-709 (1993).

Miaou, S. P., and H. Lum, "A Statistical Evaluation of the Effects of Highway Geometric Design on Truck Accident Involvements," Transportation Research Record 1407, 11-23 (1993).

Middendorf, D. P., and M. S. Bronzini, The Productivity Effects of Truck Size and Weight Policies, ORNL-6840, Oak Ridge National Laboratory, Oak Ridge, Tenn., November 1994.

Middendorf, D. P., M. S. Bronzini, and J. Jacoby, "Effect of Longer Combination Vehicles on the Total Logistics Costs of Truckload Shippers," pp. 107-25 in Proceedings of the 36th Annual Forum of the Transportation Research Forum, vol. 1, Daytona Beach, Fla., November 3-5, 1994.

Miller, R. L., Environmental Assessment for the Warren Station Externally Fired Combined Cycle Demonstration Project, DOE/EA-1007, Oak Ridge National Laboratory, Oak Ridge, Tenn., April 1995.

Miller, R. L., T. C. Ruppel, and E. W. Evans, "Reaching an Agreement to Build a New Coal-Fired Power Plant near a National Park by Mitigating Potential Environmental Impacts," pp. 165-72 in Proceedings of the Eleventh Annual International Pittsburgh Coal Conference, "Coal-Energy and the Environment," Pittsburgh, Pa., September 12-16, 1994.

Miller, R. L., et al., Final Environmental Impact Statement for the Proposed Healy Clean Coal Project, DOE/EIS-0186, Oak Ridge National Laboratory, Oak Ridge, Tenn., December 1993.

Miller, W. A., and H. Perez-Blanco, "Vertical-Tube Aqueous LiBr Falling Film Absorption Using Advanced Surfaces," pp. 185-202 in Proceedings of the International Absorption Heat Pump Conference, AEX vol. 31, New Orleans, La., January 1994.

Munro, J. F., "Sustainable Development as an Organizing Principle for U.S. Foreign Policy: Opportunities and Enduring Constraints," pp. 332-42 in Environmental Challenges: The Next 20 Years, proceedings of the National Association 
of Environmental Professionals (NAEP) 20th Annual Conference and Exposition, Washington, D.C., June 10-13, 1995.

Murphy, R. W., "Magnetic Refrigeration Cycle Analysis Using Selected Thermodynamic Property Characterizations for Gadolinium Gallium Garnet," pp. 640-50 in Proceedings of the Sixth Annual Conference on Superconductivity and Applications, American Institute of Physics, New York, 1993.

Murphy, R. W., Thermodynamic Property Evaluation and Magnetic Refrigeration Cycle Analysis for Gadolinium Gallium Garnet, ORNL/TM-12664, Oak Ridge National Laboratory, Oak Ridge, Tenn., December 1994.

Peelle, E. B., "From Public Participation to Stakeholder Involvement: The Rocky Road to More Inclusiveness," pp. 186-201 in Environmental Challenges: The Next Twenty Years, proceedings of the National Association of Environmental Professional (NAEP) 20th Annual Conference and Exposition, Washington, D. C., June 10-13, 1995.

Peele, E. B., "Voluntary vs Directed Siting-or Somewhere in Between?" pp. 201-12 in Proceedings of the Fifth Annual Conference on High-Level Radioactive Waste Management, Las Vegas, Nevada, May 22-26, vol. 1, 1994.

Perlack, R. D., "Determination of the Potential Market Size and Opportunities for Biomass-to-Electricity Projects in China," pp. 49-54 in Proceedings of the Second Biomass Conference of the Americas, Portland, Ore., August 21-24, 1995.

Perlack, R. D., and L. L. Wright, "Economic Status of Dedicated Biomass Feedstock Supply Systems," Energy: The International Journal 20(4), 279-84 (April 1995).

Perlack, R. D., et al., Biomass Fuel from Woody Crops for Electric Power Generation, ORNL/6871, Oak Ridge National Laboratory, Oak Ridge, Tenn., June 1995.

Petrich, C. H., Review of Partnerships for Global Development: The Clearing Horizon, in Forum for Applied Research and Public Policy 9(4), (Winter 1994).

Petrich, C. H., "Science and the Inherently Subjective: The Evolution of Aesthetic Assessment Since NEPA," pp. 249-73 in Environmental Analysis: The NEPA Experience, Lewis Publishers, Boca Raton, Fla., 1993.

Phadke, A. G., S. H. Horowitz, and J. S. Thorp, Anatomy of Power Systems Blackout and Preventive Strategies by Rational Supervision and Control of Protection Systems, ORNL/Sub/89-SD630C/1, Oak Ridge National Laboratory, Oak Ridge, Tenn., January 1995.

Phadke, A. G., and J. S. Thorp, Monitoring and Simulating Real-Time Electric Power System Operation with Phasor Measurements, ORNL/Sub/88-SC203C/1, Oak Ridge National Laboratory, Oak Ridge, Tenn., January 1995.

Pillai, R. S., and A. K. Rathi, Maxband Version 3.1: Heuristic and Optimal Approach for Setting the Left Turn Phase Sequences in Signalized Networks, ORNL/TM-12869, Oak Ridge National Laboratory, Oak Ridge, Tenn., February 1995.

Poz, M. Y., and J. C. Conklin, "Heat Exchanger Analysis for Nonazeotropic Refrigerant Mixtures," ASHRAE Transactions 100(1), 727-35 (November 1994).

Purucker, S. L., "Reliability Centered Maintenance," in Proceedings of the EPRI Workshop on Advanced Diagnostics for Substation Equipment, EPRI TR-103848, New Orleans, La., November 3-5, 1993.

Ralston, B. A., J. J. Ray, and I. G. Harrison, "Issues in the Transportation of Food Aid," pp. 57-59 in Eliminating Hunger in Africa: Technical and Human Perspectives, Prentice Hall, New York, 1993.

Reed, R. M., and C. R. Boston, "Federal and State Experience-Introduction," pp. 605-7 in Environmental Analysis: The NEPA Experience, Lewis Publishers, Boca Raton, Fla., 1993.

Reed, R. M., and J. B. Cannon, “The NEPA Process," pp. 9-11 in Environmental Analysis: The NEPA Experience, Lewis Publishers, Boca Raton, Fla., 1993.

Reiner, R. H., and A. Zaltash, "Densities and Viscosities of Ternary Ammonia/Water Fluids," pp. 49-56 in Proceedings of the 1993 ASME Winter Annual Meeting, American Society of Mechanical Engineers, New Orleans, La., 1993.

Report Briefs: March-September 1993, Oak Ridge National Laboratory, Oak Ridge, Tenn., March 1994.

Report Briefs: September-June 1994, Oak Ridge National Laboratory, Oak Ridge, Tenn., July 1994.

Report Briefs: June-September 1994, Oak Ridge National Laboratory, Oak Ridge, Tenn., November 1994.

Report Briefs: October-December 1994, Oak Ridge National Laboratory, Oak Ridge, Tenn., February 1995.

Report Briefs: Current Publications of the Energy Division, Oak Ridge National Laboratory, First Quarter 1995, Oak Ridge National Laboratory, Oak Ridge, Tenn., July 1994.

Report Briefs: Current Publications of the Energy Division, Oak Ridge National Laboratory, Second Quarter 1995, Oak Ridge National Laboratory, Oak Ridge, Tenn., September 1994. 
Rice, C. K., P. K. Bansal, and L. S. Wright, "Thermodynamic Cycle Evaluation Model for R-22 Alternatives in Heat Pumps: Initial Results and Comparisons," pp. 81-96 in Proceedings of Second International Conference on Heat Pumps in Cold Climates, Moncton, New Brunswick, Canada, August 16-17, 1993, Caneta Research, Inc., January 1994.

Richards, L. W., and R. L. Miller, "Analysis of the Potential for a Coal-Fired Power Plant to Cause Visibility Impairment in a National Park," pp. 1-13 in Proceedings of the Air and Waste Management Association's 88th Annual Meeting and Exhibition, No. 95-WP96.02, San Antonio, Texas, June 18-23, 1995.

Rosselli, A. T., M. S. Bronzini, and D. A. Weekly, "Computer Simulation and Capacity Evaluation of Panama Canal Alternatives," sect. 2, pp. 153-60 in Proceedings of the 28th International Navigation Congress, Permanent International Association of Navigation Congresses, Seville, Spain, May 1994.

Sale, M. J., and C. Coutant, Proposed Modifications to the Lower Mokelumne River Project, California: Draft Environmental Impact Statement, FERC/FEIS-0067, Office of Hydropower Licensing, Washington, D.C., November 1993.

Sand, J. R., S. K. Fischer, and J. A. Jones, "Carnahan-Starling-Desantis and Lee-Kesler-Plocker Interaction Coefficients for Several Binary Mixtures of Ozone-Safe Refrigerants," International Journal of Refrigeration 17(2), 123-29 February 1994.

Sand, J. R., and S. K. Fischer, "Modeled Performance of Non-chlorinated Substitutes for CFC-11 and CFC-12 in Centrifugal Chillers," International Journal of Refrigeration 17(1), 40-48 (January 1994).

Sand, J. R., E. A. Vineyard, and R. H. Bohman, "Investigation of Design Options for Improving the Energy Efficiency of Conventionally Designed Refrigerator-Freezers," ASHRAE Transactions 100(1), 1359-68 (1994).

Saulsbury, J. W., et al., Environmental Resources of Selected Areas of Hawaii: Socioeconomics, ORNL/TM-12860, Oak Ridge National Laboratory, Oak Ridge, Tenn., March 1995.

Saylor, R. E., and L. N. McCold, "Bounding Analyses in NEPA Documents: When Are They Appropriate?" The Environmental Professional 16, 285-91 (December 1994).

Schexnayder, S. M., "A Screening Approach for Identifying Environmental Justice Issues in Environmental Impact Statements," p. 303 in Environmental Challenges: The Next 20 Years, proceedings of the National Association of Environmental Professionals (NAEP) 20th Annual Conference and Exposition, Washington, D.C., June 10-13, 1995.

Schweitzer, M., Municipal Electric Utilities: Establishment and Transportation, ORNL/CON-416, Oak Ridge National Laboratory, Oak Ridge, Tenn., June 1995.

Schweitzer, M., M. English, and S. M. Schexnayder, "Decision-Making in Demand-Side Management Collaboratives: The Influence of Non-Utility Parties on Electric-Utility Policies and Programs," pp. 543-50 in Environmental Challenges: The Next 20 Years, proceedings of the National Association of Environmental Professionals (NAEP) 20th Annual Conference and Exposition, Washington, D.C., June 10-13, 1995.

Schweitzer, M., M. English, and J. Altman, "DSM/IRP Collaboratives: What Have They Accomplished?" Energy Sources: Journal of Extraction, Conversion, and the Environment 16(1), 161-76 (January/March 1994).

Schweitzer, M., M. English, and S. M. Schexnayder, "Electric Utility/Advocacy Group Interaction," Strategic Planning for Energy and the Environment 14(3), 22-36 (1995).

Schweitzer, M., M. English, and S. M. Schexnayder, Energy Efficiency Advocacy Group: A Study of Selected Interactive Efforts and Independent Initiatives, ORNL/CON-377, Oak Ridge National Laboratory, Oak Ridge, Tenn., March 1994.

Schweitzer, M., and M. Pye, Key Factors Responsible for Changes in Electric-Utility DSM Usage, ORNL/CON-421, Oak Ridge National Laboratory, Oak Ridge, Tenn., September 1995.

Schweitzer, M., and S. M. Schexnayder, "Predicting Social Impacts Associated with Roadway Development in a Scenic Area," pp. 357-67 in Global Strategies for Environmental Issues, proceedings of the National Association of Environmental Professionals (NAEP) 19th Annual Conference, New Orleans, La., June 12-15, 1994.

Schweitzer, M., and T. R. Young, State Regulation and Its Effects on Electric-Utility Use of DSM Resources, ORNL/CON-391, Oak Ridge National Laboratory, Oak Ridge, Tenn., August 1994.

Sharp, T. R., Development and Application of a High-Speed, High-Resolution Data Acquisition System for Monitoring Power at the Service Entrance to Buildings, ORNL/TM-12921, Oak Ridge National Laboratory, Oak Ridge, Tenn., February 1995.

Sharp, T. R., "Measured Performance of the National Energy Audit," Home Energy 12(3), 35-39 (May/June 1995). 
Sharp, T. R., "Non-Intrusive Load Monitoring Systems: Considerations for Use and Potential Applications," pp. 241-48 in Proceedings of the 1994 ACEEE Summer Study on Energy Efficiency in Buildings, vol. 2, Pacific Grove, Calif., 1994.

Sharp, T. R., The North Carolina Field Test: Field Performance of the Preliminary Version of an Advanced Weatherization Audit for the Department of Energy's Weatherization Assistance Program, ORNL/CON-362, Oak Ridge National Laboratory, Oak Ridge, Tenn., June 1994.

Shelton, R. B., M. A. Kuliasha, and J. B. Cannon, Energy Division Annual Progress Report for Period Ending September 30, 1993, ORNL-6813, Oak Ridge National Laboratory, Oak Ridge, Tenn., 1994.

Shumpert, B. L., and A. P. Watson, Planning Standards for Response-Phase Decontamination: Planning Guidance for the Chemical Stockpile Emergency Preparedness Program, Appendix L, ORNL/M-1704, Oak Ridge National Laboratory, Oak Ridge, Tenn., December 1993.

Shumpert, B. L., A. P. Watson, and J. H. Sorensen, Planning Guidance for the Chemical Stockpile Emergency Preparedness Program, ORNL-6764, Oak Ridge National Laboratory, Oak Ridge, Tenn., February 1995.

Socolof, M. L., "Health Care Reform-So Many Problems, So Few Solutions," Forum for Applied Research and Public Policy 10(1), 147 (Spring 1995).

Socolof, M. L., M. S. Salk, and A. H. Curtis, Environmental Data and Analyses for the Proposed Management of Spent Nuclear Fuel on the DOE Oak Ridge Reservation, ORNL/TM-13065, Oak Ridge National Laboratory, Oak Ridge, Tenn., August 1995.

Socolof, M. L., R. E. Saylor, and L. N. McCold, "Replacement of Chlorofluorocarbons (CFCs) at the U.S. DOE Gaseous Diffusion Plants: An Assessment of Global Impacts," pp. 555-65 in Global Strategies for Environmental Issues, National Association of the Environmental Professionals (NAEP) 19th Annual Conference Proceedings, New Orleans, La., June 12-15, 1994.

Sorensen, J. H., "Adoption and Maintenance of Warning Systems," in National Research Council, Facing the Challenge: The U.S. National Report to the IDNR World Conference on Natural Disaster Reduction, National Academy Press, Washington, D.C., 1994.

Sorensen, J. H., "Modeling Protective Action Dose Reduction," Cameo Today 4(1), 11-12 (November/December 1993). Southworth, F., A Technical Review of Urban Land Use-Transportation Models as Tools for Evaluating Vehicle Travel Reduction Strategies, ORNL-6881, Oak Ridge National Laboratory, Oak Ridge, Tenn., July 1995.

Staub, W. P., and H. K. Hardee, "Post-Paleozoic Crustal Responses to the Contemporary Stress Field in the Eastern United States," pp. 666-71 in Fourth DOE Natural Phenomena Hazards Mitigation Conference, Atlanta, October 19-22.

Staub, W. P., and R. M. Reed, Environmental Resources of Selected Areas of Hawaii: Geological Hazards, ORNL/TM-12857, Oak Ridge National Laboratory, Oak Ridge, Tenn., March 1995.

Staub, W. P., and R. M. Reed, Environmental Resources of Selected Areas of Hawaii: Groundwater in the Puna District of the Island of Hawaii, ORNL/TM-12858, Oak Ridge National Laboratory, Oak Ridge, Tenn., March 1995.

Stefanovic, V., Adjustable Speed Drives: Applications and R\&D Needs, ORNL/Sub/80-SN772, Oak Ridge National Laboratory, Oak Ridge, Tenn., September 1995.

Stevens, S. S., B. E. Tonn, and F. Southworth, "A Study of the Potential for Cooperation Between Models and Modelers," Social Sciences Computer Review 12(2), 231-41 (June 1994).

Ternes, M. P., and W. P. Levins, "Weatherization Assistance: The Fuel Oil Study," Home Energy Magazine 11(4), 13-15 (July/August 1994).

Ternes, M. P., K. E. Wilkes, and H. A. McLain, "Cooling Benefits from Exterior Masonry Wall Insulation," Home Energy 11(2), 33-35 (March/April 1994).

Ternes, M. P., K. E. Wilkes, and H. A. McLain, "Cooling Energy Performance and Installation of a Retrofitted Exterior Insulation and Finish System on Masonry Residences in the Southwestern United States," in Development, Use, and Performance of Exterior Insulation and Finish Systems (EIFS), ASTM STP 1187, ed. M. F. Williams, R. G. Lampo, and R. G. Reitter II, American Society for Testing and Materials, 1995.

Ternes, M. P., K. E. Wilkes, and H. A. McLain, "Exterior Wall Insulation in Arizona Homes," CADDET Newsletter, no. 4, pp. 18-20 (December 1993).

Terry, J. W., and C. W. Hagan, Environmental Impact Statement Scoping Summary Report-Shieldalloy Metallurgical Corporation Facility, Newfield, New Jersey, ORNL/M-3460, Oak Ridge National Laboratory, Oak Ridge, Tenn., April 1994. 
Terry, J. W., R. O. Johnson, and B. M. Vogt, Construction and Operation of the Proposed Regional Medical Technology Center at Waxahachie, Texas: Final Environmental Assessment, ORNL/M-4285, Oak Ridge National Laboratory, Oak Ridge, Tenn., May 1995.

Tesche, F. M., and P. R. Barnes, "MHD-EMP Interaction with Power Transmission and Distribution Systems," Journal of Radiation Research 12(1), 77-82 (January 1994).

Thompson, P. G., et al., "An Integrated Approach to Technological Risk Analysis and Protective Action Decision-Making," pp. 232-37 in Proceedings of TIEMEC '94, ed. J. D. Sullivan and S. Tufekci, International Emergency Management and Engineering Conference, Hollywood, Fla., April 18-21, 1994.

Tonn, B. E., "Expected Values from Imprecise Probability: Comparisons with Classical Probability," pp. 273-74 in Proceedings of the Ninth Conference on Applied Climatology, American Meteorological Society, Dallas, 1995.

Tonn, B. E., Using the National Information Infrastructure for Social Science, Education, and Informed Decision Making: A White Paper, ORNL-12651, Oak Ridge National Laboratory, Oak Ridge, Tenn., January 1994.

Tonn, B. E., E. A. Hirst, and D. C. Bauer, IRP and the Electricity Industry of the Future: Workshop Results, ORNL/CON-398, Oak Ridge National Laboratory, Oak Ridge, Tenn., September 1994.

Tonn, B. E., E. A. Hirst, and D. C. Bauer, Public-Policy Responsibilities in a Restructured Electric Industry, ORNL/CON-420, Oak Ridge National Laboratory, Oak Ridge, Tenn., June 1995.

Tonn, B. E., H. L. Hwang, and S. R. Elliott, Methodologies for Estimating One-Time Hazardous Waste Generation for Capacity Assurance, ORNL/TM-12741, Oak Ridge National Laboratory, Oak Ridge, Tenn., May 1994.

Tonn, B. E., and C. E. Oliver, National Information Infrastructure Education Forum: A Summary Report, ORNL/TM-12671, Oak Ridge National Laboratory, Oak Ridge, Tenn., May 1994.

Tonn, B. E., and A. J. Schaffhauser, An Approach to Understanding, Representing, and Managing Uncertainty in Integrated Resource Planning, ORNL/CON-399, Oak Ridge National Laboratory, Oak Ridge, Tenn., January 1995.

Tonn, B. E., and A. J. Schaffhauser, Perspectives on the Future of the Utility Industry, ORNL/CON-385, Oak Ridge National Laboratory, Oak Ridge, Tenn., April 1994.

Tonn, B. E., and C. G. Wagner, Handling Uncertainty in Quantitative Estimates in Integrated Resource Planning, ORNL/CON-388, Oak Ridge National Laboratory, Oak Ridge, Tenn., January 1995.

Tonn, B. E., and R. Weiher, Uncertainty and Global Climate Change Research: Knoxville Workshop, ORNL/M-3704, Oak Ridge National Laboratory, Oak Ridge, Tenn., July 1994.

Treitler, I. E., "Tribal and Agency Strategies for Assessing Impacts," Federal Law, Native Americans, and Cultural Resources, special issue of Practicing Anthropology 16(3), 21-24 (Summer 1994).

Treitler, I. E., D. Ruppert, and R. Stoffle, "The Changing Culture of Resource Management," Federal Law, Native Americans, and Cultural Resources, special issue of Practicing Anthropology 16(3), 3-6 (Summer 1994).

Trettin, C. C., et al., Environmental Resources of Selected Areas of Hawaii: Ecological Resources, ORNL/TM-12863, Oak Ridge National Laboratory, Oak Ridge, Tenn., March 1995.

Truett, L. F., et al., "Coordination of Software Development Activities Among Sites That Are Geographically Separated," pp. 70-75 in Proceedings of the 17th Annual International Computer Software and Applications Conference, IEEE Computer Society Press, Phoenix, Arizona, 1993.

Truett, L. F., J. P. Loftis, and E. Z. Faby, Database Specification for the Worldwide Port System (WPS) Regional Integrated Cargo, ORNL/TM-12725, Oak Ridge National Laboratory, Oak Ridge, Tenn., March 1994.

Trumble, D. A., and J. M. MacDonald, Extension to Phase 2 Energy Savings Evaluation of the Commercial Direct Investment Program, ORNL/CON-360, Oak Ridge National Laboratory, Oak Ridge, Tenn., August 1994.

Uman, M. A., M. Rubinstein, and Z. Yacoub, The Effects of Lightning and High-Altitude Electromagnetic Pulse on Power Distribution Lines, ORNL/Sub/89-89650/2, Oak Ridge National Laboratory, Oak Ridge, Tenn., January 1995.

Vineyard, E. A., "Energy Efficiency of HFC-134a versus HFC-152a," pp. 86-91 in Proceedings of the International Chlorofluorocarbon (CFC) Conference, Alliance for Responsible CFC Policy, Washington, D.C., October 1993.

Vineyard, E. A., A. J. Brown, and J. C. Conklin, "Cycle Performance Testing of Nonazeotropic Mixtures of HFC-143a/HCFC-124 and HFC-32/HCFC-124 with Enhanced Surface Heat Exchangers," ASHRAE Transactions 99(2), 97-108 (December 1993).

Vogt, B. M., "Managing the Impacts of Sea Level Rise: Coastal Policies in the United States and the Implication of Hazard Management from Sea Level Rise," p. 324 in World Congress of Sociology, Sociological Abstracts, July 18-23, 1994, Supplement 173, Bielfield, Germany, July 18-23, 1994. 
Vogt, B. M., and J. H. Sorensen, Risk Communications and the Chemical Stockpile Emergency-Planning Program, ORNL-6824, Oak Ridge National Laboratory, Oak Ridge, Tenn., September 1994.

Vogt, B. M., J. H. Sorensen, and H. Hardee, Environmental Assessment and Social Justice, ORNL/TM-12919, Oak Ridge National Laboratory, Oak Ridge, Tenn., March 1995.

Vogt, D. P., and W. L. Jackson, National Infrastructure Information System/Regional Impact Module, computer program for the Federal Emergency Management Agency (FEMA), M93-66935, Oak Ridge National Laboratory, Oak Ridge, Tenn., October 1993.

Wade, M. C., 1995 Area 1 Bird Survey / Zone 1, Operable Unit 2, Robins Air Force Base, Georgia, ORNL/TM-13051, Oak Ridge National Laboratory, Oak Ridge, Tenn., September 1995.

Wade, M. C., and R. Barnett, Spring 1994 Wildlife Survey, Norton Air Force Base, California, ORNL/TM-12798, Oak Ridge National Laboratory, Oak Ridge, Tenn., August 1994.

Wade, M. C., and B. L. Beatty, Spring 1995 Wildlife and Vegetation Survey, Norton Air Force Base, California, ORNL/TM-12997, Oak Ridge National Laboratory, Oak Ridge, Tenn., July 18, 1995.

Wade, M. C., B. L. Beatty, and P. Philip, Fall 1994 Wildlife and Vegetation Survey, Norton Air Force Base, California, ORNL/TM-12886, Oak Ridge National Laboratory, Oak Ridge, Tenn., December 1994.

Wade, M. C., T. J. Blasing, and S. A. Chin, Study Plan for Preparing an Environmental Report on Section $8 B$ of the Foothills Parkway, ORNL/M-3756, Oak Ridge National Laboratory, Oak Ridge, Tenn., August 1994.

Wade, M. C., and B. K. Hope, Final Baseline Ecological Risk Assessment, Williams Air Force Base, report prepared for U.S. Air Force in collaboration with IT Corporation, Knoxville, Tenn., Oak Ridge National Laboratory, Oak Ridge, Tenn., December 1993.

Wade, M. C., M. L. Socolof, and B. Rosensteel, Wetlands Assessment for Site Characterization, Advanced Neutron Source (ANS), Oak Ridge National Laboratory, Oak Ridge, Tenn., October 1994.

Wade, M. C., W. Webb, and W. Hedberg, Technical Environmental Report: The Use of Drilling by the U.S. Antarctic Program, ORNL/TM-12809, Oak Ridge National Laboratory, Oak Ridge, Tenn., August 1994.

Wang, J. C., "Model for Impedance of a Solid Ionic Conductor Sandwiched Between Blocking Electrodes," Electrochima Acta 38(14), 2111-14 (1993).

Wang, J. C., D. W. Lee, and R. H. Ketelle, "Determination of Operating Limits for Radionuclides for a Proposed Landfill at Paducah Gaseous Diffusion Plant," pp. 95-106 in Tenth Proceedings of Nuclear Thermal Hydraulics, sponsored by the Thermal Hydraulics Division, American Nuclear Society, 1994 Winter Meeting, Washington, D.C., November 13-17, 1994.

White, D. L., and P. E. Mihlmester, U.S. Department of Energy Integrated Resource Planning Program: Accomplishments and Opportunities, ORNL/CON-370, Oak Ridge National Laboratory, Oak Ridge, Tenn., January 1994.

Wilbanks, T. J., "'Sustainable Development' in Geographic Perspective," Annals of the Association of American Geographers 84(4), 541-56 (December 1994).

Wilson, C. R., M. A. Brown, and R. D. Perlack, Process Evaluation of the Regional Biomass Energy Program, ORNL/CON-374, Oak Ridge National Laboratory, Oak Ridge, Tenn., March 1994.

Witherspoon, M. J., et al., A Weatherization Manual for LIHEAP Policy Makers and Program Administrators, ORNL/Sub/92-SK904, Oak Ridge National Laboratory, Oak Ridge, Tenn., September 1993.

Witten, A. J., "A Field Demonstration: Density Diffraction Tomography," Geophysical Research Letters 20, 2155-58 (October 22, 1993).

Witen, A. J., and W. C. King, "Advanced Signal Processing in Geophysical Remote Sensing," pp. 1521-28 in Proceedings of the Joint ASCE-CSCE Meeting on Environmental Engineering, vol. 2, McGill University, Montreal, 1993.

Witten, A. J., W. C. King, and J. R. Ursic, "High-Resolution Image Processing of Geophysical Remote Sensing Data with Diffraction Tomography," pp. 577-93 in Army Science: The New Frontiers, Borg Biomedical Books, 1993.

Wolfe, A. K., M. A. Brown, and D. A. Trumble, Measuring Persistence: A Literature Review Focusing on Methodological Issues, ORNL/CON-401, Oak Ridge National Laboratory, Oak Ridge, Tenn., March 1995.

Wolfe, A. K., D. P. Vogt, and H. L. Hwang, "Incorporating Environmental Justice into Environmental Decision Making," pp. 277-85 in Environmental Challenges: The Next 20 Years, Proceedings of the 20th Annual Conference of the National Association of Environmental Professionals (NAEP), Washington, D.C., June 10-13, 1995.

Wright, J. A., L. Brockman, and P. Herman, The Role of IRP in the Natural Gas Industry: A Case Study, ORNL/Sub/93-03369, Oak Ridge National Laboratory, Oak Ridge, Tenn., September 1994. 
Zaininger, H. W., P. R. Ellis, and J. C. Schaefer, The Integration of Renewable Energy Sources into Electric Power Distribution Systems, vol. 2, ORNL-6775, Oak Ridge National Laboratory, Oak Ridge, Tenn., June 1994. (For vol. 1, see Barnes, Van Dyke, and Tesche.)

Zaltash, A., and G. Grossman, Simulation and Performance Analysis of Basic GAX and Advanced GAX Cycles with Ammonia/Water and Ammonia/Water/LiBr Absorption Fluids, ORNL/CF-94/223, Oak Ridge National Laboratory, Oak Ridge, Tenn., October 1994. 


\section{Energy Division \\ Organization Chart}




\section{ENERGY DIVISION \\ February 1996}

\begin{tabular}{|c|}
\hline INTERMATIONAL PROGRAMS \\
\hline T. J. Wilbanks', Corporate Fellow. \\
Developing Country Programs \\
N. Dominguez ', Mexico and Latin America \\
\hline
\end{tabular}

R. B. Shelton, Director

K. R. Grubb

T. M. Bodine 1

G. E. Courville, Associate Director

L. S. Edwards ${ }^{1}$

T. D. Ferguson ${ }^{1}$, Administrative Assistant C. A. Patillo

S. M. Cohn', Technical Assistant

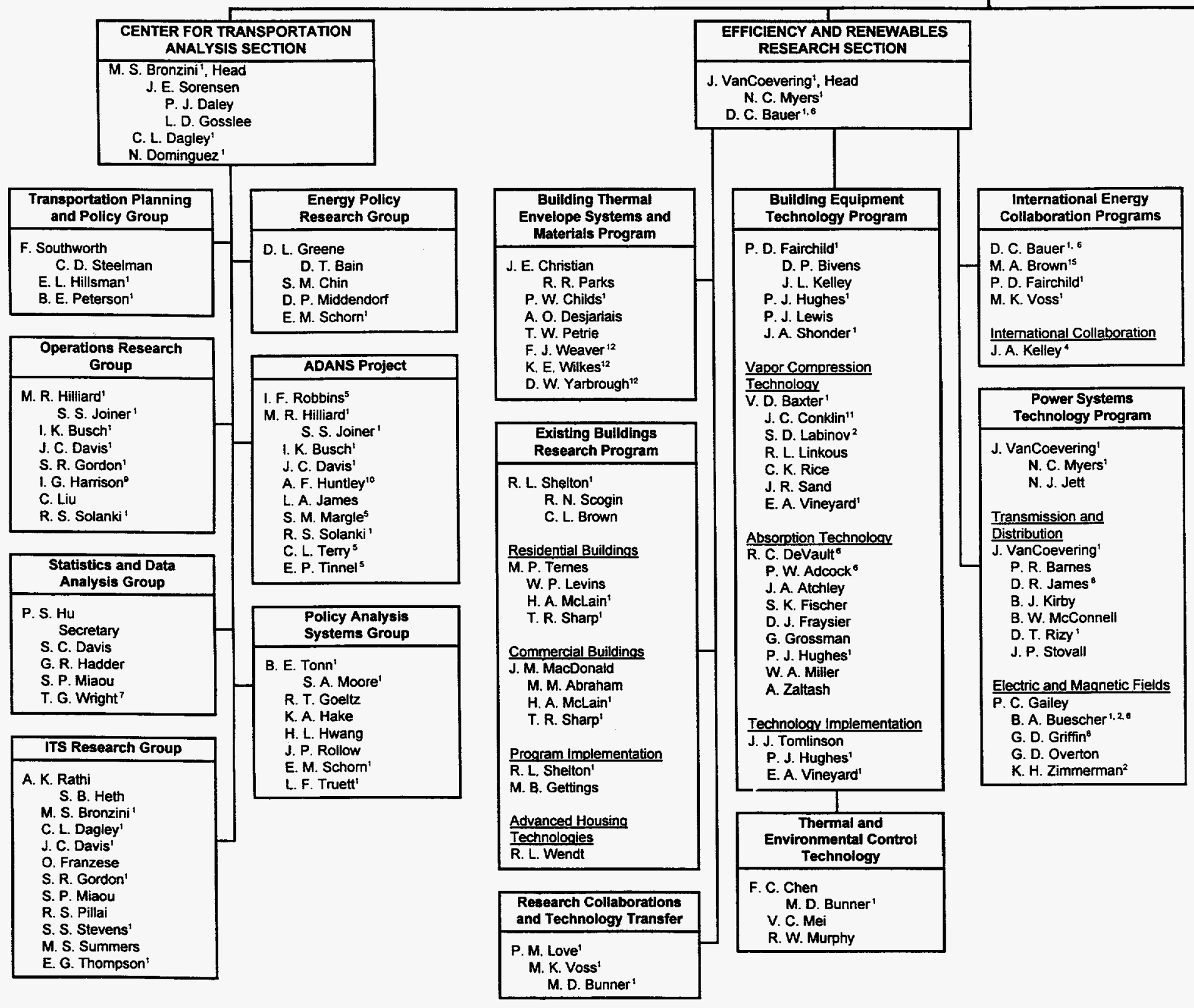

LEGEND:

1. Dual Capacity

2. Part-Time

3. Finance and Budget Division

4. Information Management Services

5. Computational Physics and Engineering Division

6. Off-Site Assignment

7. Computing and Mathematical Sciences Division

8. Health Sciences Research Division
9. Leave of Absence

10. Dala Systems R\&D Program

11. Engineering Technology Division

12. Metals and Ceramics Division

13. Chernical Technology Division

14. Emvironmentad Sciences Division

15. Centra Management Offices 
WASHINGTON OFFICE

\begin{tabular}{|c|c|}
\hline $\begin{array}{l}\text { J. F. Eisenberg } 1,6 \\
\text { L. S. Edwards } \\
\text { P. W. Adcock } 6 \\
\text { D. C. Bauer } 1,6\end{array}$ & $\begin{array}{l}\text { D. R. Bohi }{ }^{6} \text {, Senior Research } \\
\text { Scientist for Public } \\
\text { Policy/ORNL/AFF } \\
\text { B. A. Buescher } 1,2,6 \\
\text { J. F. Munro } 1,6\end{array}$ \\
\hline
\end{tabular}

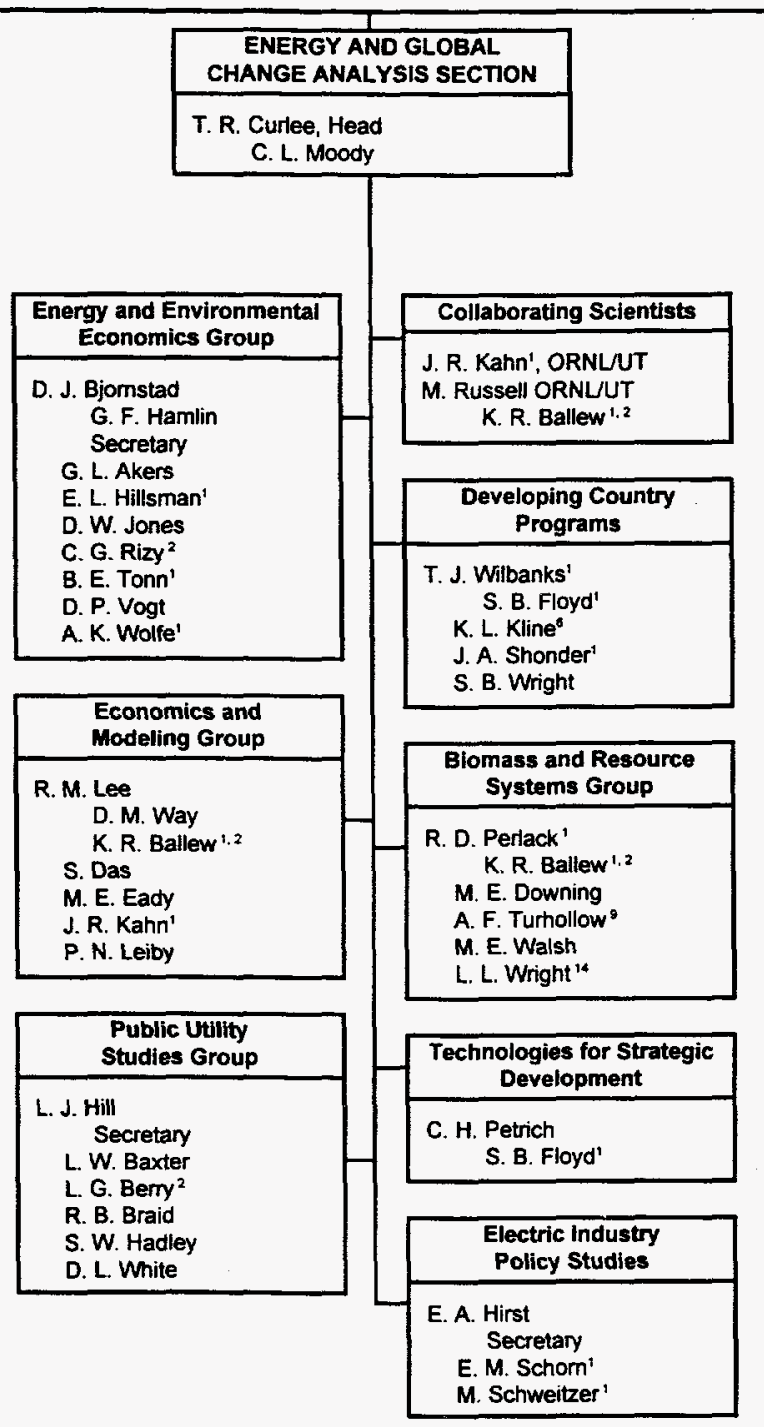

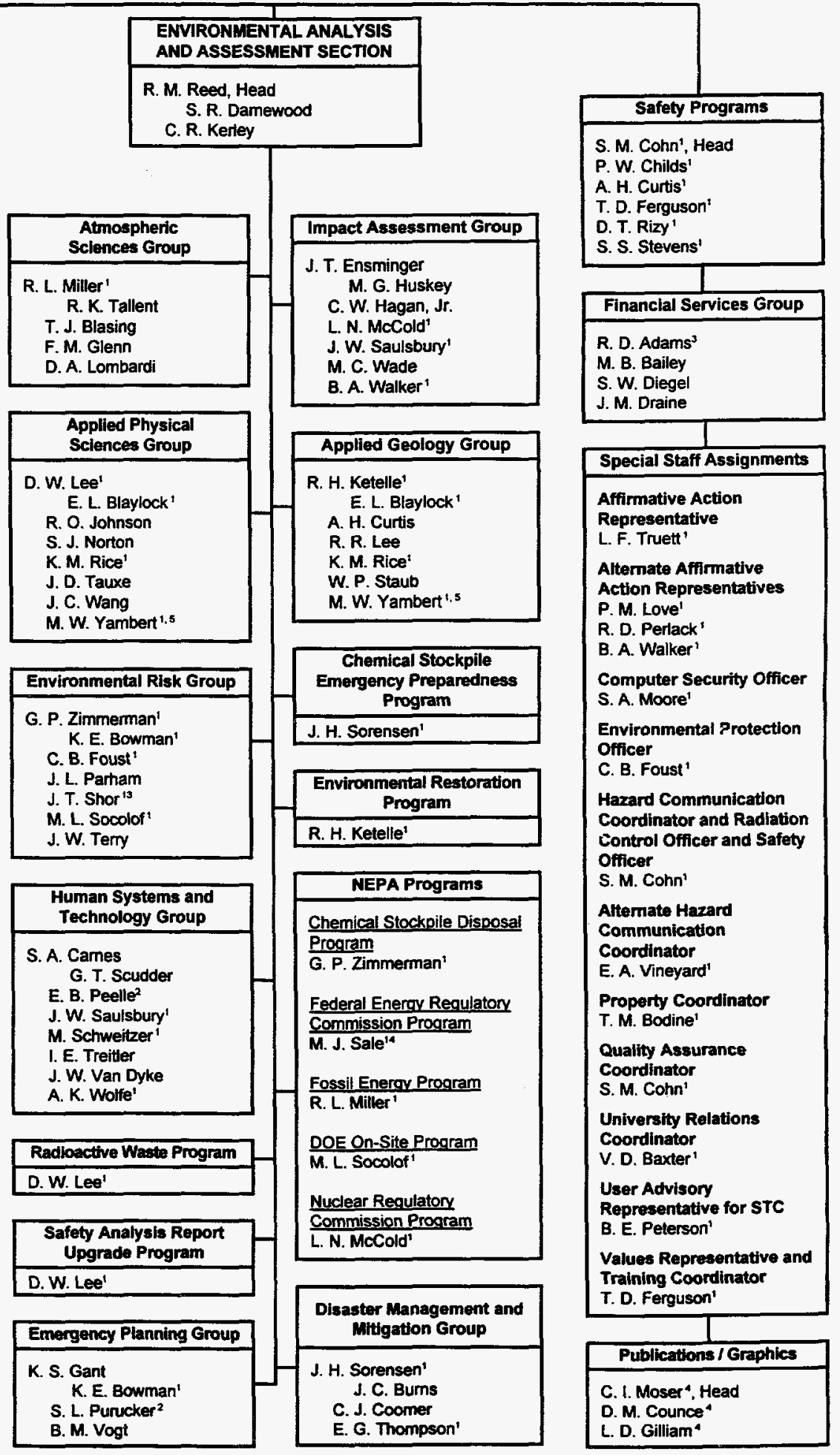





\section{INTERNAL DISTRIBUTION}

1. M. M. Abraham

2. B. R. Appleton

3. D. C. Bauer

4. L. W. Baxter

5. V. D. Baxter

6. L. G. Berry

7. B. A. Berven

8. D. P. Bivens

9. D. J. Bjornstad

10. T. J. Blasing

11. E. L. Blaylock

12. T. M. Bodine

13. R. B. Braid

14-24. M. S. Bronzini

25. C. i. Brown

26. M. A. Brown

27. J. B. Cannon

28. S. A. Carnes

29. J. E. Christian

30. G. E. Courville

31. T. R. Curlee

32. S. R. Damewood

33. S. Das

34. S. C. Davis

35. T. P. Depp

36. A. O. Desjarlais

37. L. S. Edwards

38. P. D. Fairchild

39. M. P. Farrell

40. T. D. Ferguson

41. S. B. Floyd

42. C. B. Foust

43. M. B. Gettings

44. R. G. Gilliland

45. G. Grossman

46. K. R. Grubb

47. G. R. Hadder

48. S. W. Hadley

49. C. W. Hagan, Jr.

50. S. Herrin

51. S. G. Hildebrand

52. E. L. Hillsman

53. E. A. Hirst

54. R. B. Honea

55. P. S. Hu

56. P. J. Hughes
57. R. O. Johnson

58. R. R. Judkins

59. M. A. Kuliasha

60. D. W. Lee

61. R. M. Lee

62. P. J. Lewis

63. W. C. Lin

64. G. M. Logsdon

65. D. A. Lombardi

66. P. M. Love

67. L. N. McCold

68. D. W. McDonald

69. H. A. McLain

70. S. P. Miaou

71. G. E. Michaels

72. D. P. Middendorf

73. R. L. Miller

74. C. L. Moody

75. C. E. Oliver

76. J. L. Parham

77. R. R. Parks

78. E. B. Peelle

79. R. D. Perlack

80. C. H. Petrich

81. T. W. Petrie

82. R. S. Pillai

83. C. E. Pugh

84. S. L. Purucker

85. A. K. Rathi

86-91. R. M. Reed

92. D. E. Reichle

93. D. T. Rizy

94. J. P. Rollow

95. M. J. Saltmarsh

96. A. C. Schaffhauser

97. W. Schramm

98. M. Schweitzer

99. R. N. Scogin

100. G. T. Scudder

101. T. R. Sharp

102. J. Sheffield

103. R. B. Shelton

104. J. E. Sorensen

105. F. Southworth

106. J. O. Stiegler

107. J. H. Swanks 
108. R. K. Tallent

109. J. D. Tauxe

110. J. W. Terry

111. M. P. Ternes

112. I. E. Treitler

113. K. C. Trent

114. A. W. Trivelpiece

115. L. F. Truett

116. R. I. Van Hook

117-120. J. VanCoevering

121. E. A. Vineyard

122. B. M. Vogt

123. M. K. Voss
124. B. T. Walton

125. J. C. Wang

126. D. A. Waters

127. T. J. Wilbanks

128. S. B. Wright

129. A. Zaltash

130. G. P. Zimmerman

131. ORNL Patent Office

132. Document Reference Section

133. Central Research Library

134-136. Laboratory Records

137. Laboratory Records (Record Copy)

\section{EXTERNAL DISTRIBUTION}

138. Dr. Thomas E. Drabek, Professor, Department of Sociology, University of Denver, Denver, Colorado 80208-0209

139. Mr. George F. Sowers, P. E., Senior Vice President, Law Companies Group, Inc., 114 Townpark Drive, Suite 250, Kennesaw, Georgia 30144-5599

140. Dr. C. Michael Walton, Ernest H. Cockrell Centennial Chair in Engineering and Chariman, Department of Civil Engineering, University of Texas at Austin, Austin, Texas 78712-1076

141. Dr. Ronald O. Hultgren, ORNL Site Manager, Department of Energy, Oak Ridge National Laboratory, Post Office Box 2008, Oak Ridge, Tennessee 37831-6269

142-144. OSTI, U.S. Department of Energy, P.O. Box 62, Oak Ridge, Tennessee 37831

145-1000. Energy Division External Distribution 